University of Rhode Island

DigitalCommons@URI

Open Access Master's Theses

1978

\title{
Study of Selected Landside Facilities at Theodore Francis Green State Airport
}

Melih Ozbilgin

University of Rhode Island

Clifford Wester

University of Rhode Island

Follow this and additional works at: https://digitalcommons.uri.edu/theses

\section{Recommended Citation}

Ozbilgin, Melih and Wester, Clifford, "Study of Selected Landside Facilities at Theodore Francis Green State Airport" (1978). Open Access Master's Theses. Paper 492.

https://digitalcommons.uri.edu/theses/492

This Thesis is brought to you for free and open access by DigitalCommons@URI. It has been accepted for inclusion in Open Access Master's Theses by an authorized administrator of DigitalCommons@URI. For more information, please contact digitalcommons-group@uri.edu. 
STUDY OF
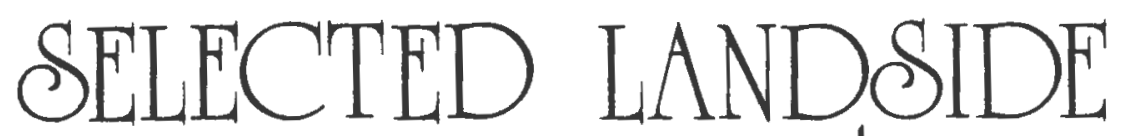

FACILITIES at

Theodore Francis Green state<smiles>[AlH2]O[AlH2]</smiles>

$\mathbf{B} \mathbf{Y}$

MELIH OZBILGIN

AND

CLIFFORD WESTER

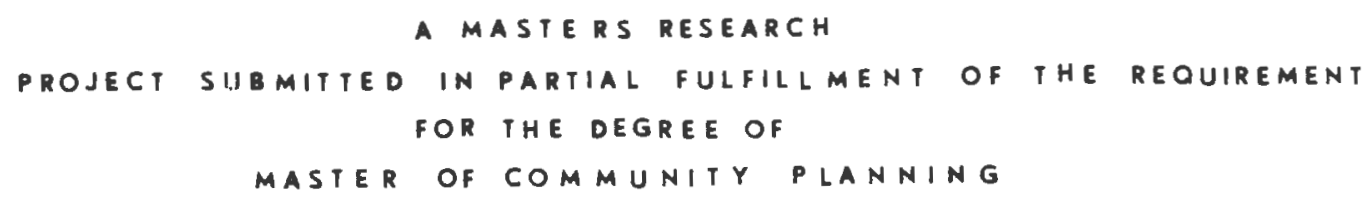

REVIEWED BY
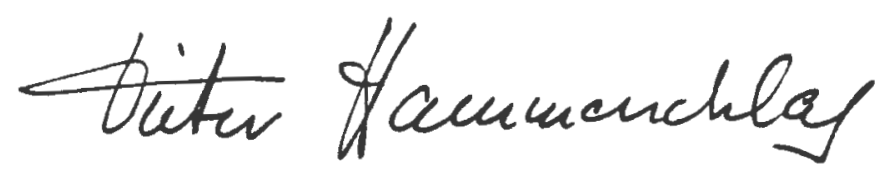

DIETER HAMMERSCHLAG PROFESSOR OF COMMUNITY PLANNING 
CONTENTS

$P A=D$

Ghapter 1: Introduction 1

Chanter 2: ت̈story of I. F. Green State linport. 5

Chanter 3: Other Jlans--1078 -aster Jlan 13

(Preliminary Drait)

Chapter 4: Criticism of 1978 "aster Plan 21

Chapter 5: Dasic Concepts 32

Chaoter 6: Desion Criteria 36

Chanter 7: Site Proposal 4?

Chapter 8: Terminal Proposal 40

Conclusion 58

Footrotes 72

Eibliography 74 
Figure 3.1 Airport Layout Plan (1977)

Figure 4.I Terminal Building 1st. Level (Master Plan-2000 Concept)

Figure 4.2 Terminal Building 2nd. Level (Master Plan-2000 Concept)

Figure 4.3 Terminal Building Basement Level 32-3 (Master Plan-2000 Concept)

Figure 5.I Airport Landside Functional Flow 34-1 Figure 5.2 Pure Concepts of Terminal Design 34-2 Figure 7.1 Terminal Area Plan (1977) 49 Figure 7.2 Terminal Area Plan (Master Plan-2000 Concept)

Figure 7.3 Proposed Terminal Area Plan 51

Figure 8.1 Proposed Terminal Building 52

Figure 8.2 Proposed Terminal Building

54

Figure 8.3 Proposed Terminal Building Baggage Pick-up Area

Figure 8.4 Proposed Terminal Building Second Level

Figure 8.5 Proposed Terminal Building Second Level-Main Building

Figure 8.6 Proposed Terminal Building Entrance Area-Ticket Counters 


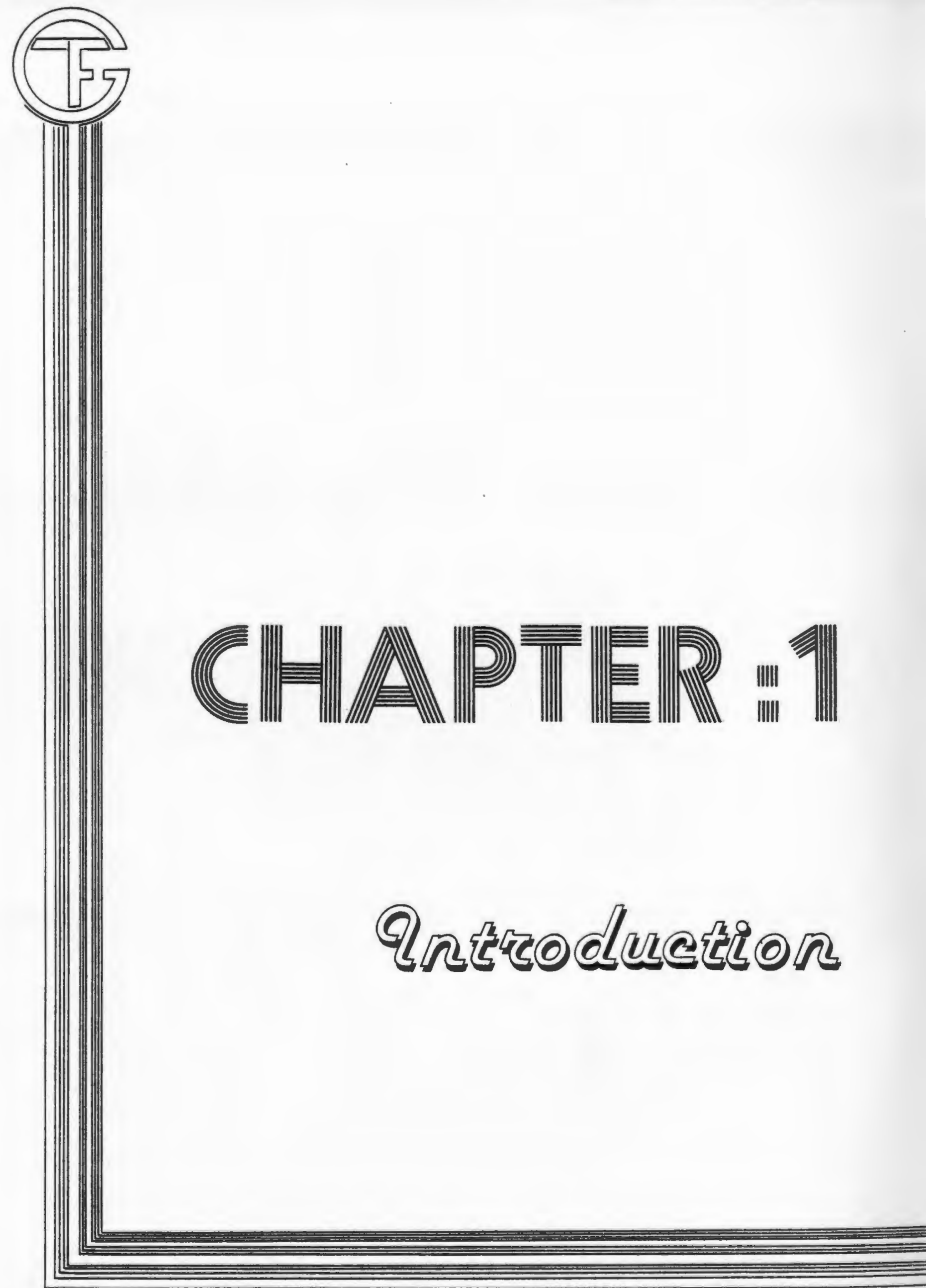


INTRODUCTION!

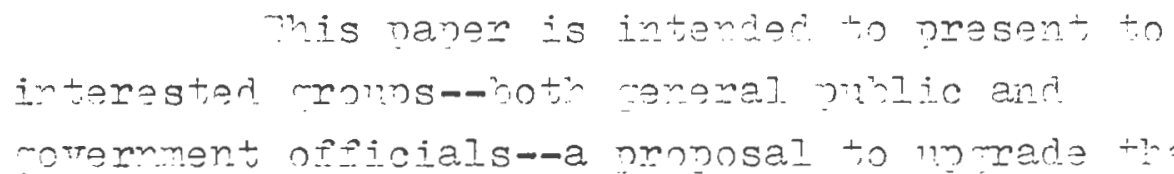
teminal vilidin , marking facilities and toaffic circulation sattemn at, $=$ - reen state lirport. It was initially conceived to study the jossing renevation and expansion of the tomminal brilding alone. Iowever, as the stridr develoned, we felt the need of relating the temminal huilding to its surrounding elements; such as myrat ststem, traffic cincrlation pattern, paring facilities, the

summounding communit, and the onvironment, ro, strdied, rithin the time limit ro hat, those eleronts and decised to concentrate on centain elements wingh ue felt were of nore importamos. Ve eliminatsad the loss important considerations. Te later decidor not to studr the runwar strstem since it is considered one of the better ones in the corntry. Mis studi now covers the terminal building, traffic cincrilation, and parlsing facilities at ה. F. Froen State iirnort.

During the course of this studir, ve consultied knowledgeable peonle at the Airnort Dirision of the Rhode Island Denartment of mrarsportation and the Rhode Island Statewide Planning Program. Ve also feel that Dieter Fammerschlag, Jrofessor of Irivan Desion at the Graduate Curriculum in Dommunity Panning and Aroa Develonment at the Tiniversit:- o: Khode Island, with his background in arcintecture and urban lanning and his experience, was most helpfrl to us in this learning grocess. 


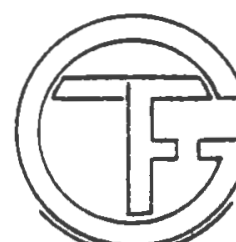

Thy did we choose to study $T$. The Green State Airport? It is princinall: because we are interested in the airport, Te are part of the prblic that uses the facility and we feel that we know the extent and trpe of development needed there. We are interested Decause we felt we could develon a proposal that is more efficient and useful than what consultant firms have oreviously proposed. We are also interested because we think this project, mar be useful to the general public as vell as decision makers in government.

The desion process out of which this study grew consists of the following six major steps: ${ }^{1}$
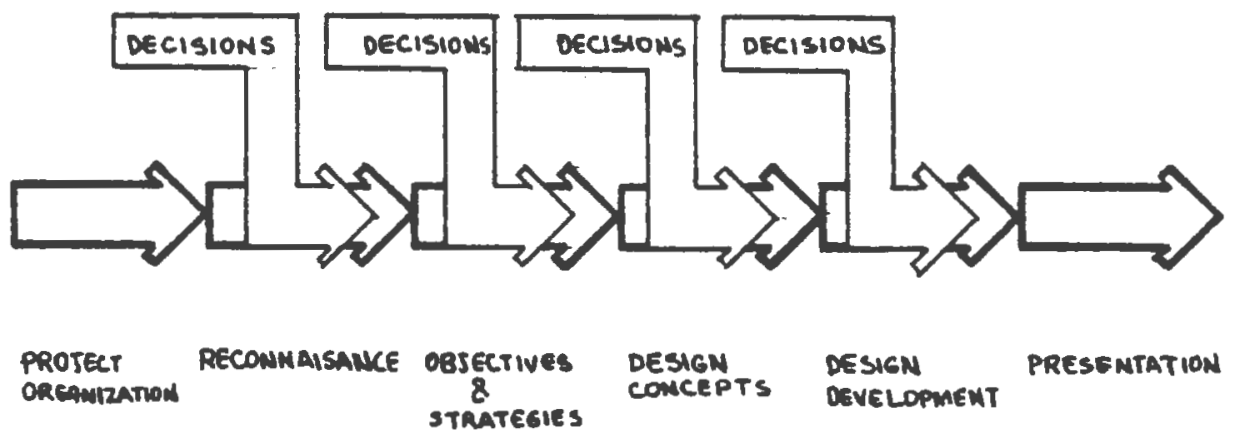

Project organization: The design team is Clifford Vester and "elih Ozbilgin; we are worling jointly in generation of the final product. Vechanics of coordination and decision maring were dereloned in consultation with zrof. Fammerschlas. 


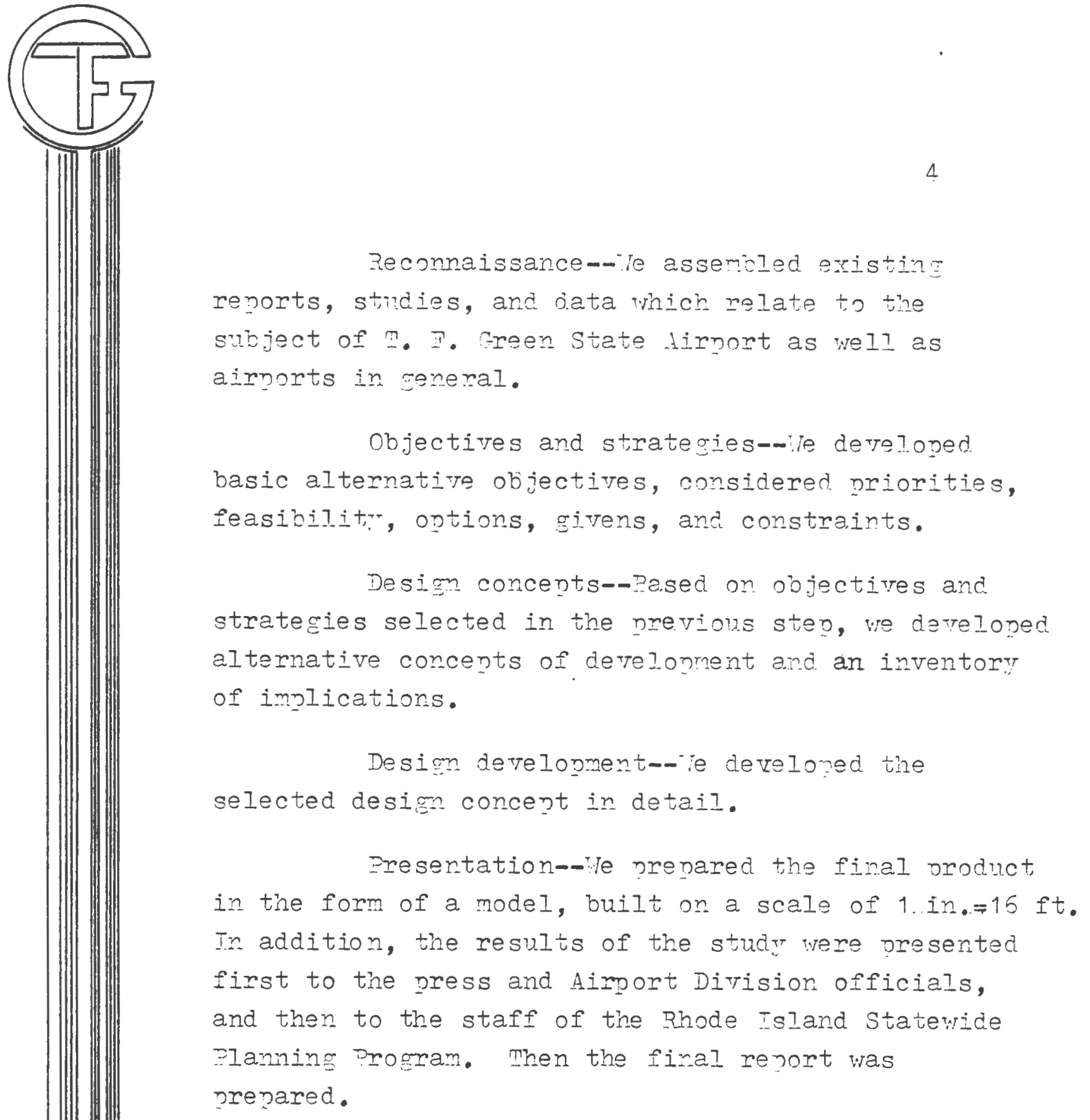




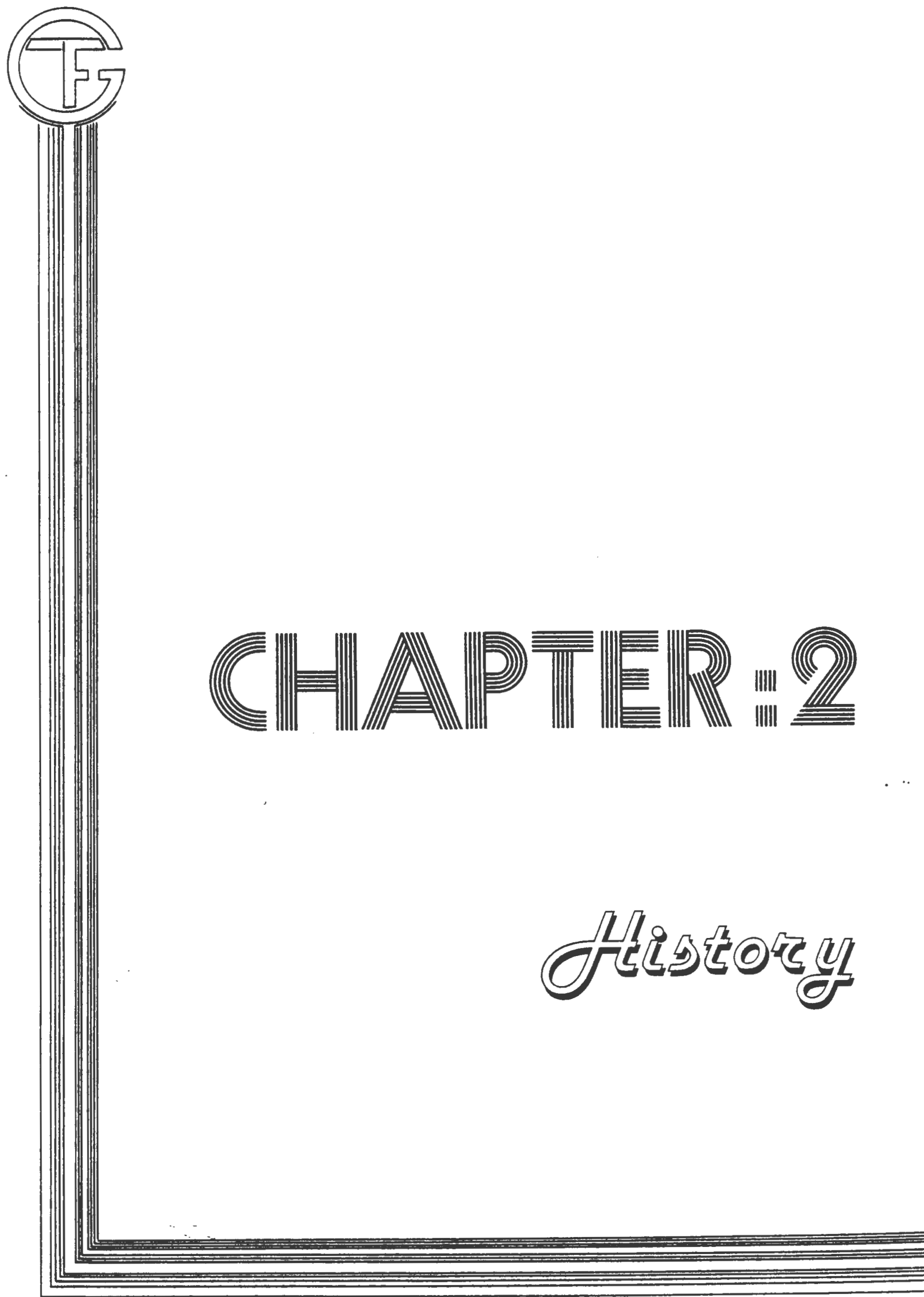


HISTORY OF T. F. GRTEN STATP AIRPORT

Prior to the late 1920 's, aviation vas viewed by the public as a spectacle--something to spend Sunday afternoons watching for amusement. However, by the late $1920^{\prime} \mathrm{s}$, several events were taking place. Those events would demonstrate to the public that aviation had many exciting possibilities in service to the public.

One of the most important of those events to Rhode Islanders was the crossing of the Atlantic by Charles Lindbergh, in May of 1927. Iindbergh came to Providence on $21 . \mathrm{JuIy}, 1927$. Janding at the ouonset rational Guard Campground, he went by land to the Providence City Hall. Iore than 300,000 turned out to see him.

The impact upon Thode Islanders of seeing this great flyer in person was demonstrated in the January session of the Rhode Island General Assembly. There, a West Varwick senator oroposed that the Drovidence River be bridged over from the New Haven Railroad tracks to Crawford Street. The space created would be used for a landing field. This was to be accomplished by a one million dollar bond issue.

The first airport in the state was built in Charlestown by the Atlantic Airport Corporation. Its being near the shore was due to the importance of seaplanes during that period. The first airport to serve the Providence area was established in Seekonk, "assachusetts in way of 1928 by the Providence Aircraft Corporation. 


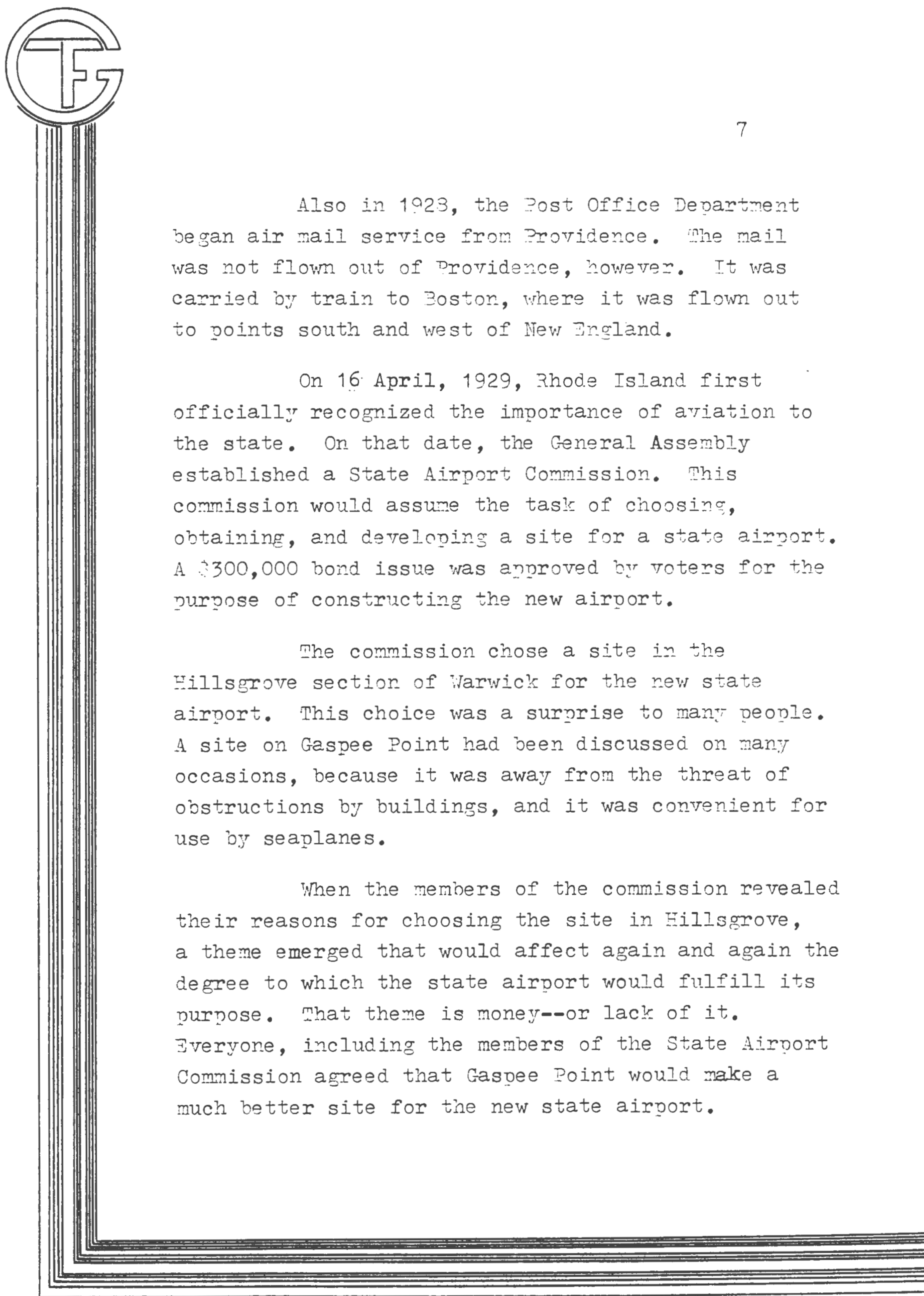




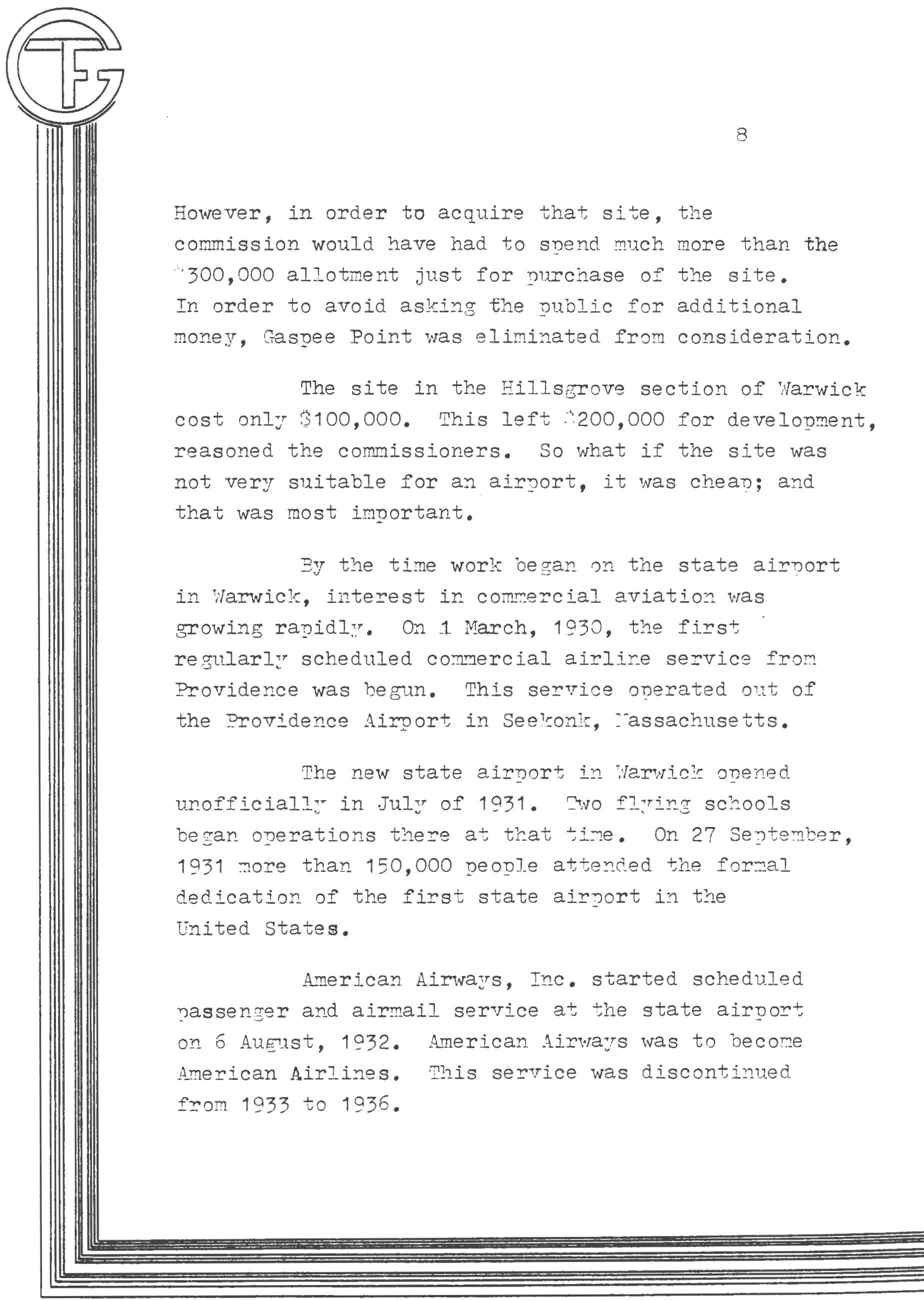


In 1935 a major reorganization of the state government of Rhode Island took place. The new chief of the Division of State Airports in the Department of Dublic iorles envisioned a major new program to improre and upgrade the state airports of Rhode Island. Eowever, the conservatism of the public of Rhode Island resulted in the defeat of a mere 83,000 loan in a special election.

However, in 1935, the state airport in Tarwick was closed for most of that rear, rhile certain improvements were nade. "ew lichting and concrete runways were installed at that time. Following those improvements, a Rhode Island Department of Public Vorks report stated that the Thode Island State Airport had "been accepted b"r commercial air companies as an alternative to "ewar? for all commercial ships coming in from the vest."

On 27 December, 1938 the state airport in Tarilick was renamed in honor of Senator Theodore Francis Green. Green had done much in gorernment in support of aviation.

By 1940, the state airport was the serenth busiest in the United States. 84,000 take-offs and landings were recorded that rear. Its extraordinany growth was demonstrated by the fact that a hangar built to handle ter rears of growth became inadequate during its second rear of onerations. 


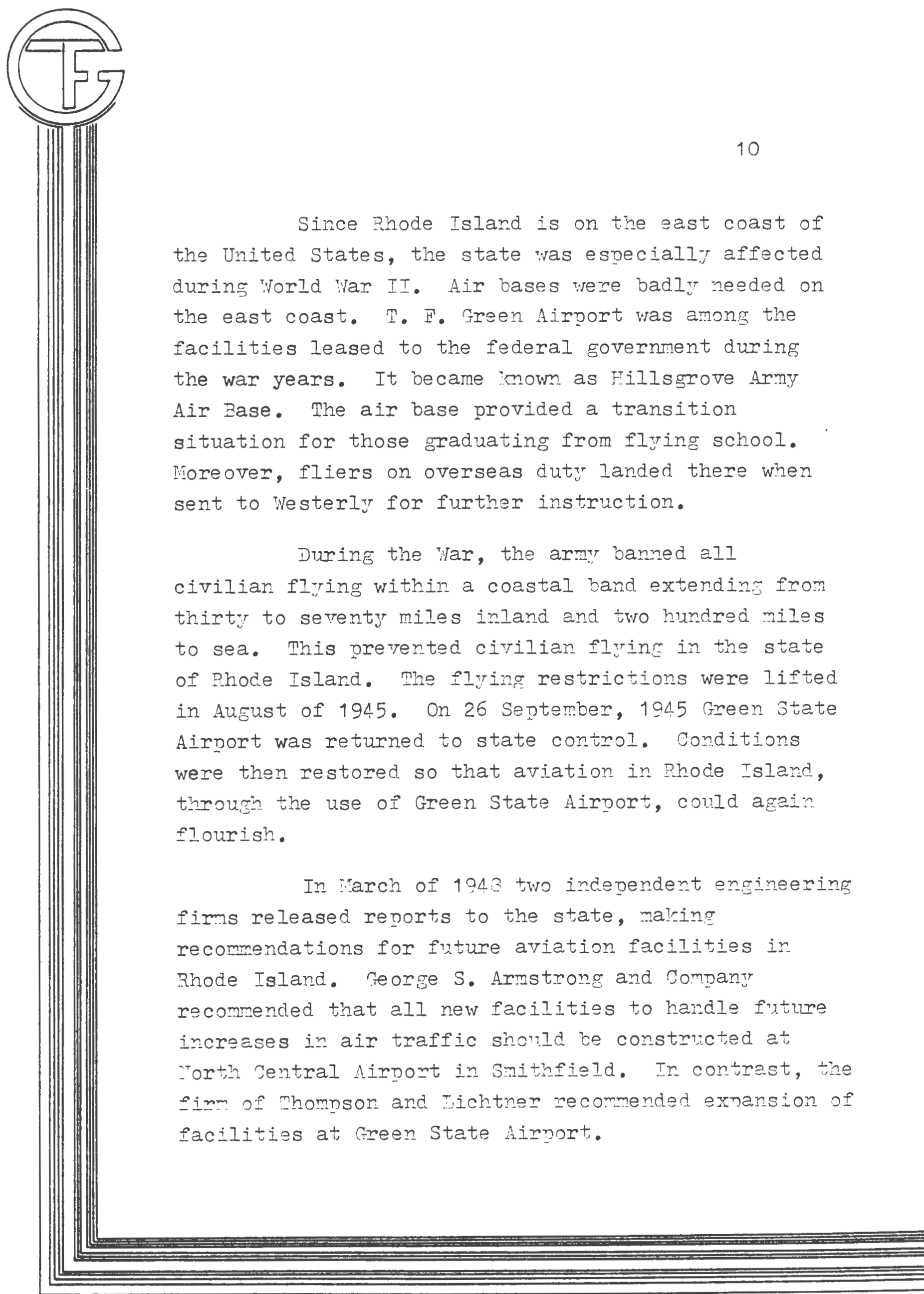


The Thompsor and Fichtiner recommendations were, of course, heeded, and in 194.9 a :3,000,000 bond issue was passed to be used for improvements at creen Airnort, as well as for facilities at Forth Central and Block Island Airports.

During the 1950's Green State Airport became well-established as a center of air travel. The number of passengers processed increased dramatically during that period. Setween 1953 and 1957 an increase of 100,000 was experienced in the number of travellers using Freen State Aimort each year. In 1957 alone there was an increase of 46,000 over the previous year.

In 1957, the number of passengers using Green State Airnort exceeded the 1960 forcast that had been nade by the Civil Aviation Authorit in 1953. Thile ranking fifty-ninth in number of passengers processed, compared with other airport,s in the United States in 1957, Green State Aingort had the ninth highest growth rate in the country.

This greatl.; increased use of Treen State Airport was the reason for increased public support for the facility. In 1956, roters aporoved a $\because 1.5$ million bond issue for improvements at the airport. rith that moner, a new terminal building was erected at Green state Airport. It was officiall. opened on 13 August, 1961. 


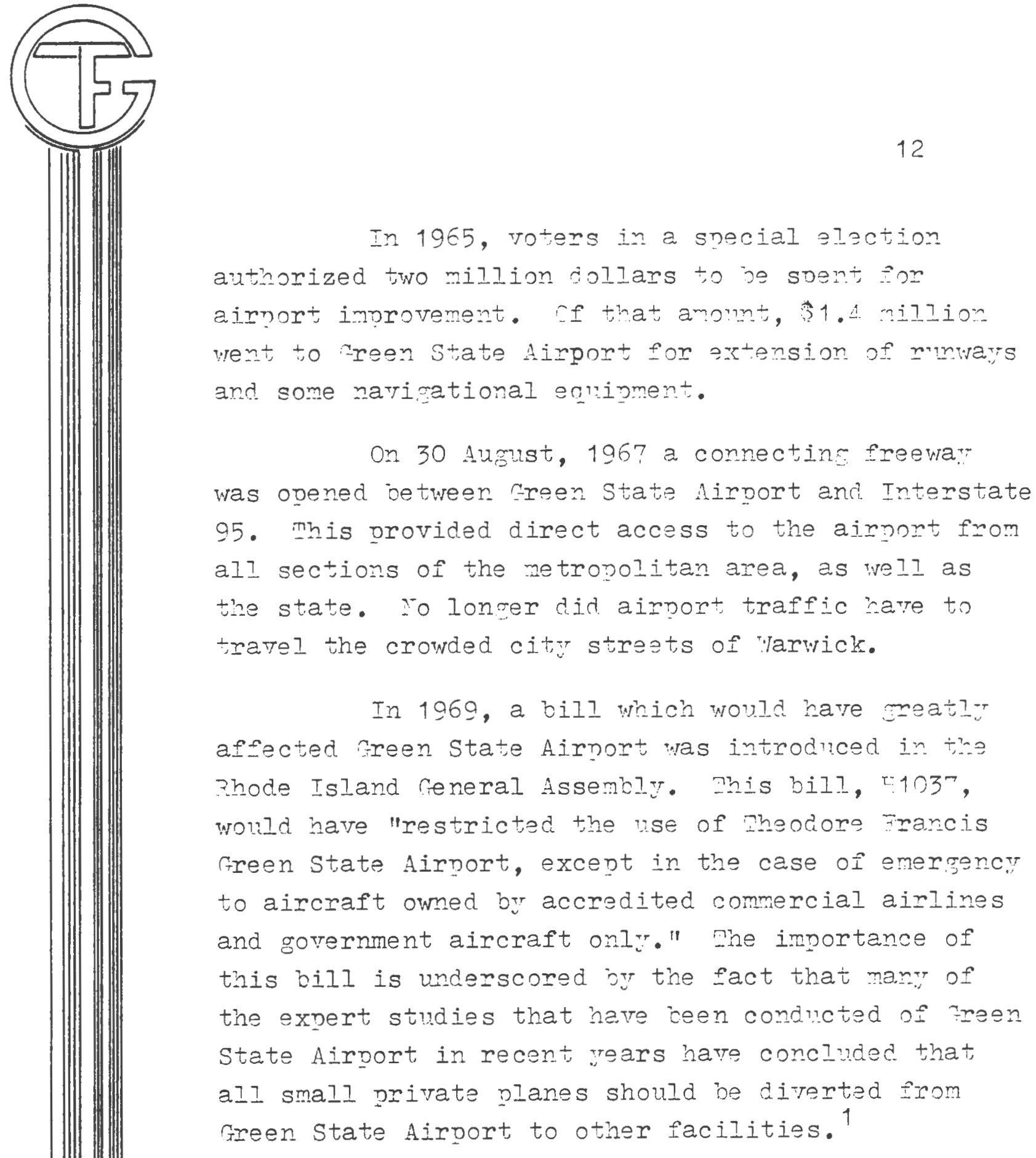




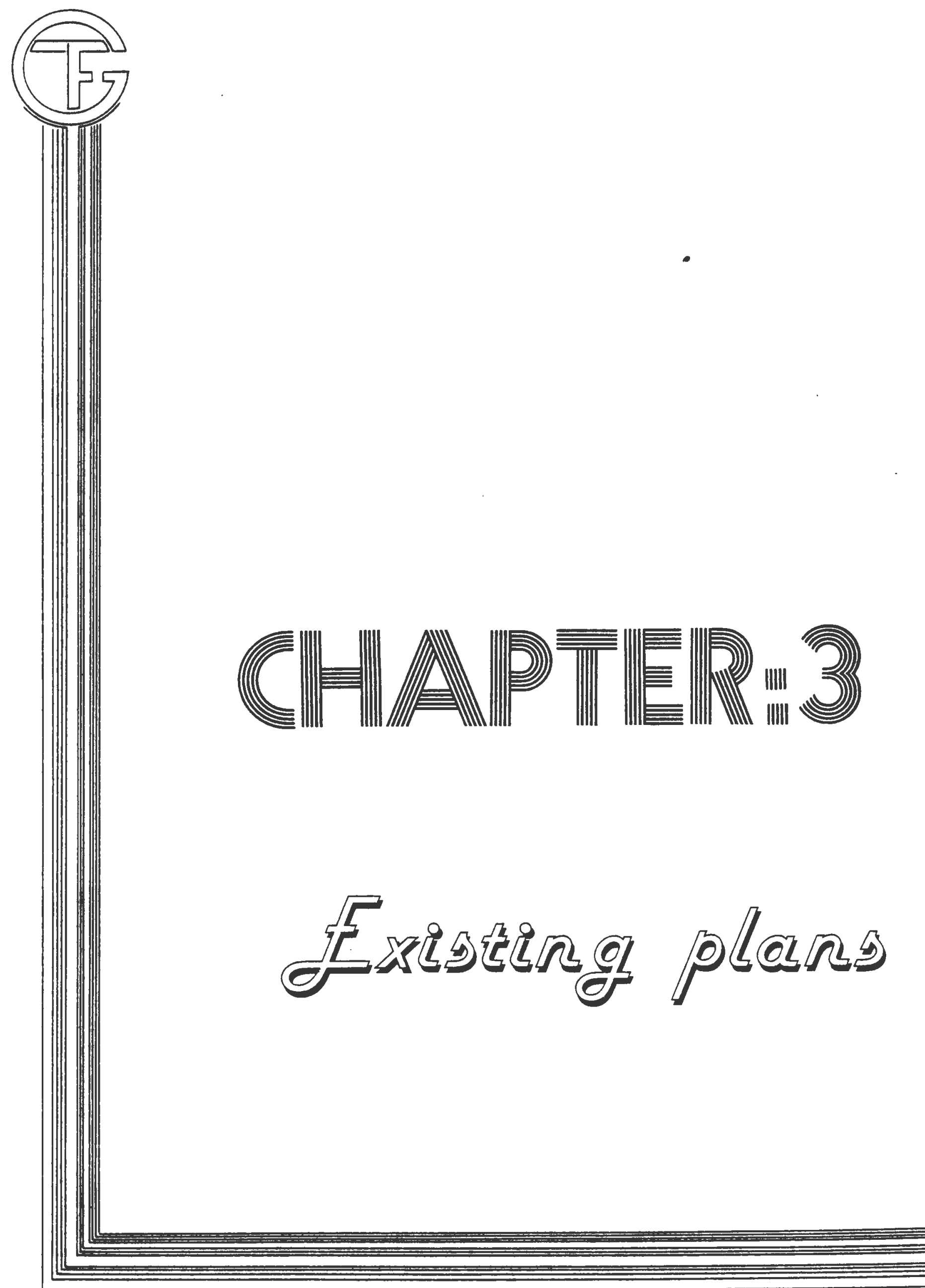




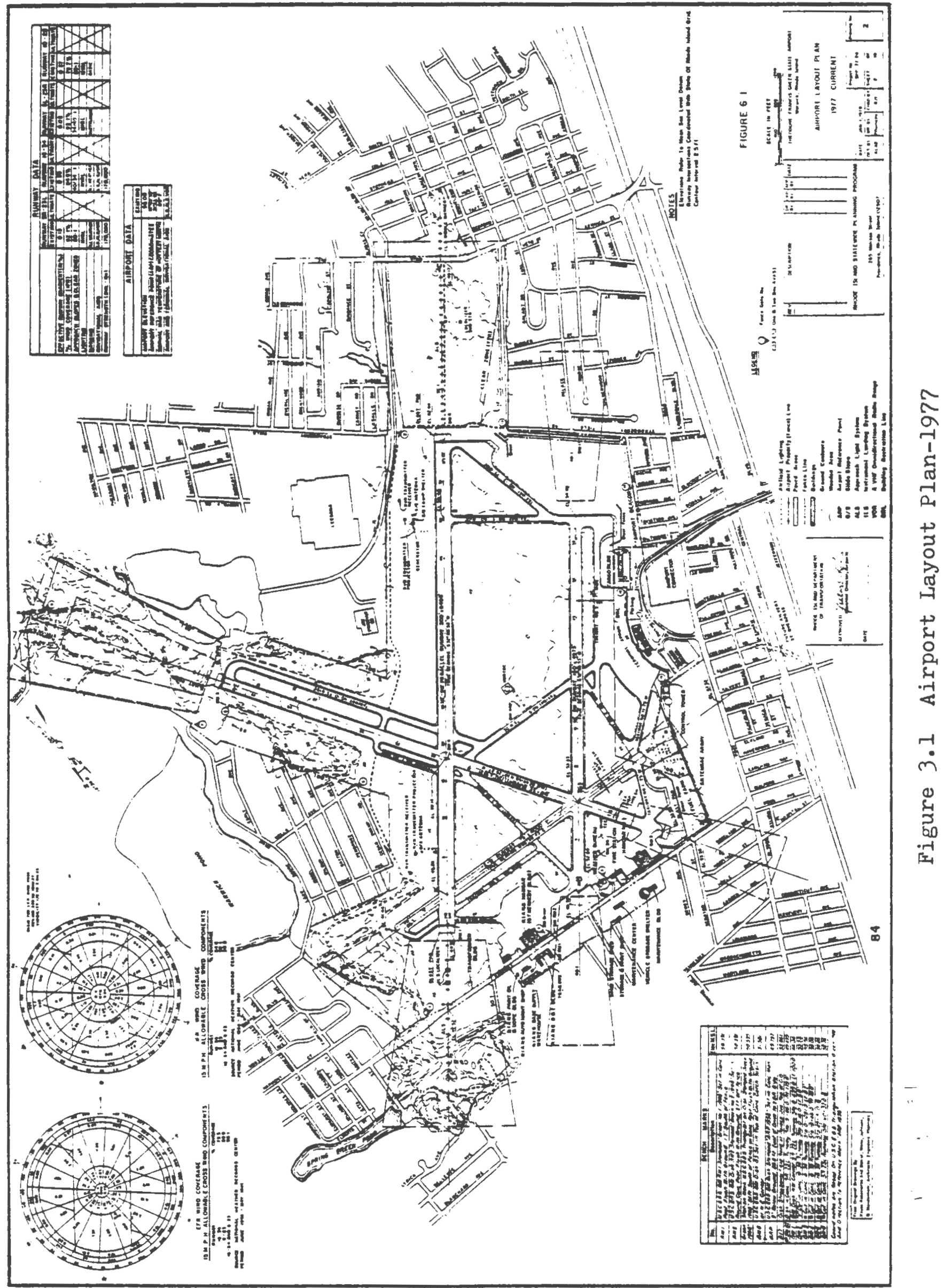


OMHER PTANS--1978 TIASTIR PLAIT (PRTIIMTMARY DRAFT)

In June of 1973, the State of Rhode Island released the preliminary draft of its latest master Dlan for T. F. Green State Airport. This is Report rumber 32 of the Rhode Island Statewide Planning Program. This draft master plan represents the latest official policy concerning present and future use of Green State Airport.

This section of the report will examine the latest official plans for Green State Airport. After the plans are described, they will be evaluated. The opinions of the writers will be offered as to how well the planned facilities will work, how adequate they are, and how desirable ther are.

The recommendations of the 1978 Airport Taster Plan are based on certain ideas as to what the goals of the master plan should be. Those goals are as follows:

1. The facility, both in its ultimate and intermediate stages, should achieve the most efficient balance between passenger comfort and convenience, airiines operational requirements, and development costs.

2. The facility should be capable of expansion without impairing its own functioning or that, of the other elements of the surrounding commuritiv.

3. The design and staging of the facility should be flexible and rasponsite to continued updating of forcasts and requirements. 


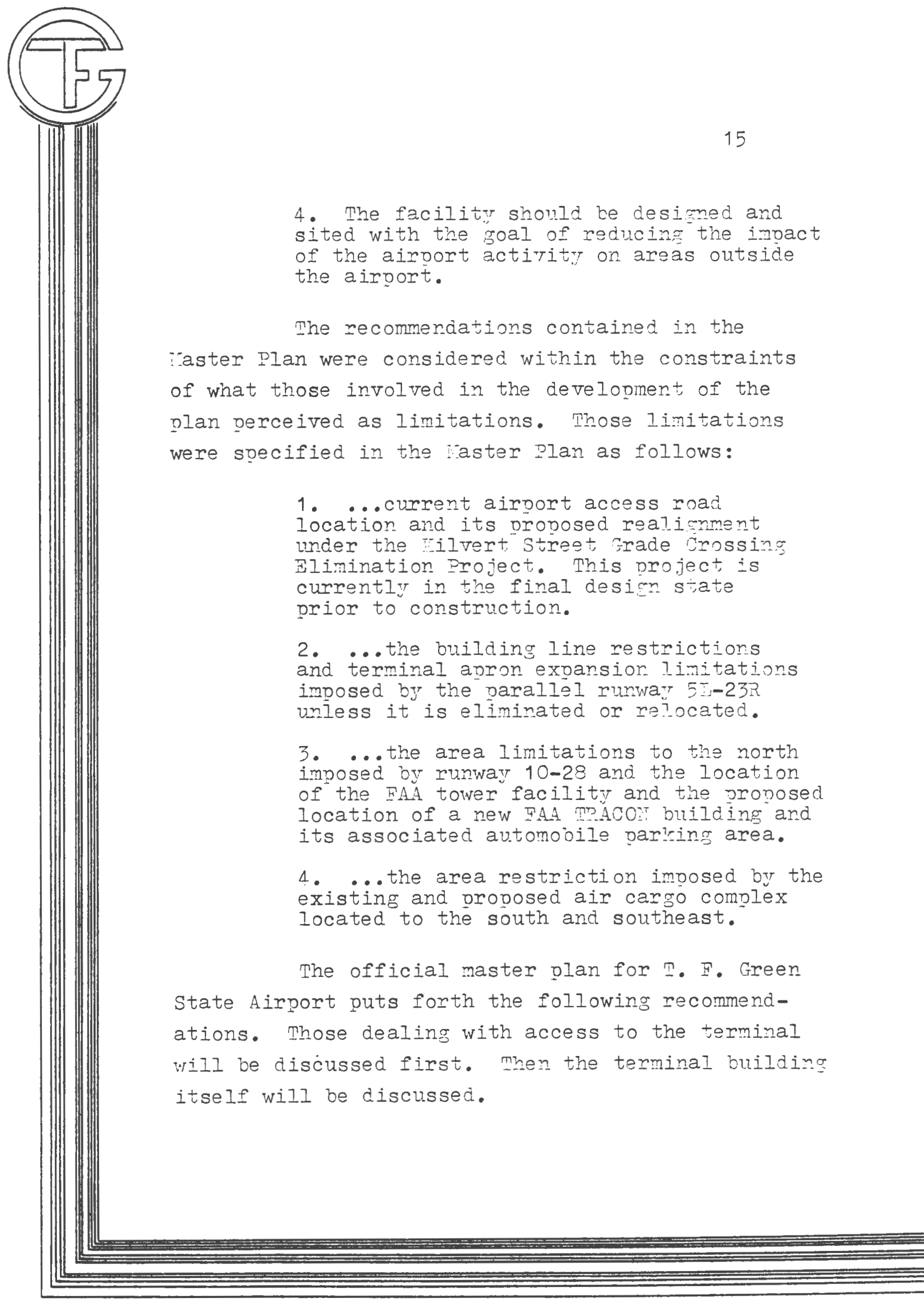


1. Realignment of the airoort access road through the present lons term parking lot to connect with the FiIrert street overpass.

2. Inlargement of the present short term parking lot to 10 a spaces.

3. Nove employees parlcing to share the present long term lot with the airport connector, providing 113 spaces.

4. Increase the capacity of the rental car parking area at the noxth end of the terminal building.

5. Construct a new long term parking lot on the opposite side of the airport connector from the terminal building, creating 579 lorg term spaces.

6. Iengthen the front curoside passenger oick-up and discharge area.

Pedestrian circulation is an important part of access to the terminal. According to the master Dlan, pedestrians going from the short term parking area to the terminal would exit from the short term parking area on the east side. They would then cross the front driveway of the terminal building, in which the following activities take place: pick-up and discharge of passengers by orivate automobiles, taxicabs, limousines, and buses; passage of vehicles exiting the medium term parking area for Interstate $95 \mathrm{via}$ the Airoort Freeway. Pedestrians from the short term parking area would then enter the terminal building. 


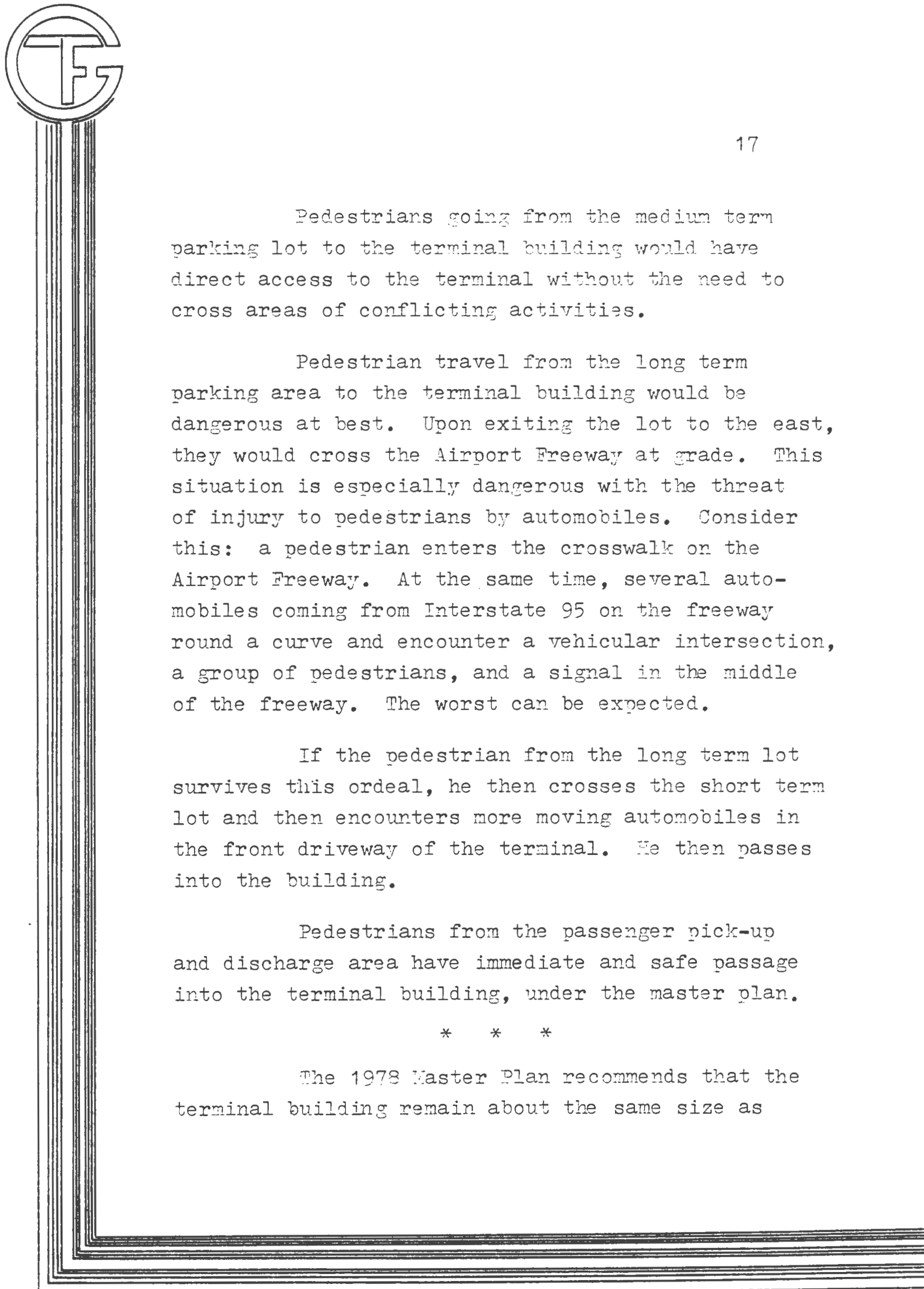




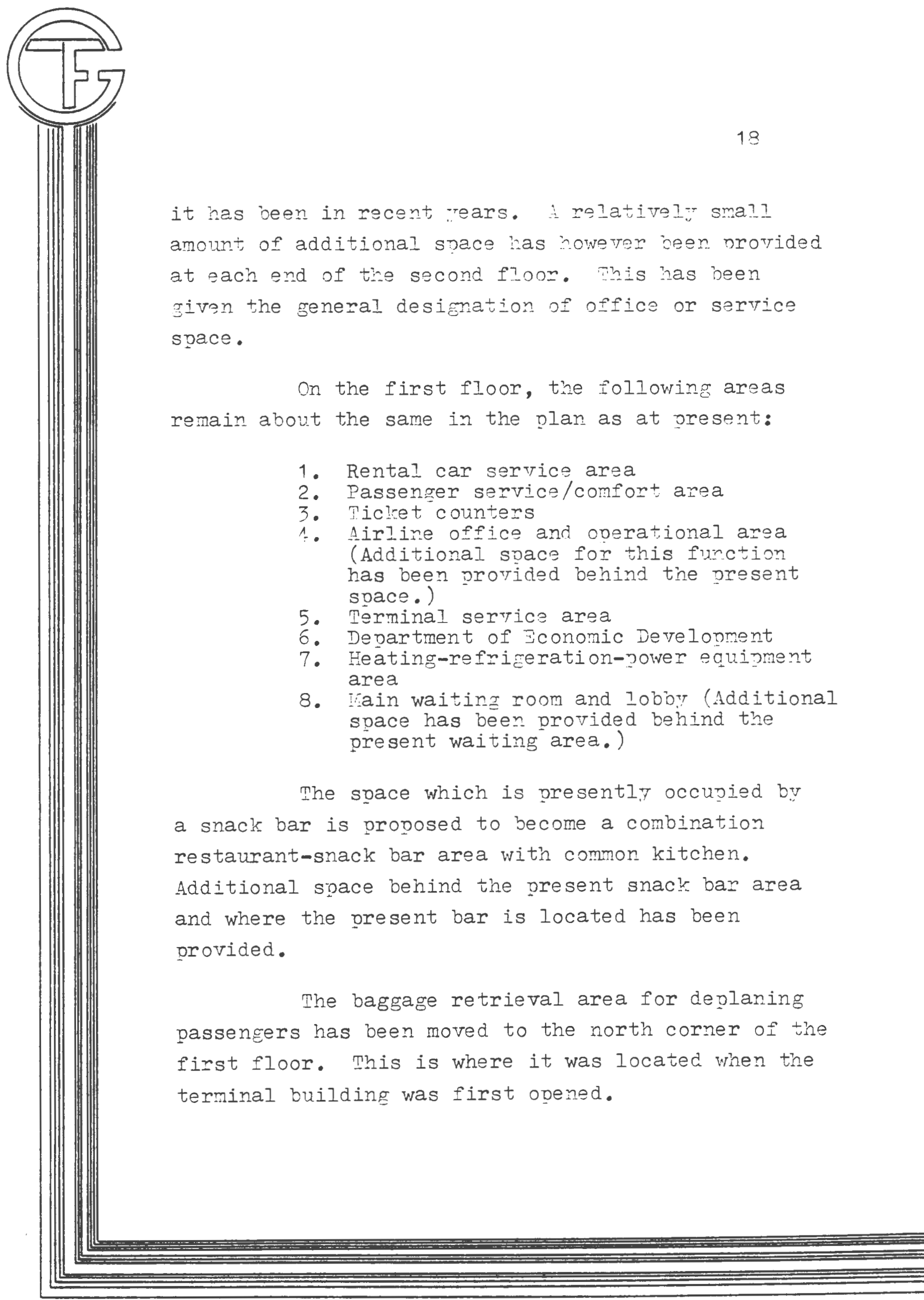


Eaggage is given out at a single station, the capacity of which has been increased over that of the present facility.

On the second floor of the terminal building, the following areas remain the same as at present: the conference room and the hanging walk. The present office space for the Division of Airports has been divided by a corridor, and additional space has been provided at the end of the corridor. Some of this space could be assigned to the Division of Airports.

The bar has been moved to the second floor to occupy the space which is presentIy used by the restaurant. An observation area that would also serve as additional lobby space has been provided on the second floor. This soace is connected to other parts of the terminal building by the hanging walk.

The sterile corridors, through which passengers walk to and from the planes, have been moved to the second floor in the master Dlan. The sterile corridors are not connected to the remainder of the second floor. Access to them is by stair, escalator, and elevator--directly from the first floor waiting area.

Thirteen gates have been provided for boarding olanes. Jach of these gates has a 


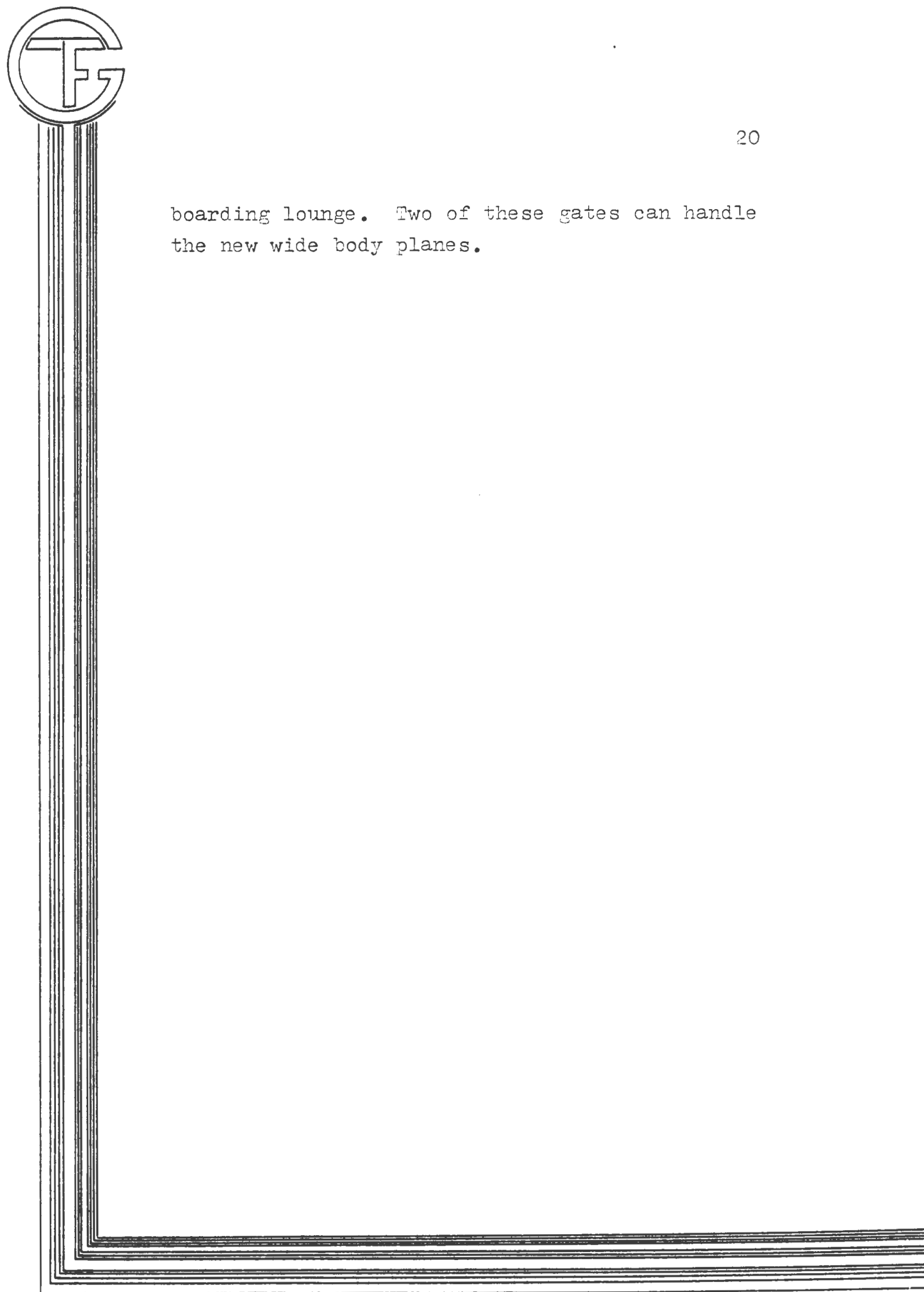




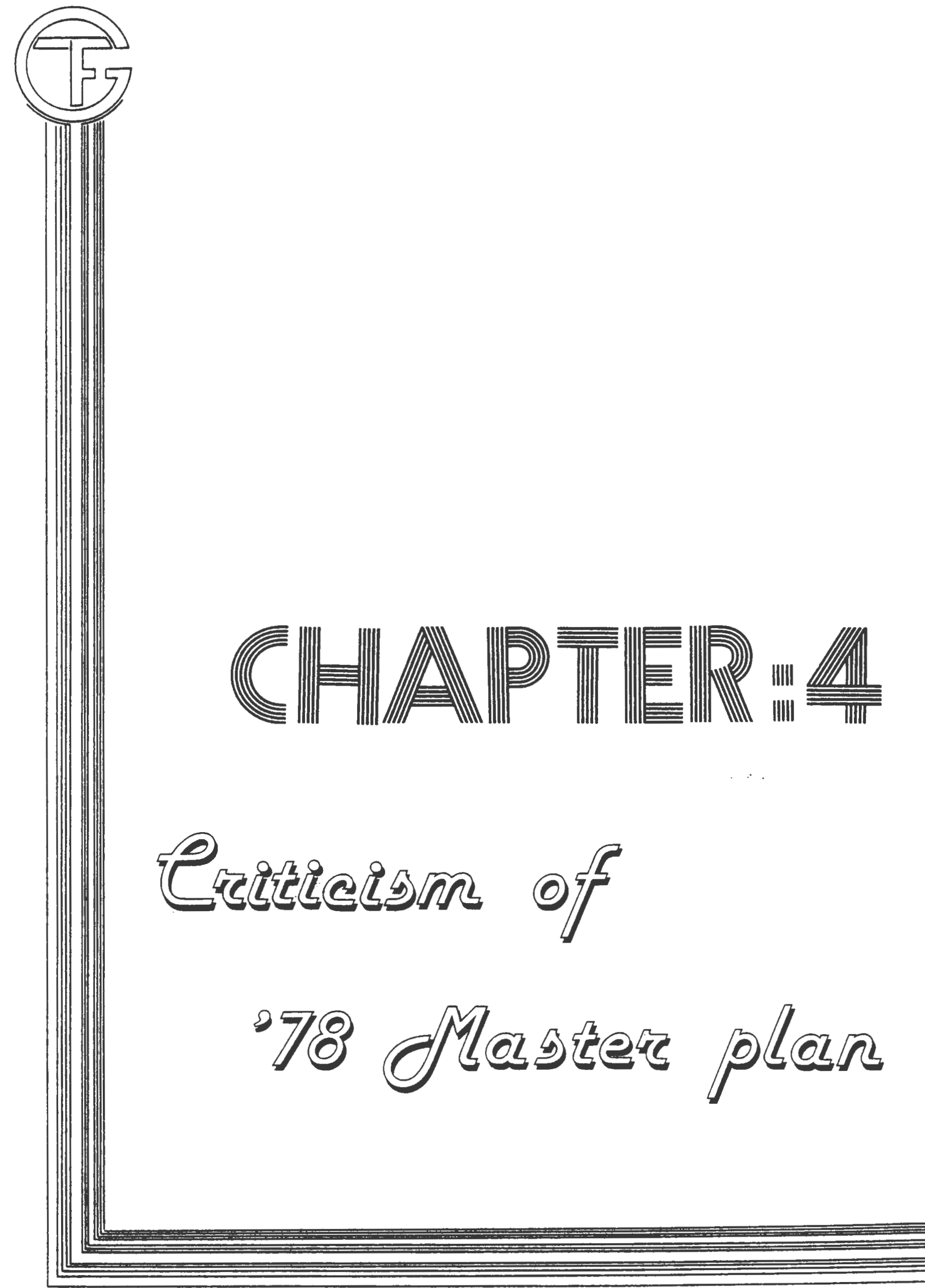


CRITICISH OF 1979 MASTER PIAT

Our evaluation of the various recommendations and proposals contained in the 1978 faster Plan will now be giten. As in previous chapters, the functions which talke place on the site outside of the terminal building will be discussed first.

There are several aspects of the master plan that are very good and deserve praise. One of those is the medium term parking area. The master plan leaves this where it is at present. Its proximity to the terminal building is quite adequate. An even more important virtue of this area is the safety of pedestrians. Airport users may leave their cars in the medium term lot and walk directly into the terminal building without the need of walring through conflicting corridors of vehicular movement.

It is true that the medium term parking lot exhibits no indications of total architectural integration of the site and termiral building. Howerer, within the context of the master plan, which makes no attemots at architectural integration, the efficient and indeed effective manner in which the medium term lot fulfills its purpose is to be commended.

Another good point of the master plan in relation to the site is the rental car parking area. The master plan provides for an increase in capacity of this area, which is certainly needed. 


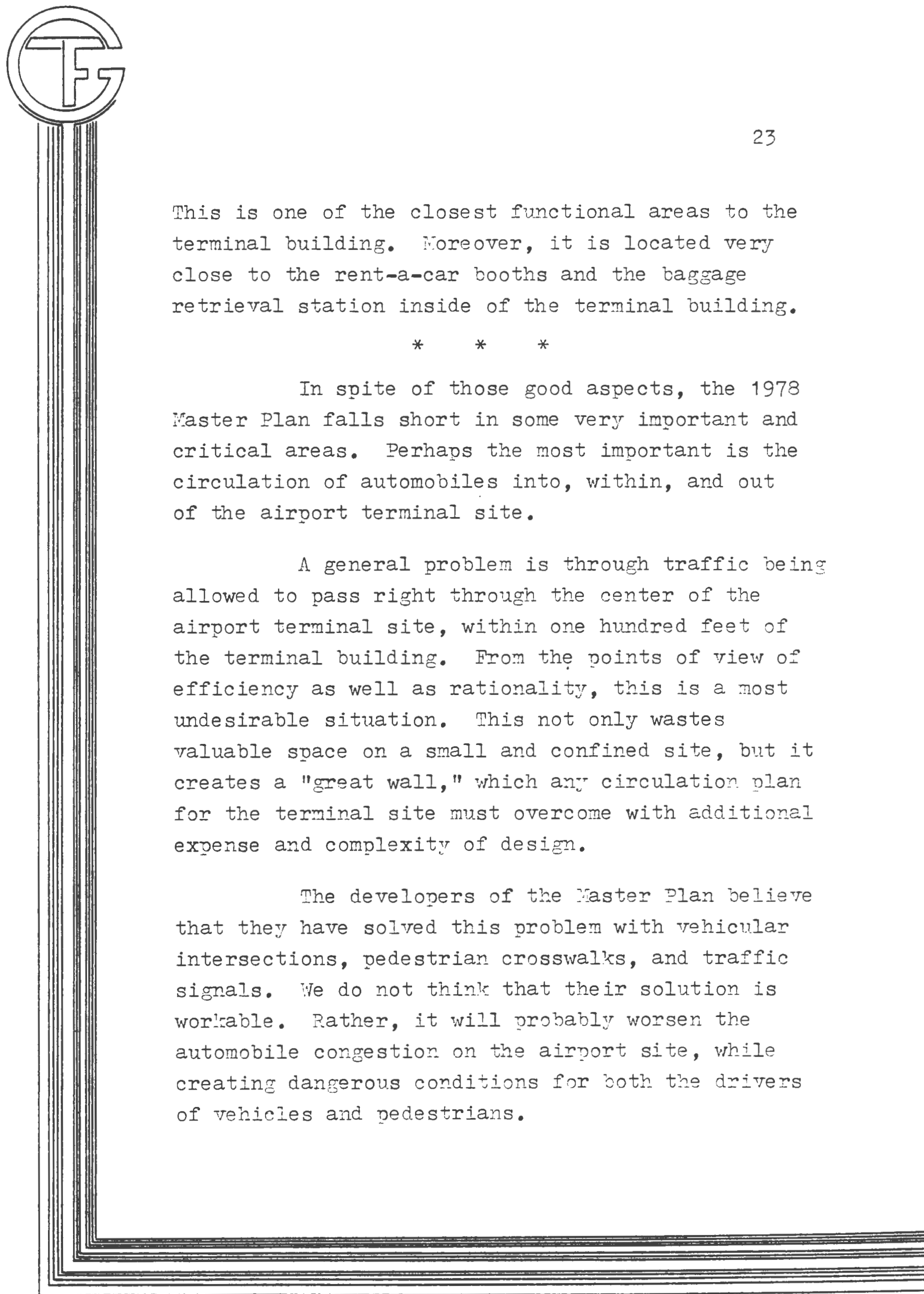




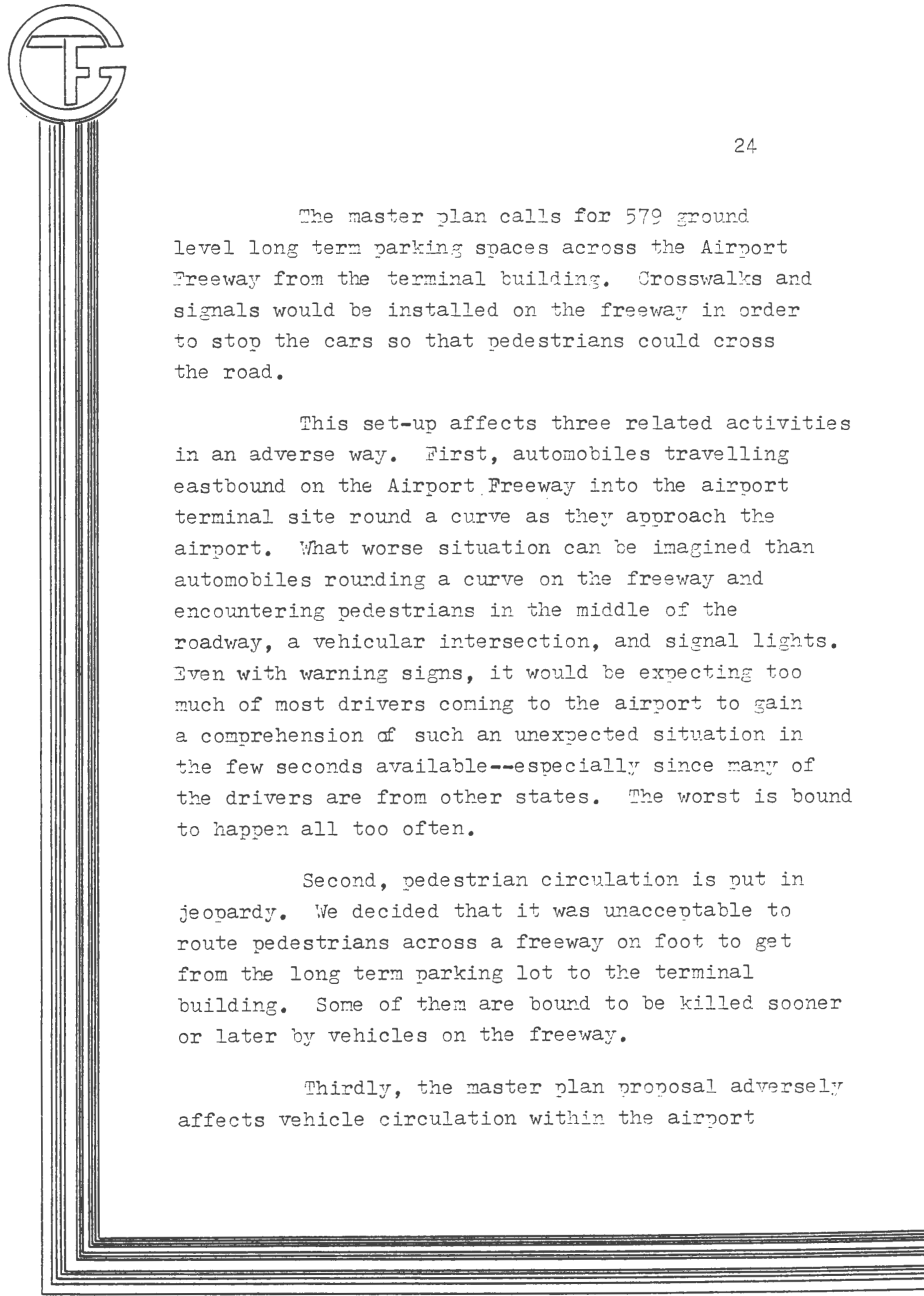


terminal site. A circular vehicular circulation pattern--countercloclwise around the short term parking area, as well as through the long term parking lot has been suggested in the master plan. Upon examination, this is an interesting idea.

However, we believe that it will never work as planned. If only airport traffic were allowed on the site of the terminal, a slightly more refined version of this traffic pattern would probably work very well. However, a freeway will dumo its traffic-much of it through traffic--into this site. With pedestrians and traffic signals further hindering traffic flow, this plan can onlt lead to a situation which is worse than what now exists.

Closely related to the vehicular circulation on the site of the terminal building is the problem of an inadequate number of parking spaces at the terminal. It appears that the amount of parting orovided in the 1978 raster zlan is not adequate even for the medium term future.

We do not question the projections of future parking demand at the airport. nnowing that those projections were generated by experts and are the most reliable available, we have used them in our analysis. We do however question the advisabilitur of recommending a olan which is known to be inadequate br its makers, as is the case of the Yaster Plan. 


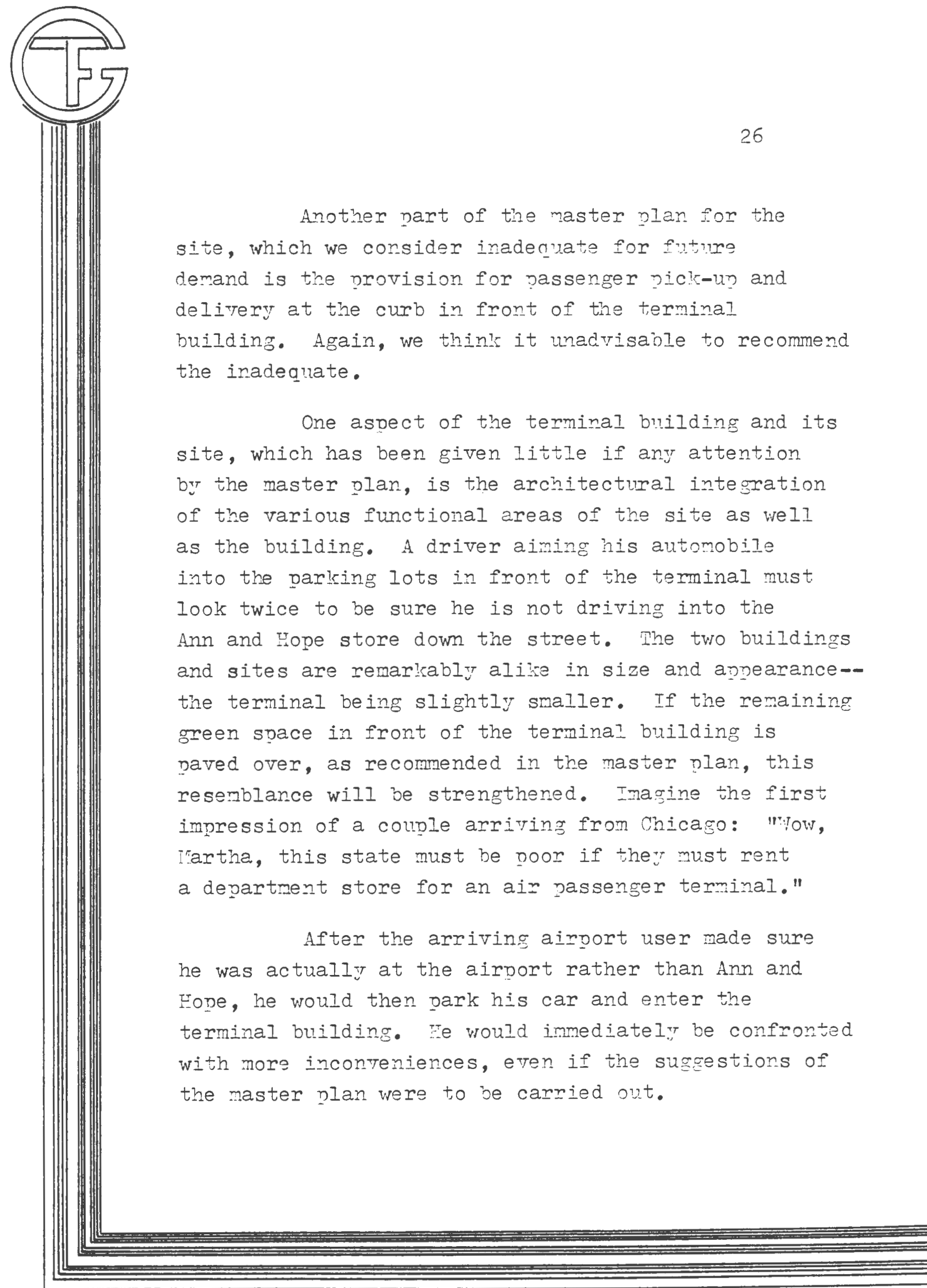




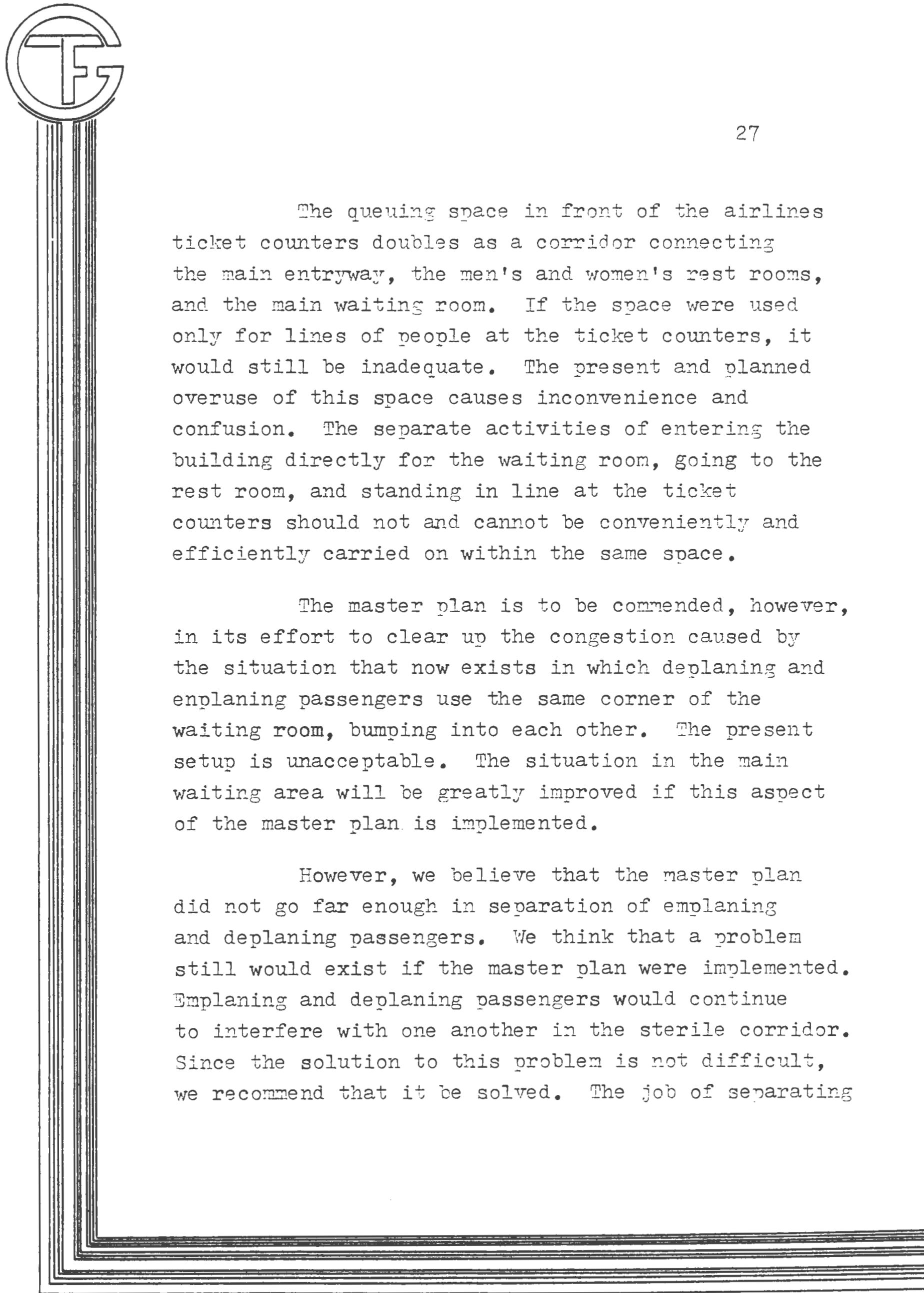




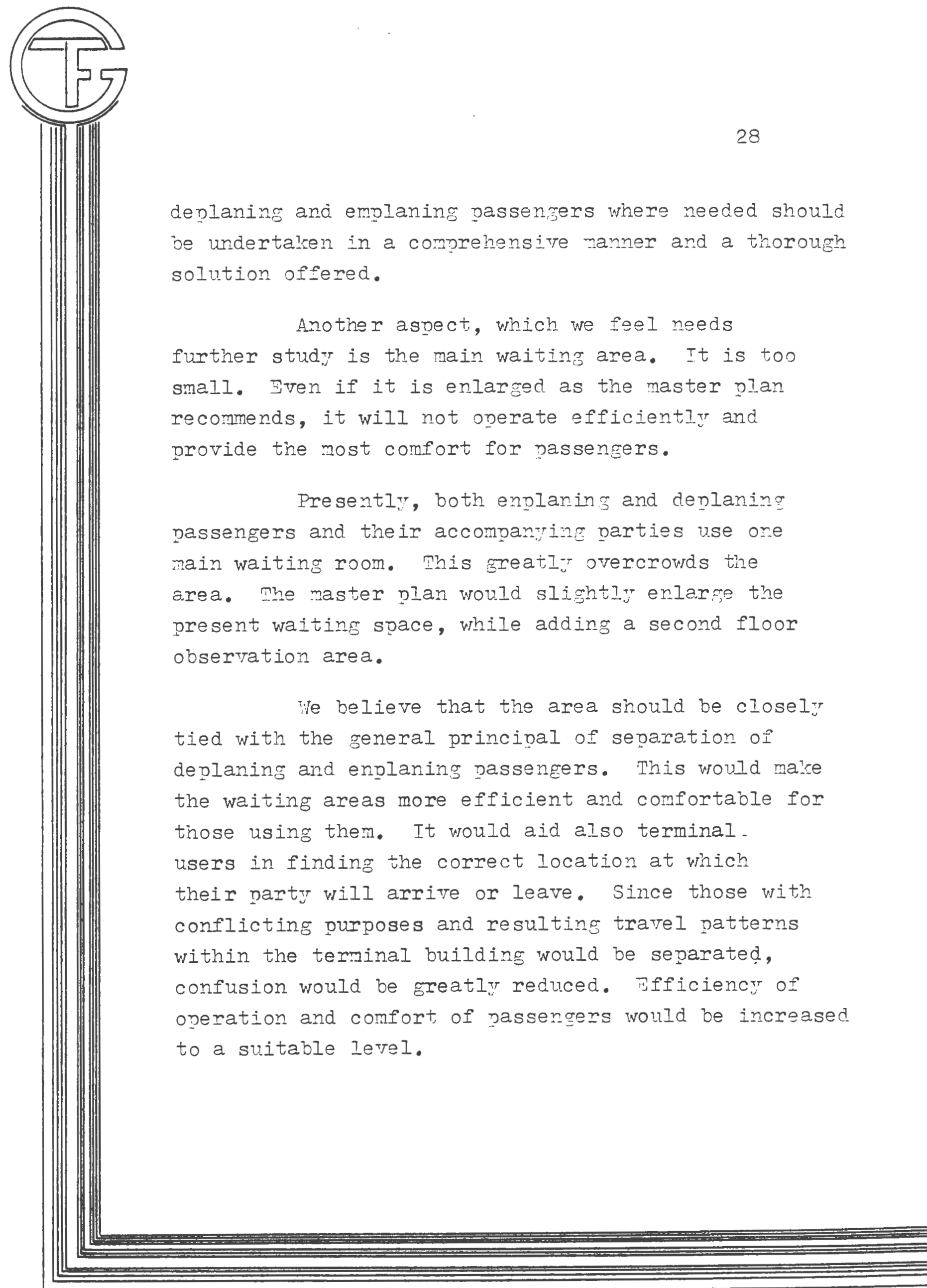




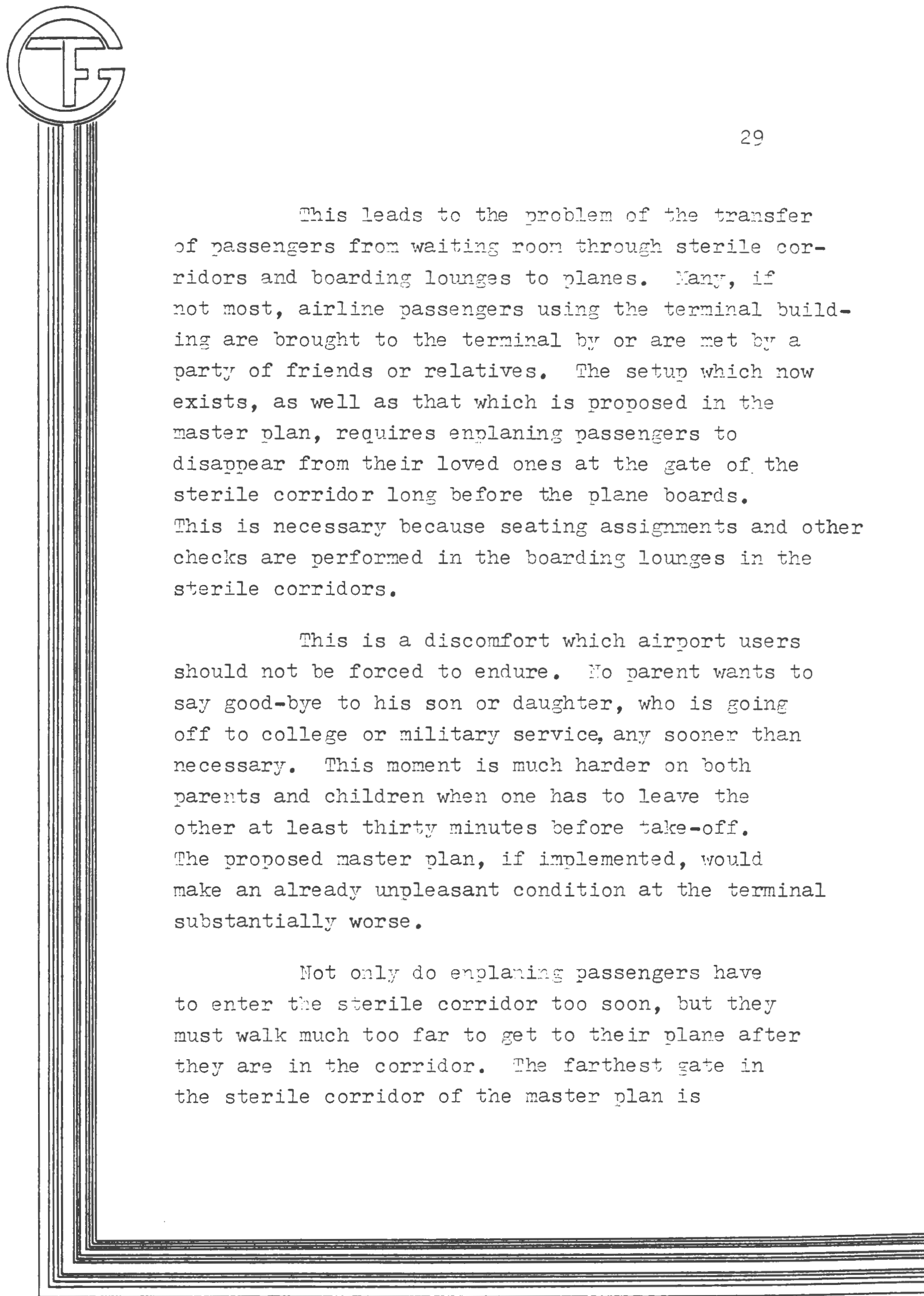




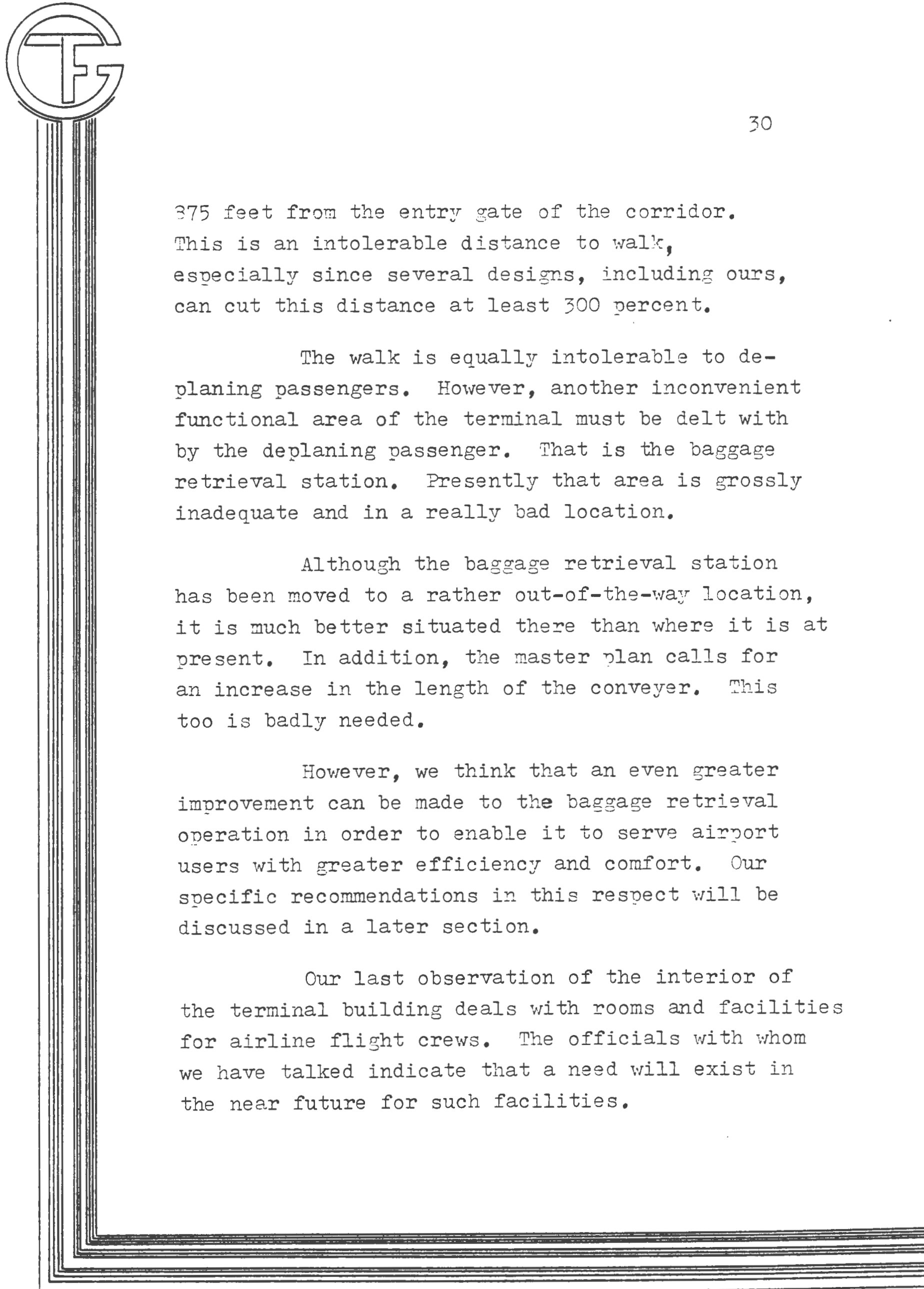


Runway facilities are being upgraded and terminal facilities are being enlarged in response to the need to bring larger ride body jets into Green State Airport. This will bring an accomnanying need for comfort and preparation areas for flight crews.

Iittle or no attention was given to this need in the master plan. And, although nassengers should of course be given top priority in comfort and service, airline personnel also should have comfortable facilities. It is no secret that economic benefits soill over from the airoort into surrounding cities when airline emplorees are brought in. This will not happen if no facilities or uncomfortable facilities are all that are available. 
$32-1$

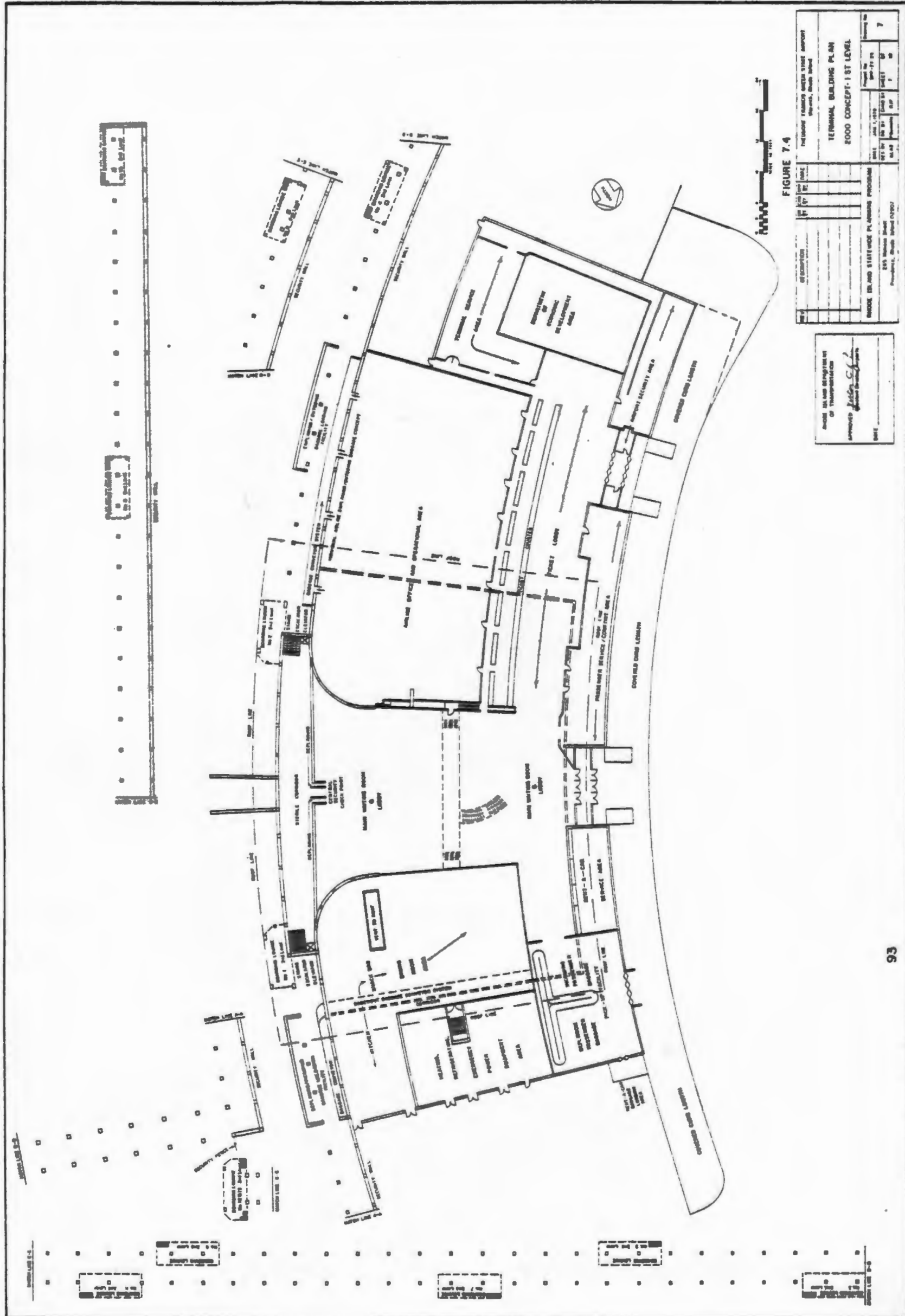

ב్ 


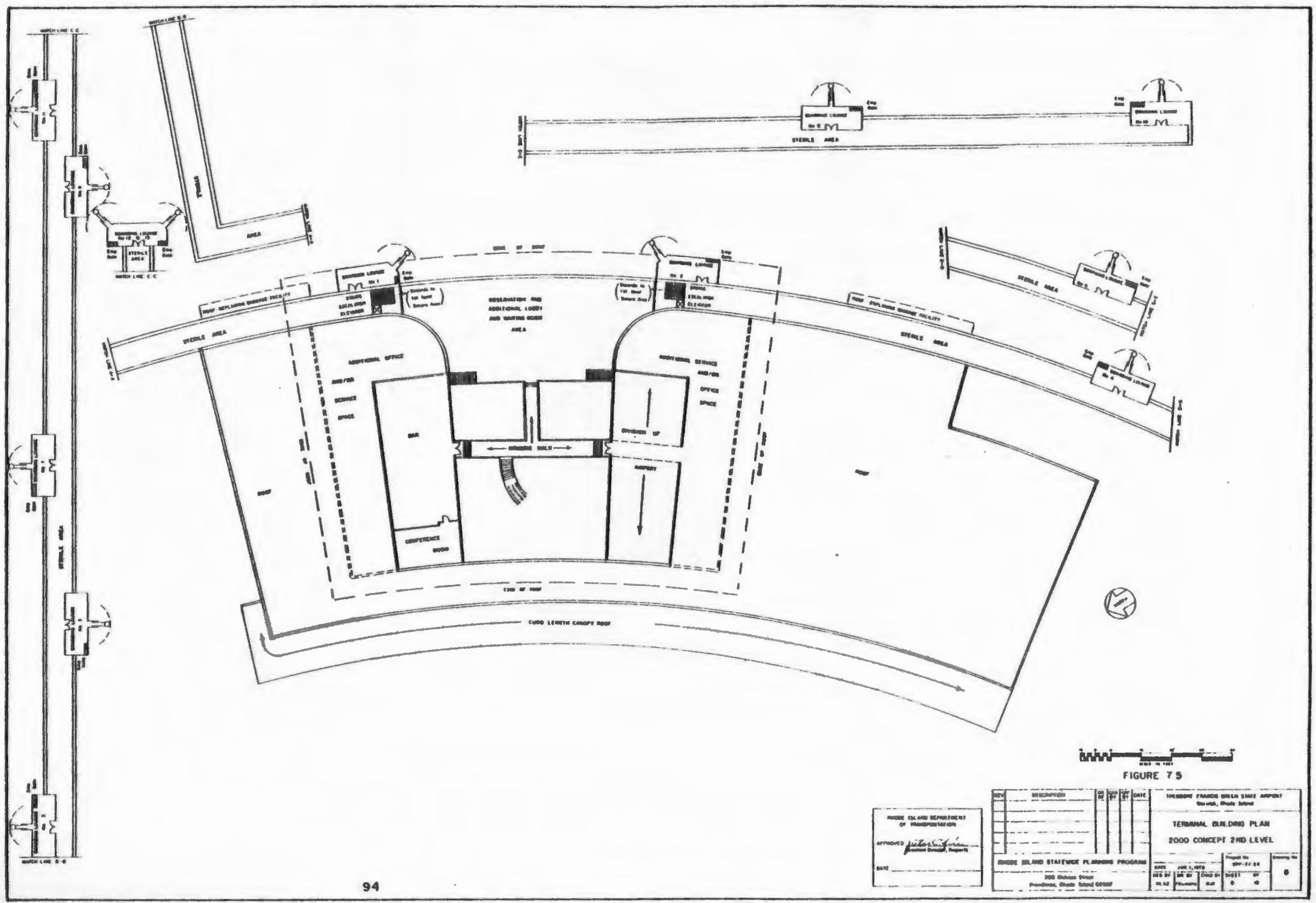

Figure 4.2 Terminal Building Second Level (Master plan) 


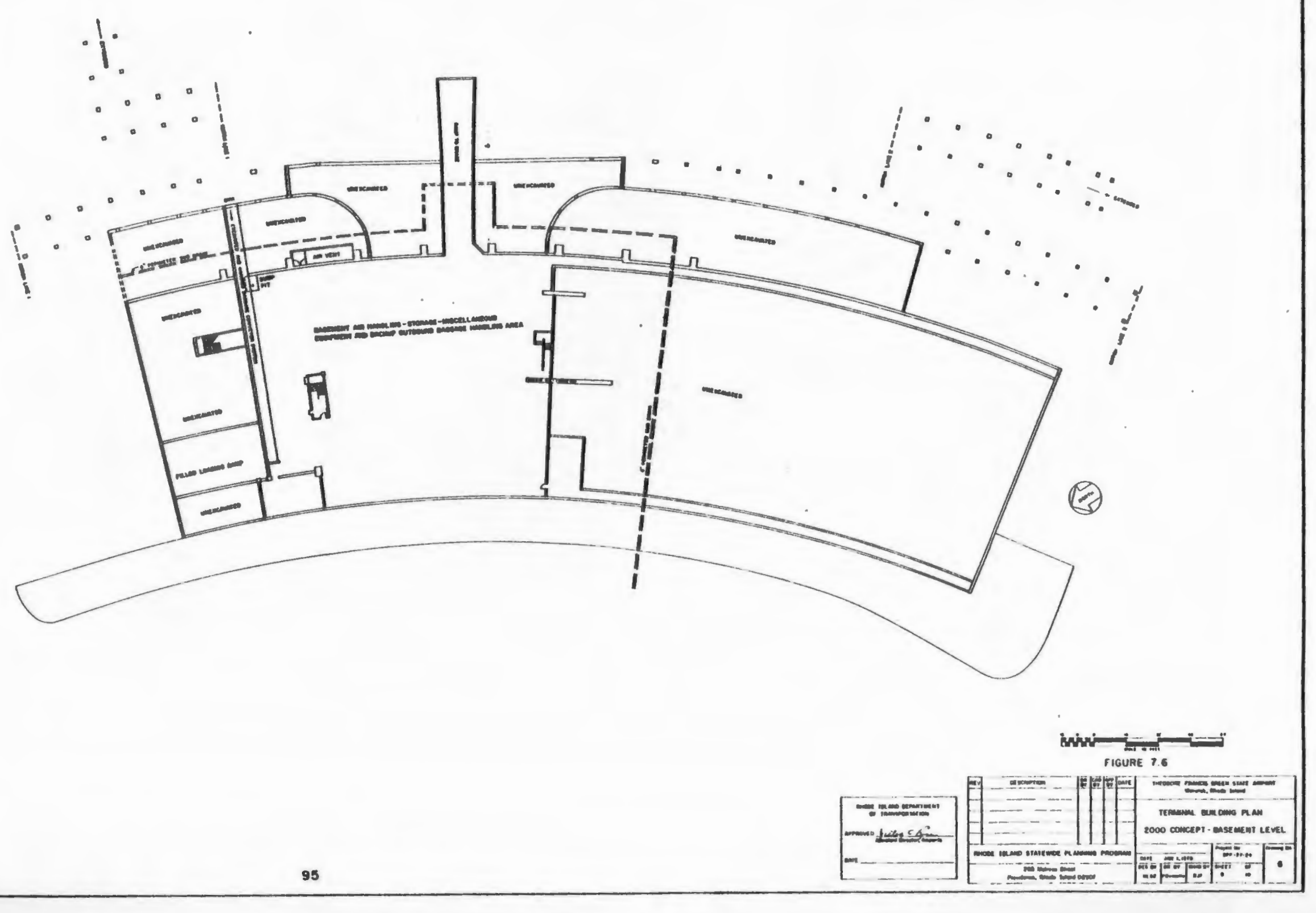

Figure 4.3 Terminal Building Basement Level (Master Plan) 


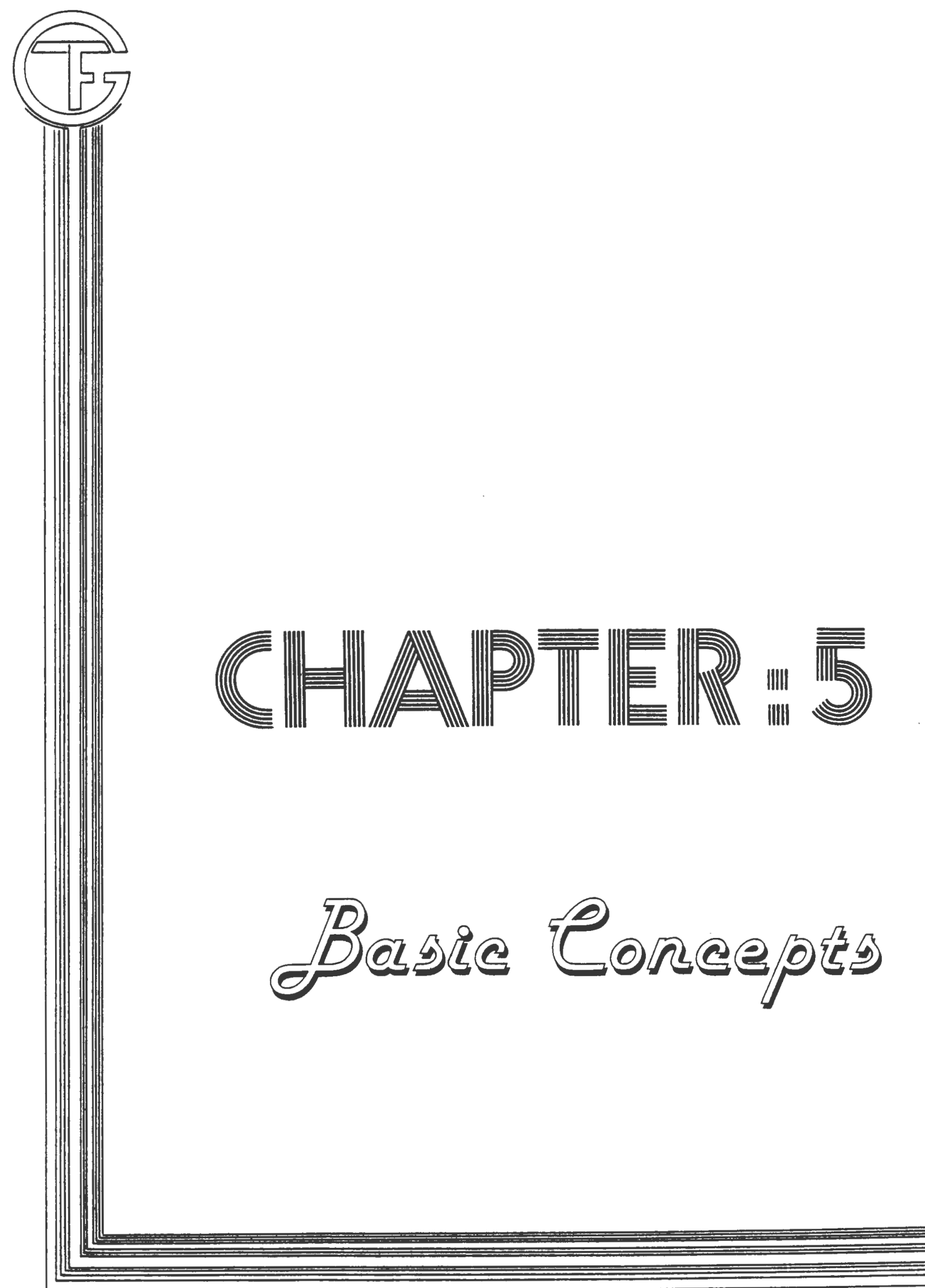




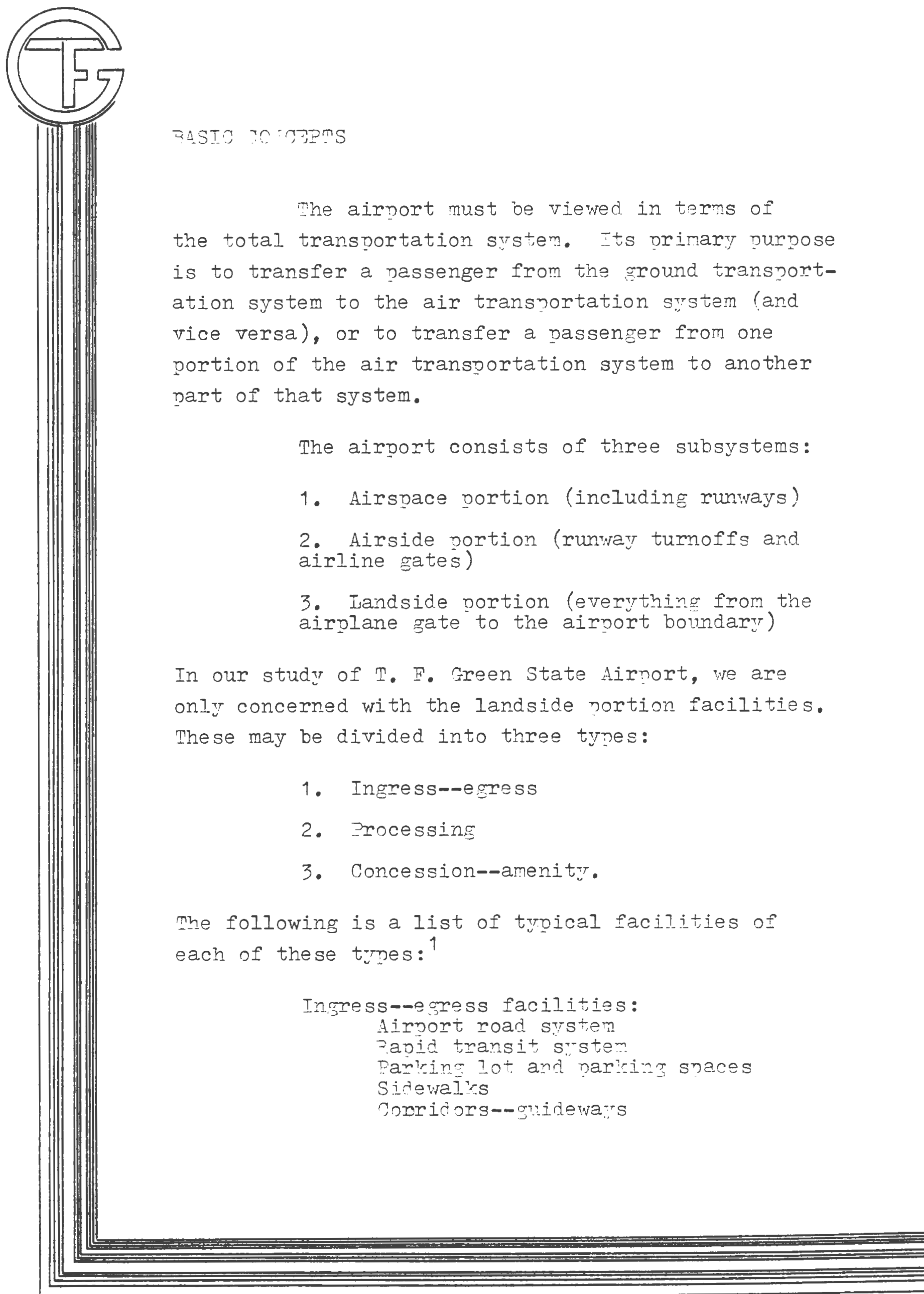




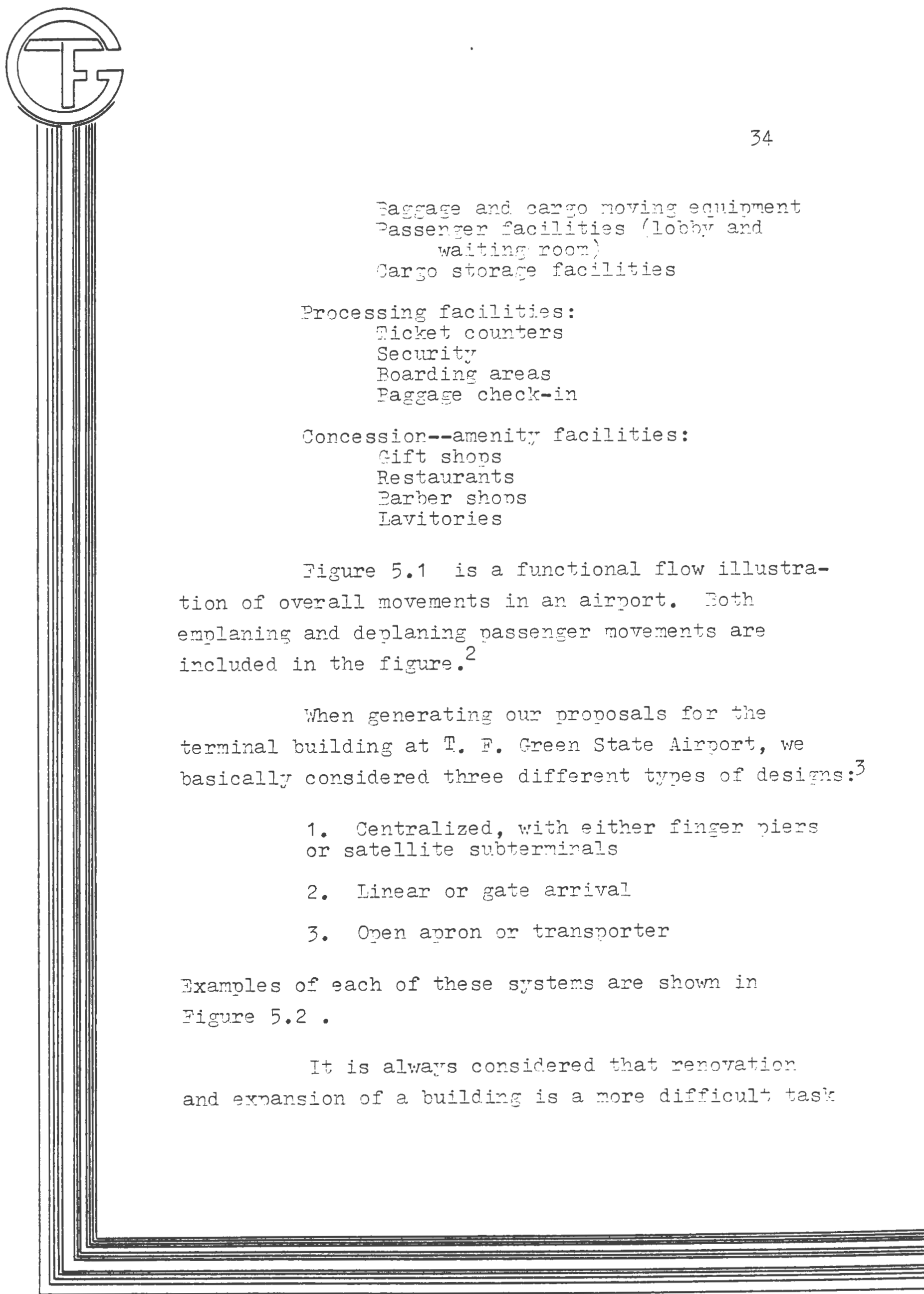


Figure 5.1

Airport landside functional flow.

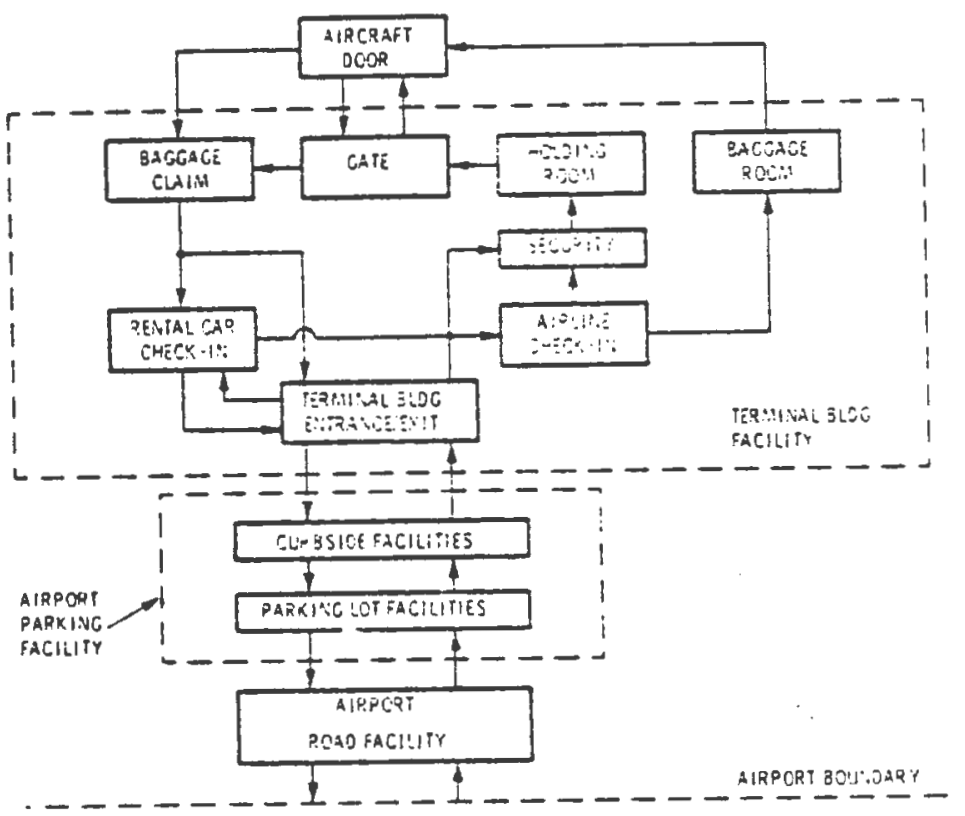




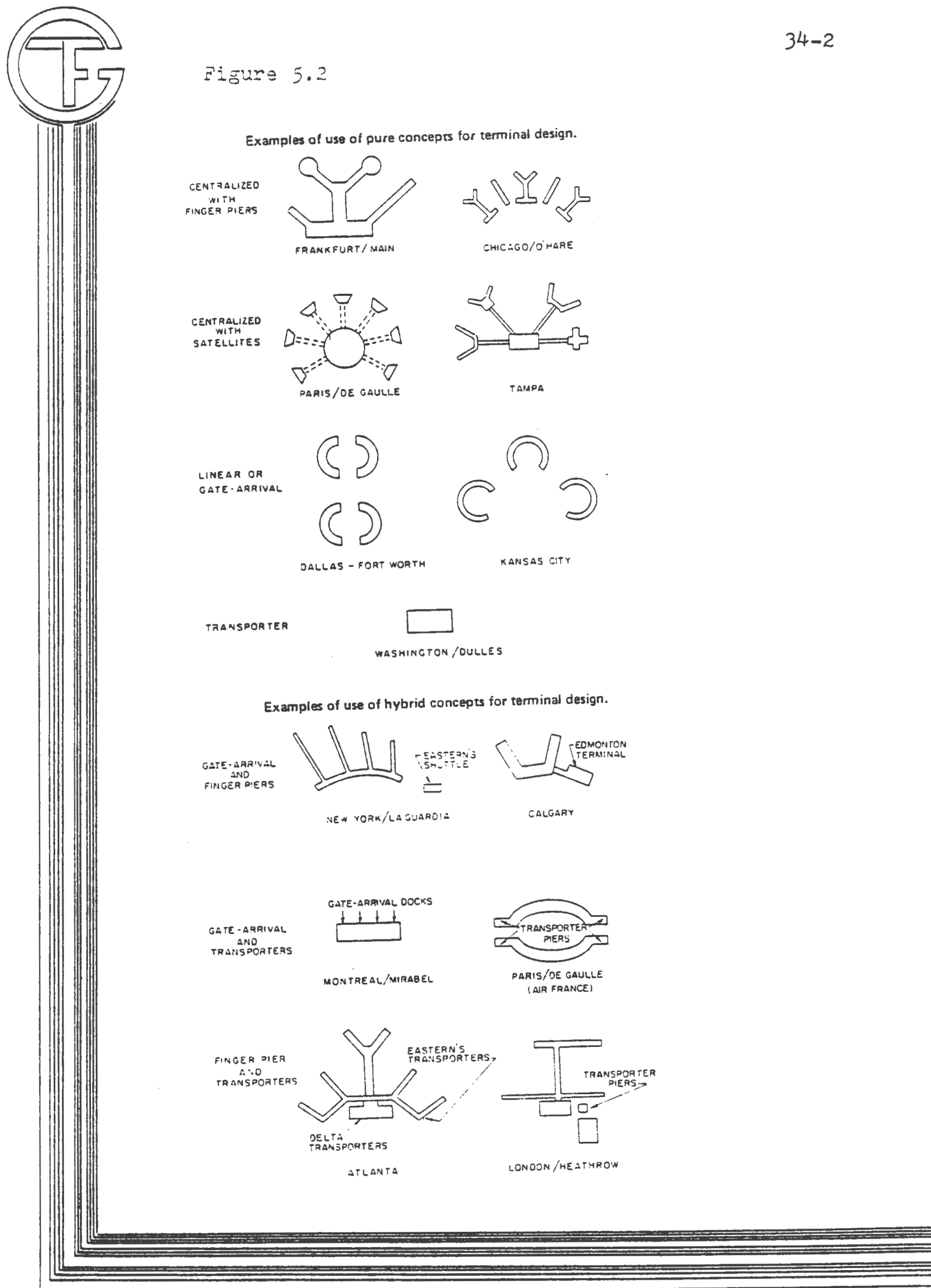


to accomplish than designing from scratch. Undertaking such a difficult task, we decided to combine two of the three fundamental designs to come up with one design, rather than choosing one of the three concepts and argue whether that or another concept is better for all purposes. We feel that a diversity of needs can be best served by a mixture of three elements that best serve each need, keeping in mind that the users and operators of an airport terminal want it to function smoothly and efficiently. They want a variety of significantly different kinds of services--such as easy access to all aircraft and easy transfers. Combination of centralized and linear design is used in our proposal. 


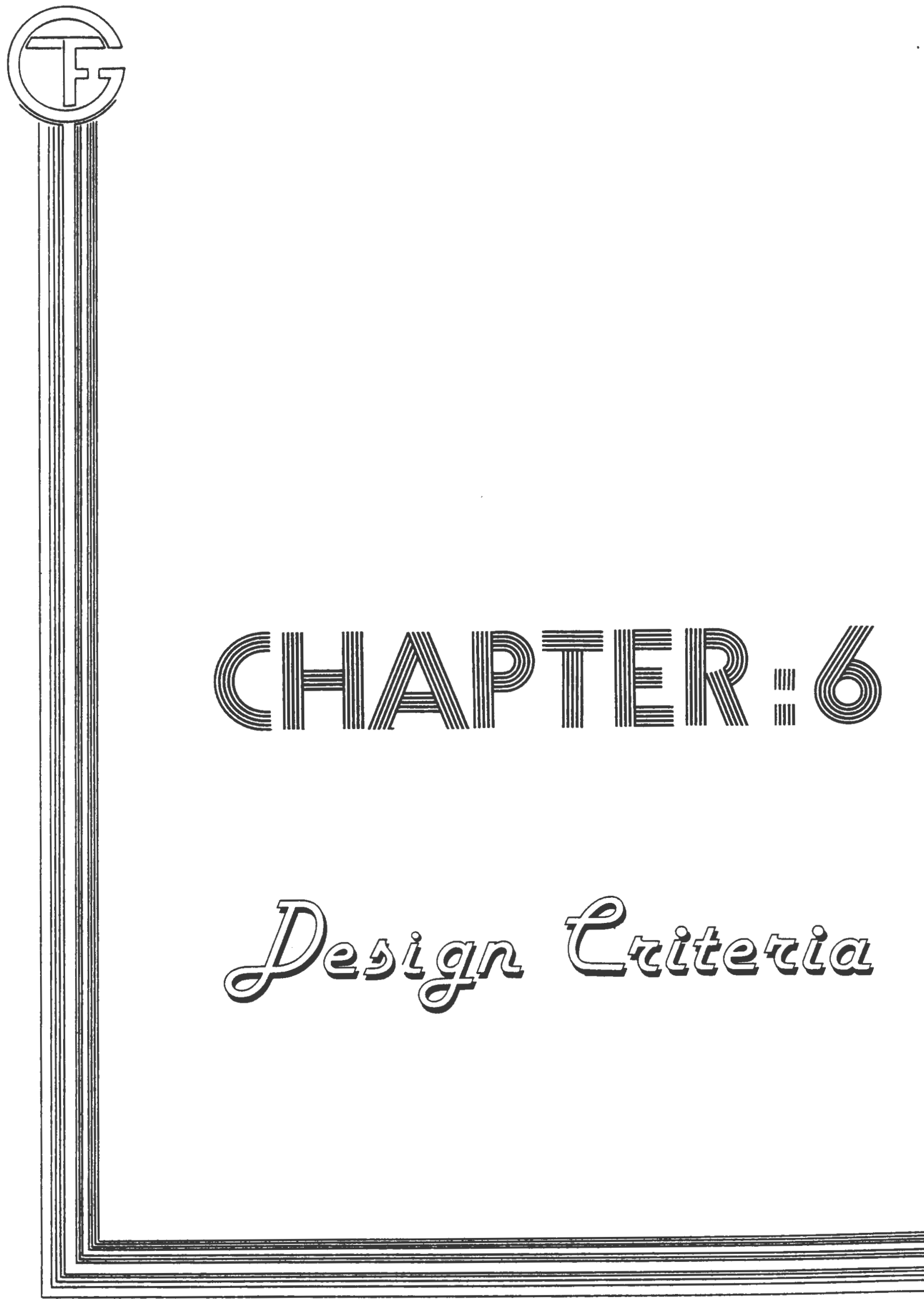




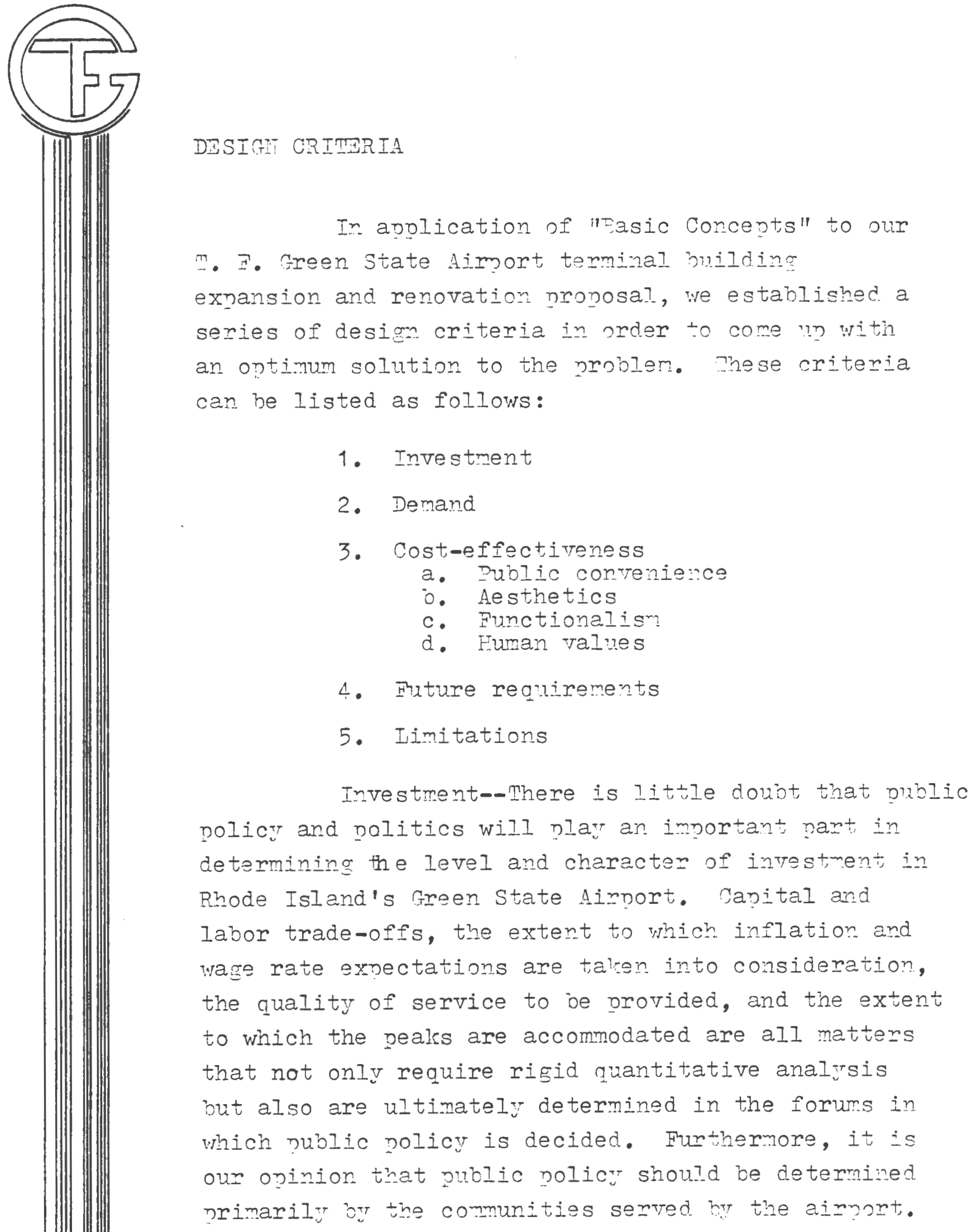




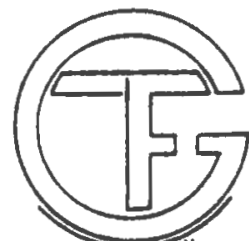

Tt is at this level that the community needs, concerns, and objectires must be defined and satisfied. Even though re have discussed such natters rith ranious state and local asencies and politicians, it is not our intension to get deenl into such study here. Although we feel that this is one of the shortcomings of our project, our objective at the beginning was to mare use of available data and to come pִ with the optimum solution to them.

Demand-a feel that the character of the airport demand is an important determinant of the character of the resources that are required to provide the airnort sistem with needed racilities. In other words, it is important to rinimize the extent to which mismatches occur betrpen the aircraft and teminal building canabilities. Cur calculations of the extent to which the terminal building should be expanded depends almost completely upon the figures taken from the 1978 - Taster Plan (Preliminary Draft) from the Rhode Island Statewide Dlanning Drogram, as irell as various other studies.

\section{Importance of cost--effectiveness--}

Terminal building design varies from the spartan to the Iuxurious. Viany factors and many parties have been responsible for providing passengers with more than they need in manr cases. At the same time, costeffectiveness plars an important part, in terminal cuilding design. 


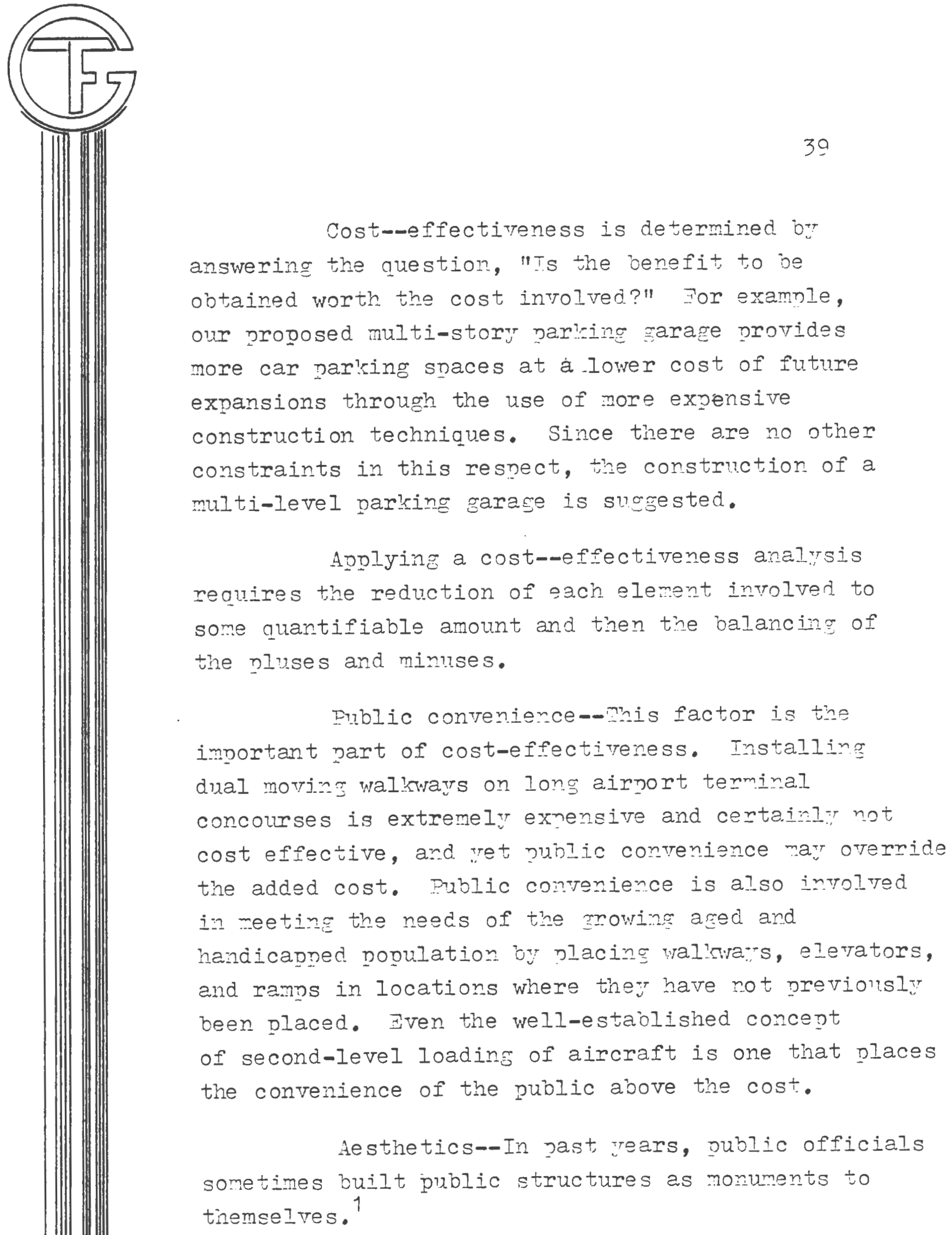




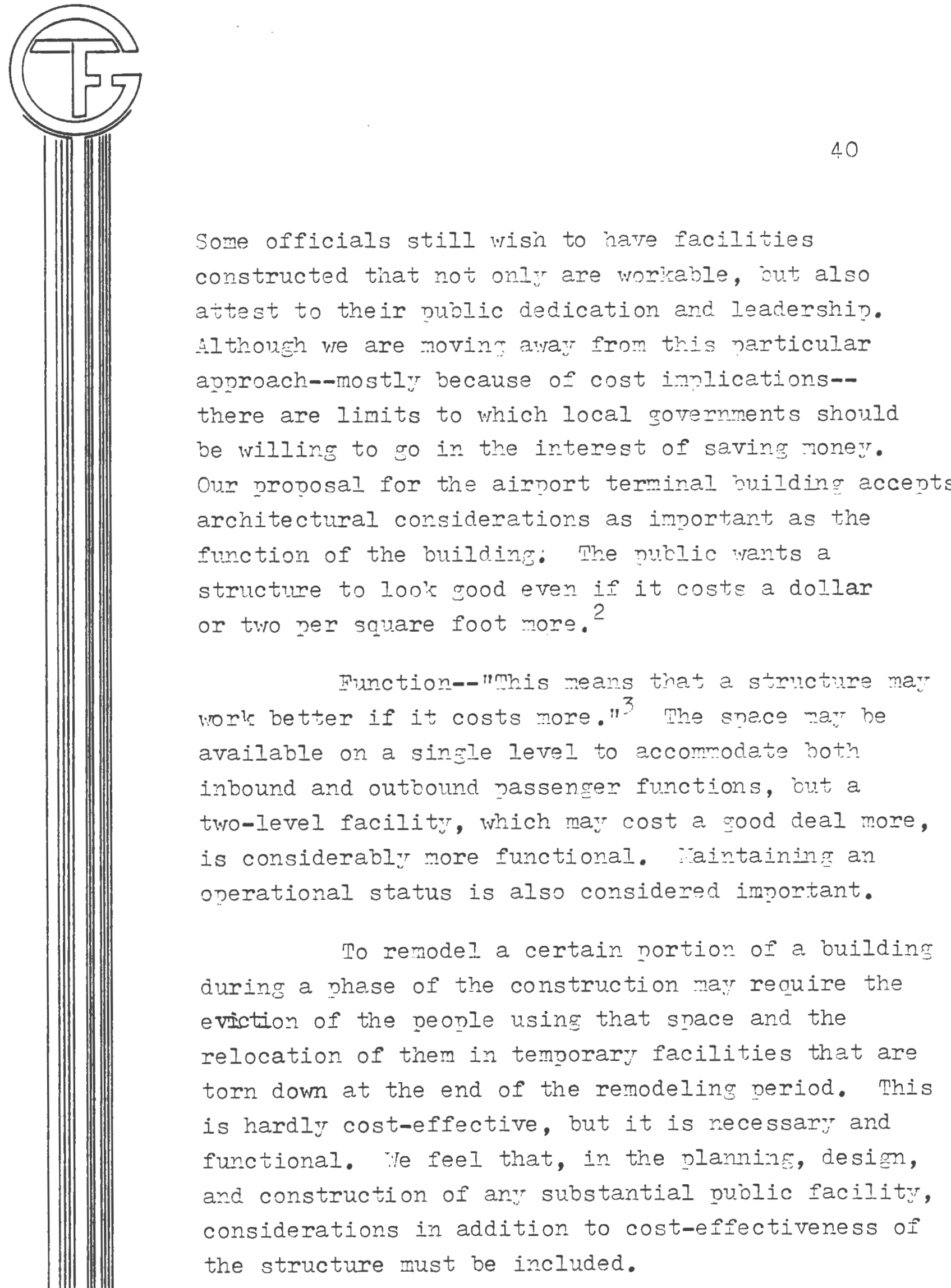




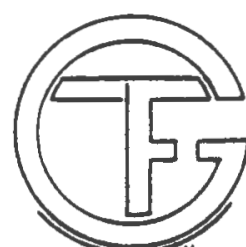

Iuman values-- These are expressed in terms of phrsical and ps:rcholozical comforts. Flements relating to physical comfort include distances necessary to walk from ground transportation to aircraft, the nassengers' baggage load and how far it must be carried, concestion encountered in various facilities the passenger desires or is required to use in reaching the aircraft, building temperatures and humidity, and size of waiting areas. ${ }^{4}$

Psychological comfort elements in our studir, such as waiting time, speed and ease of check-in, etc. are not studied in depth unless related directit: to phrisical comfort.

Answers to questions re asred indicate that people seem to complain more about the followin? problems that ther encounter in the terminal building of Greer State Airport:

1. Slow baggare reclaim unon arrival

2. Slow check-in upon departure

3. Tong wales to the aircraft

4. Inadequate narleing facilitios

5. Congestion encountered on the aimort site as they tror to get their venicles into the pariring lots. 


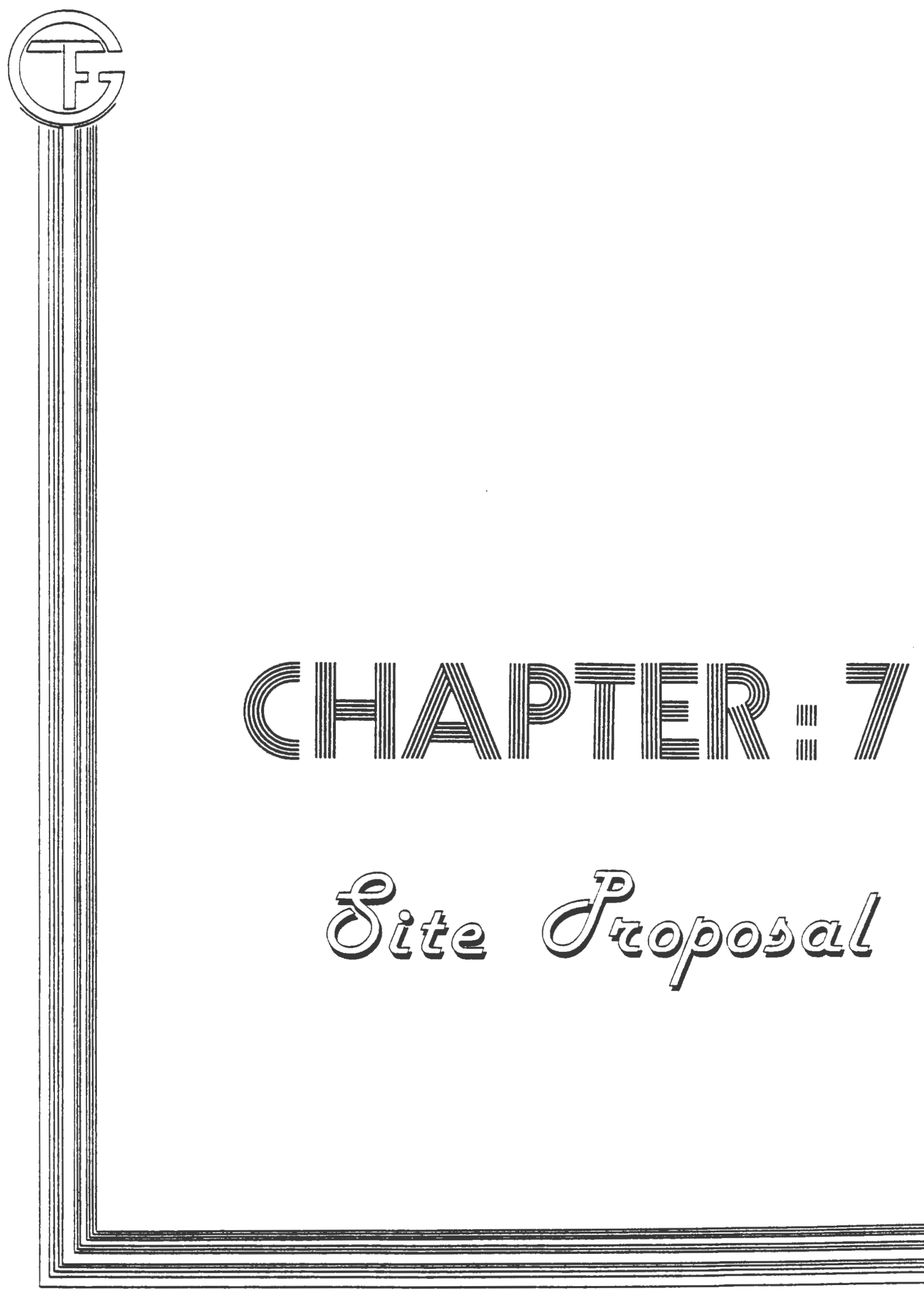




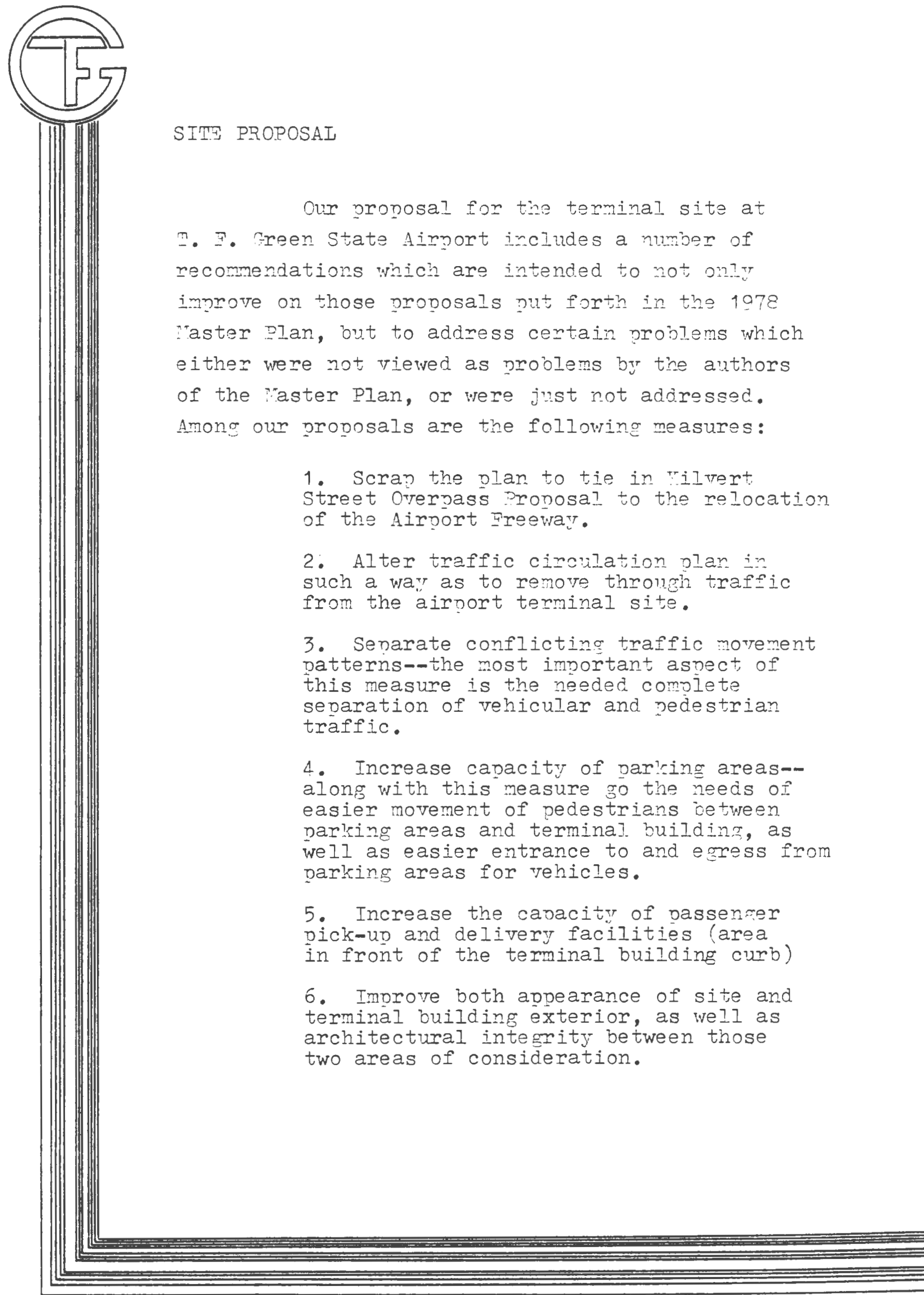




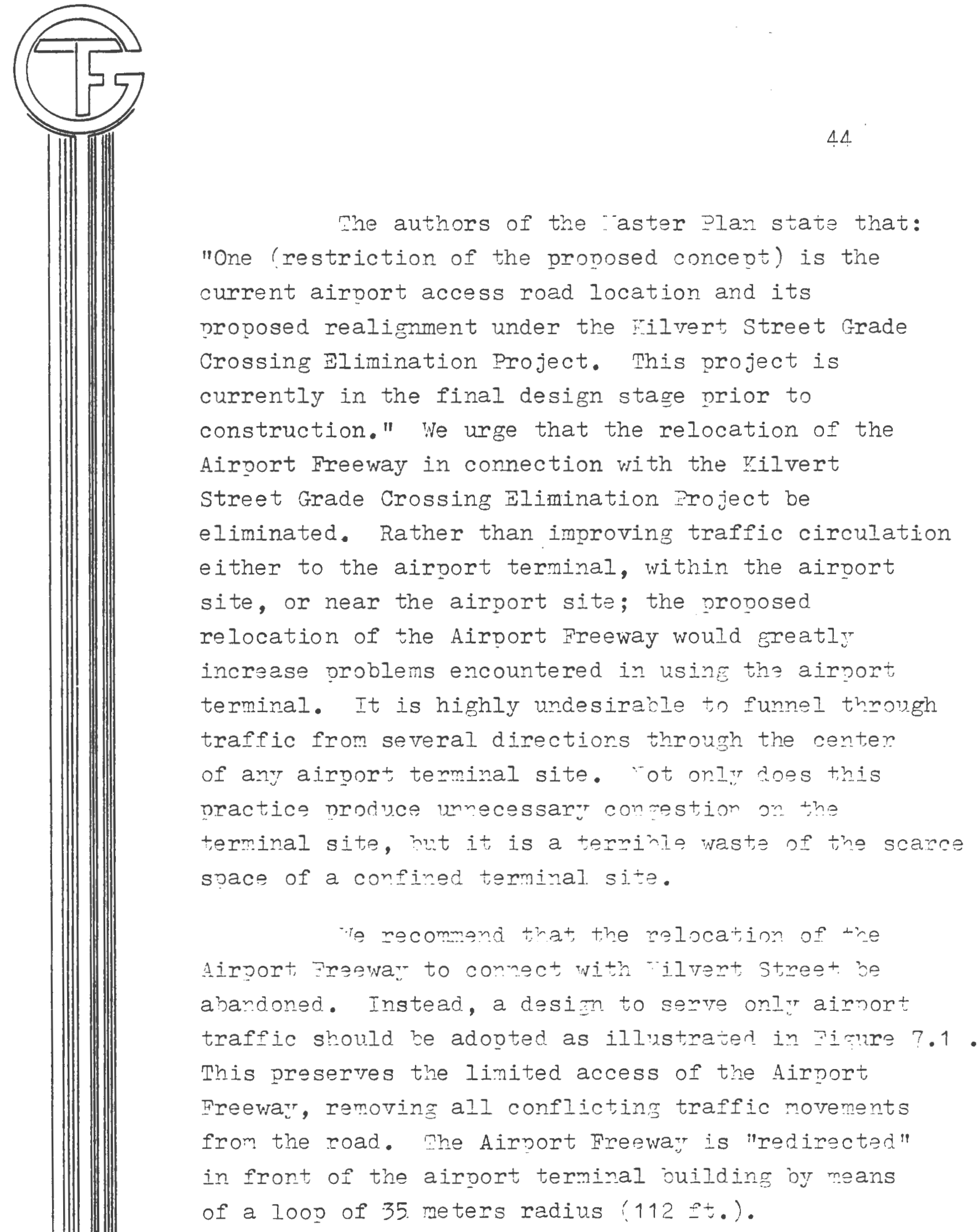




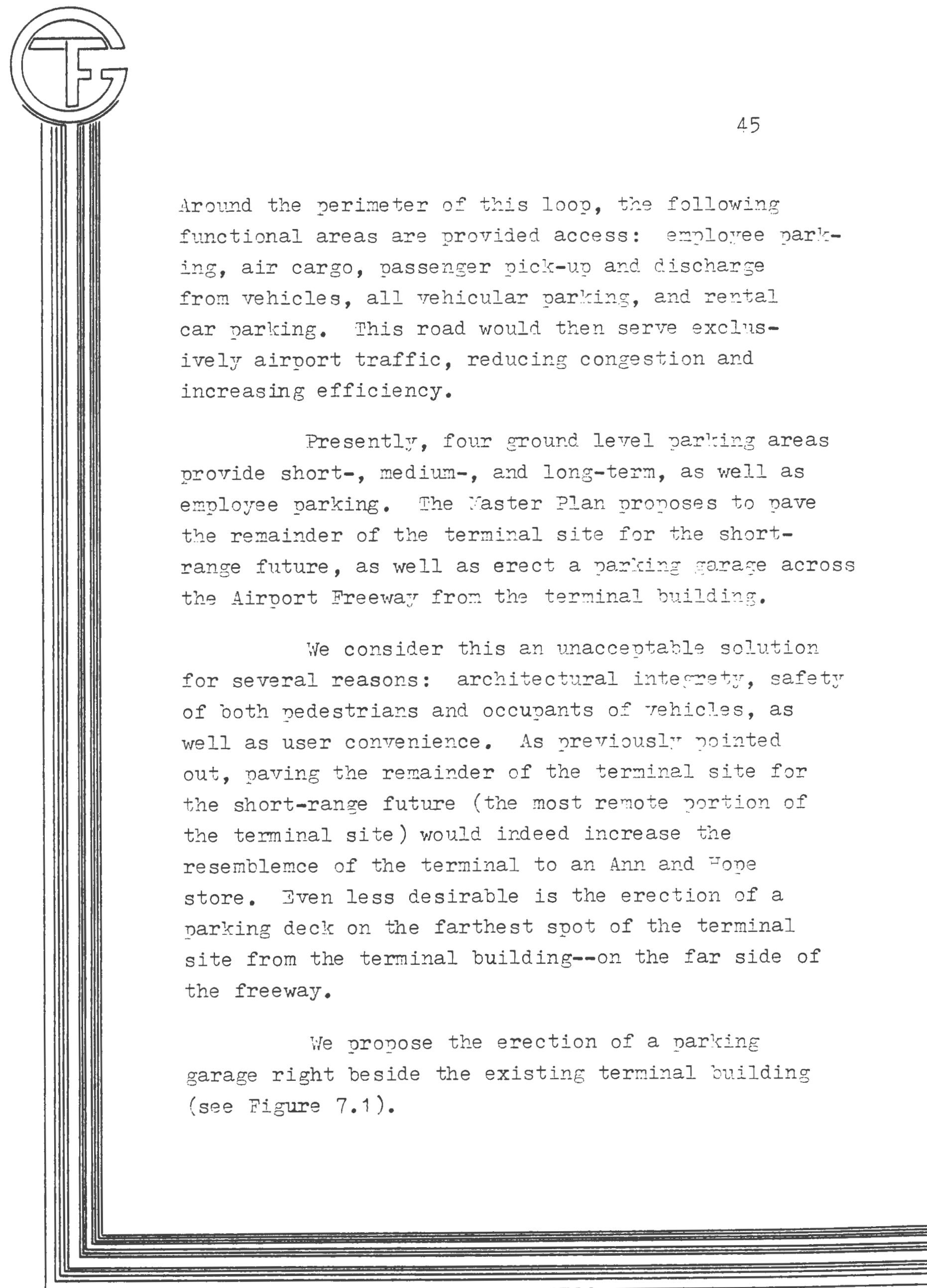




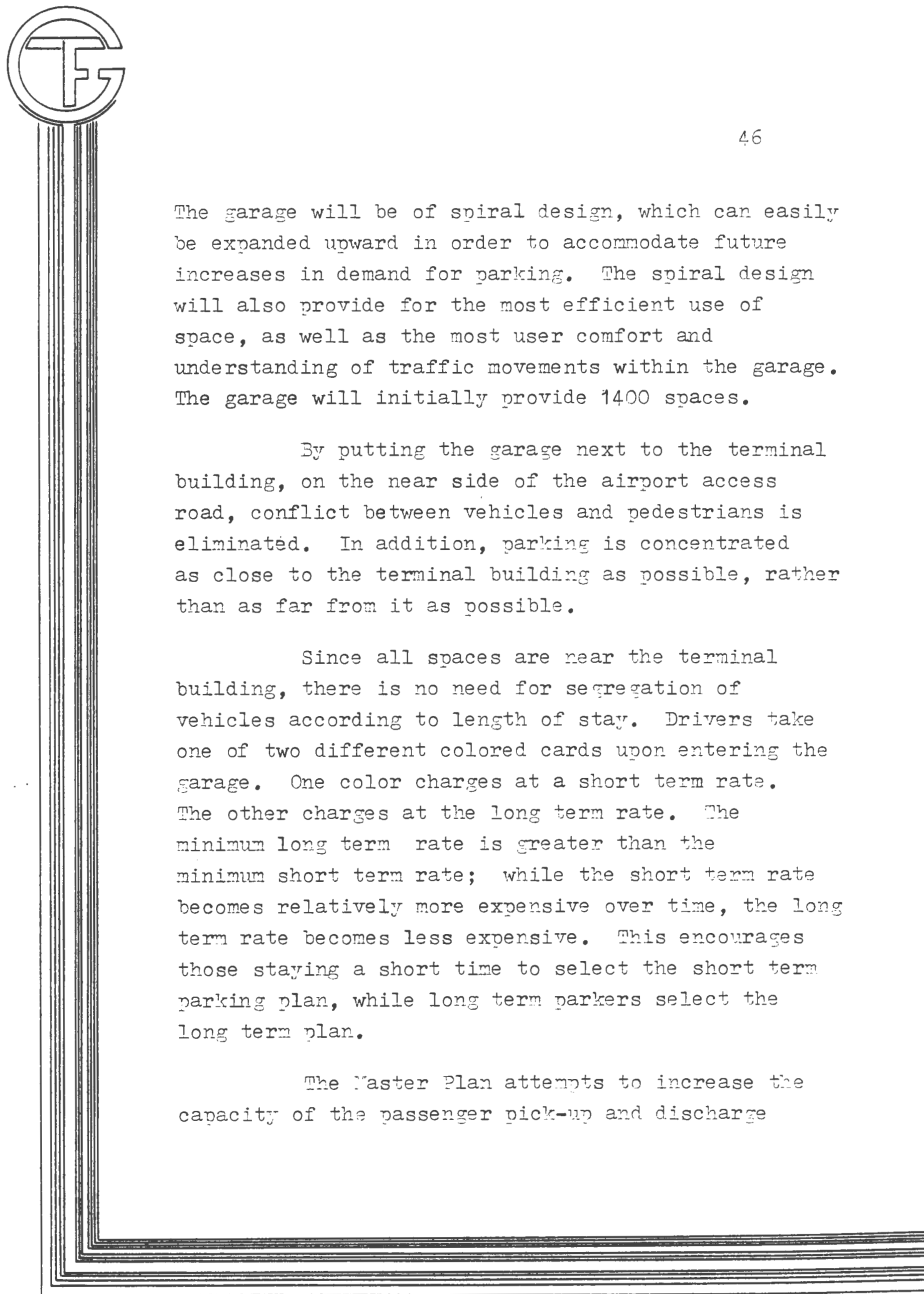




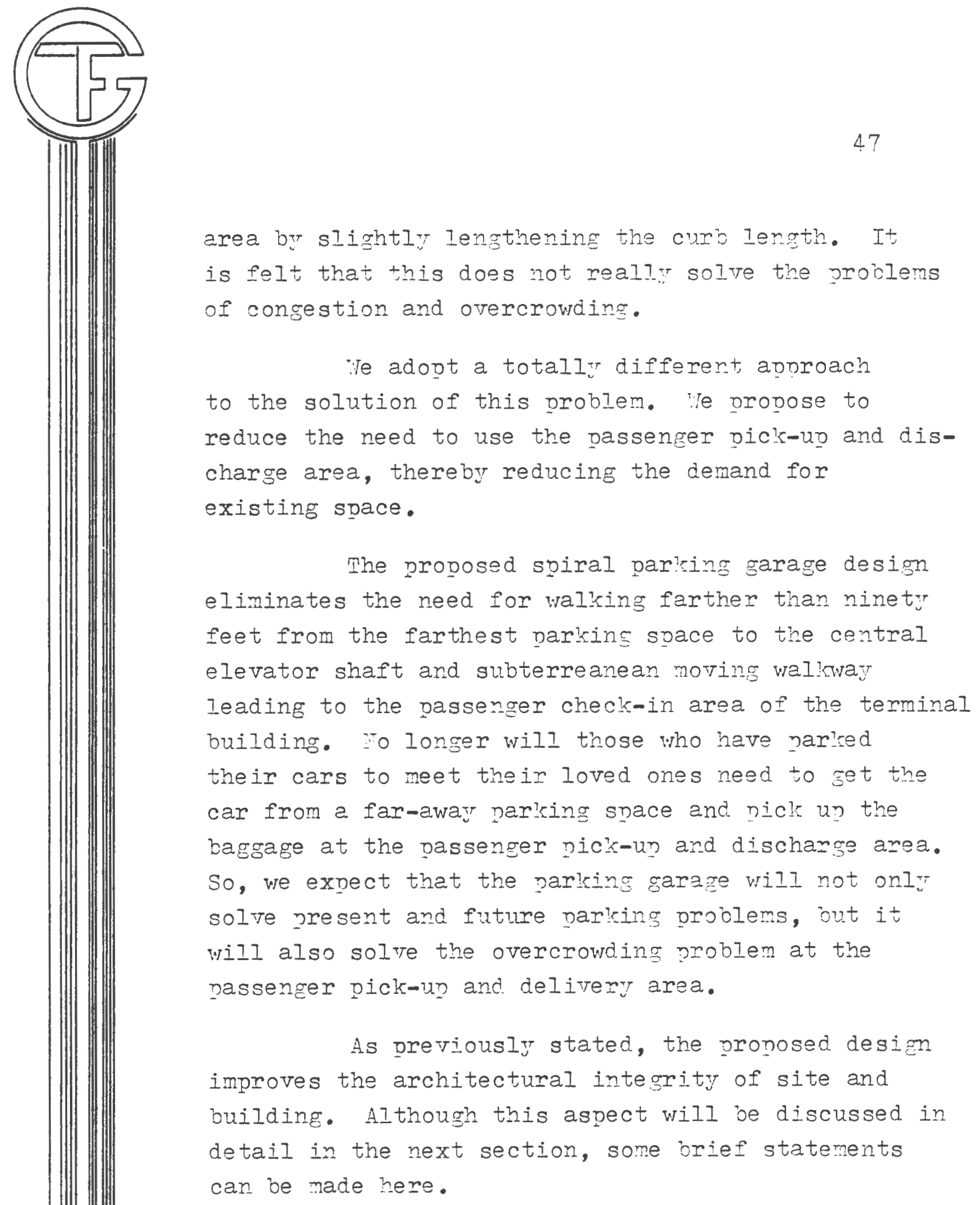




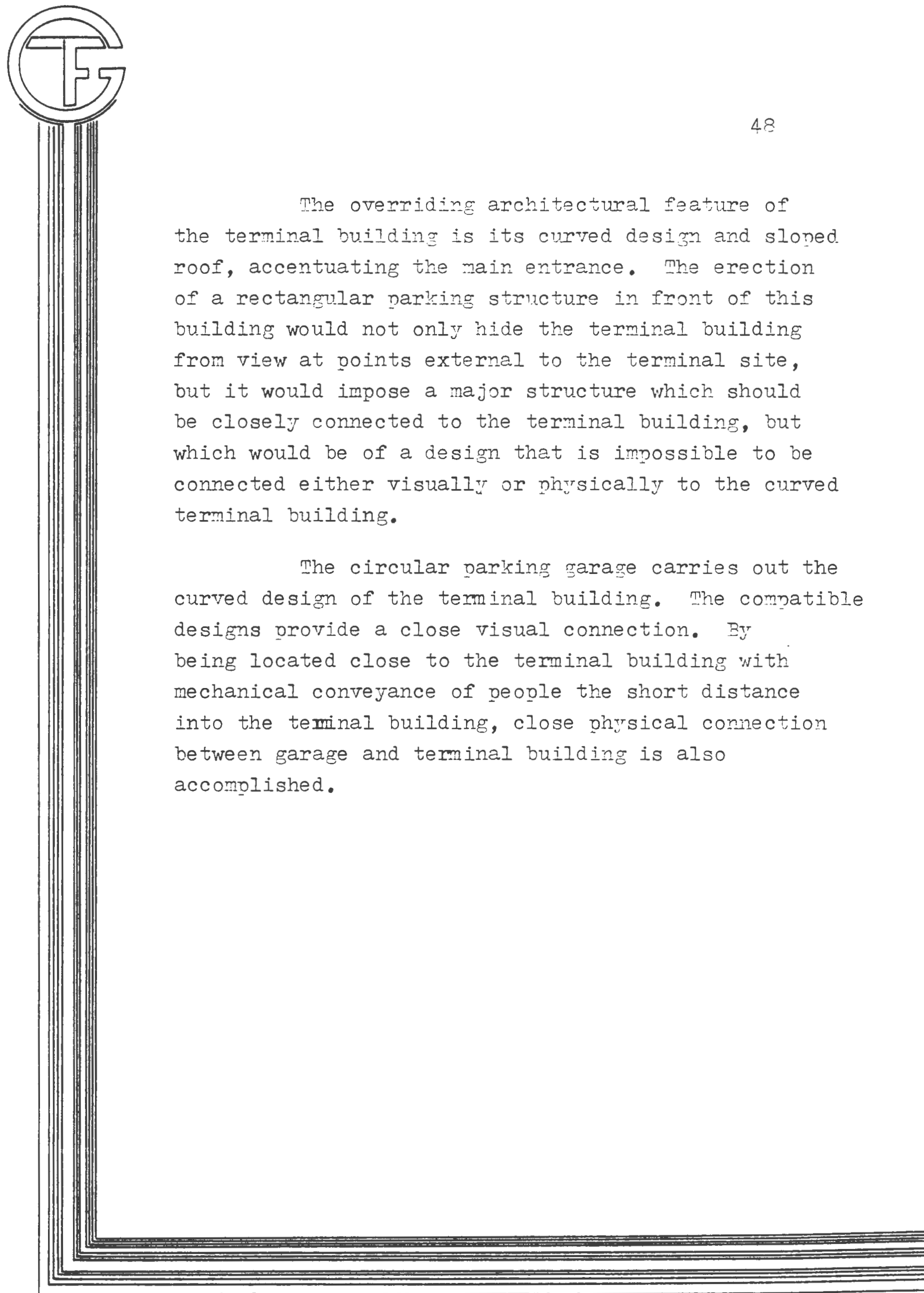




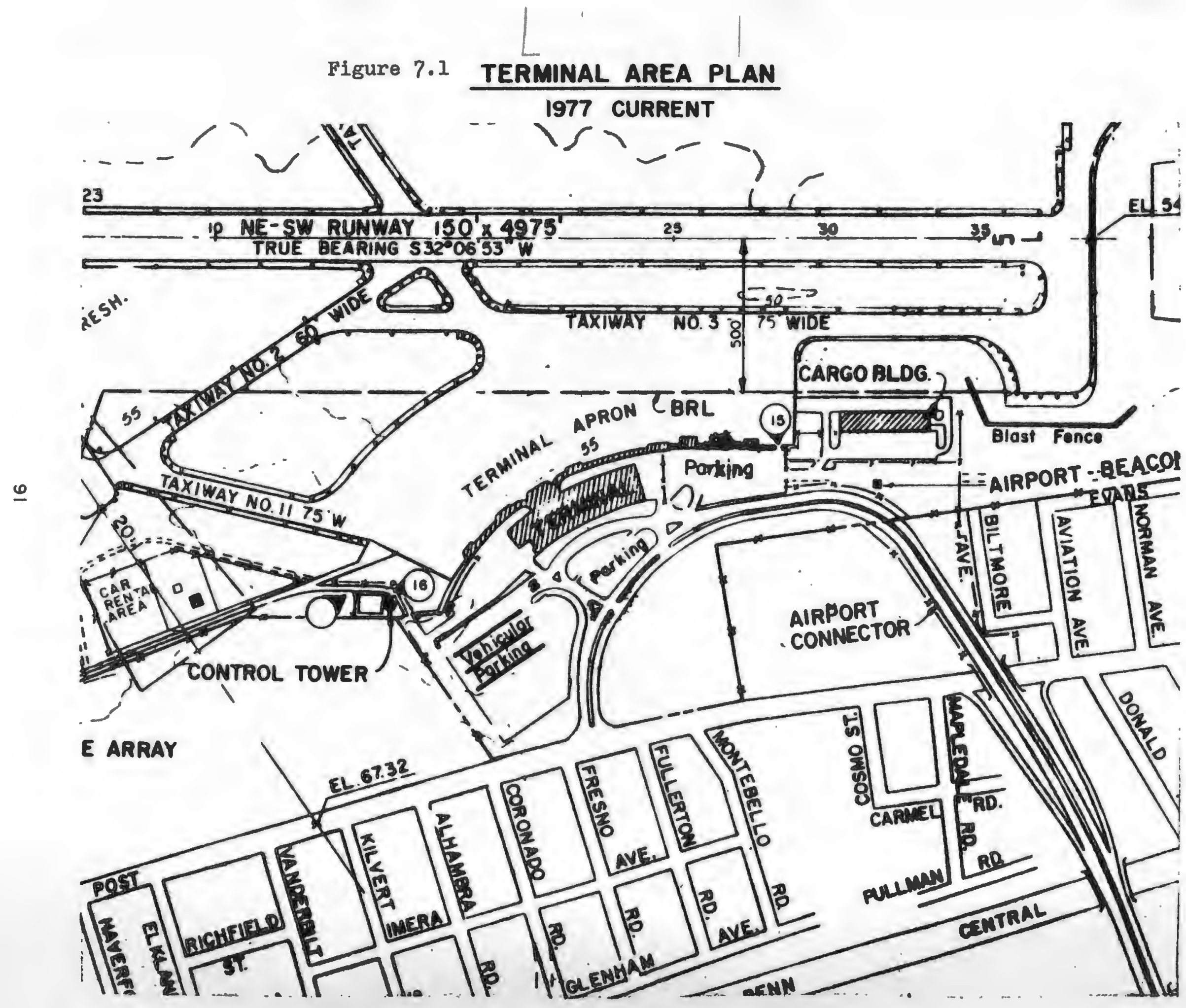


Figure 7.2 Terminal Area Plan (Master plan)

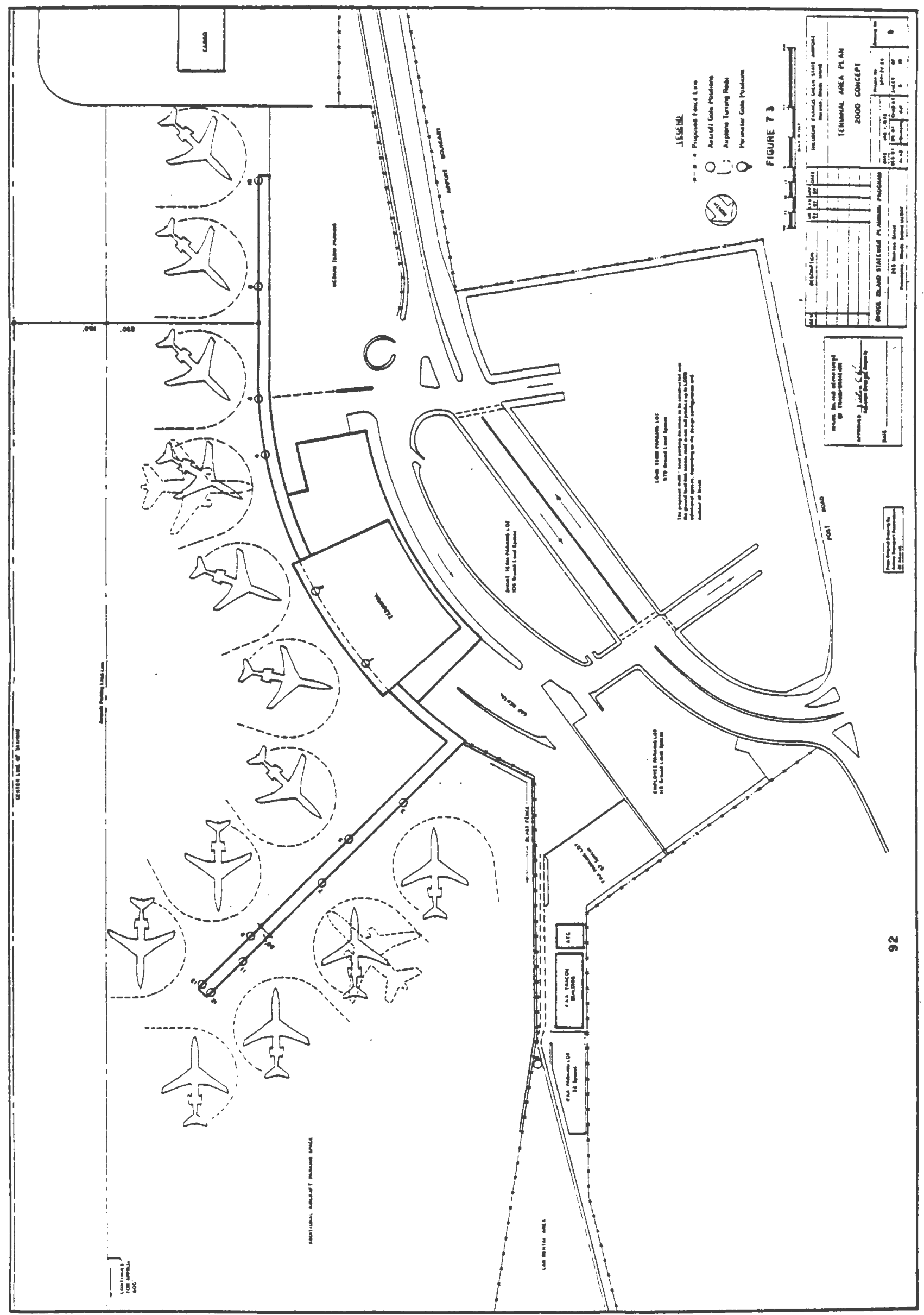




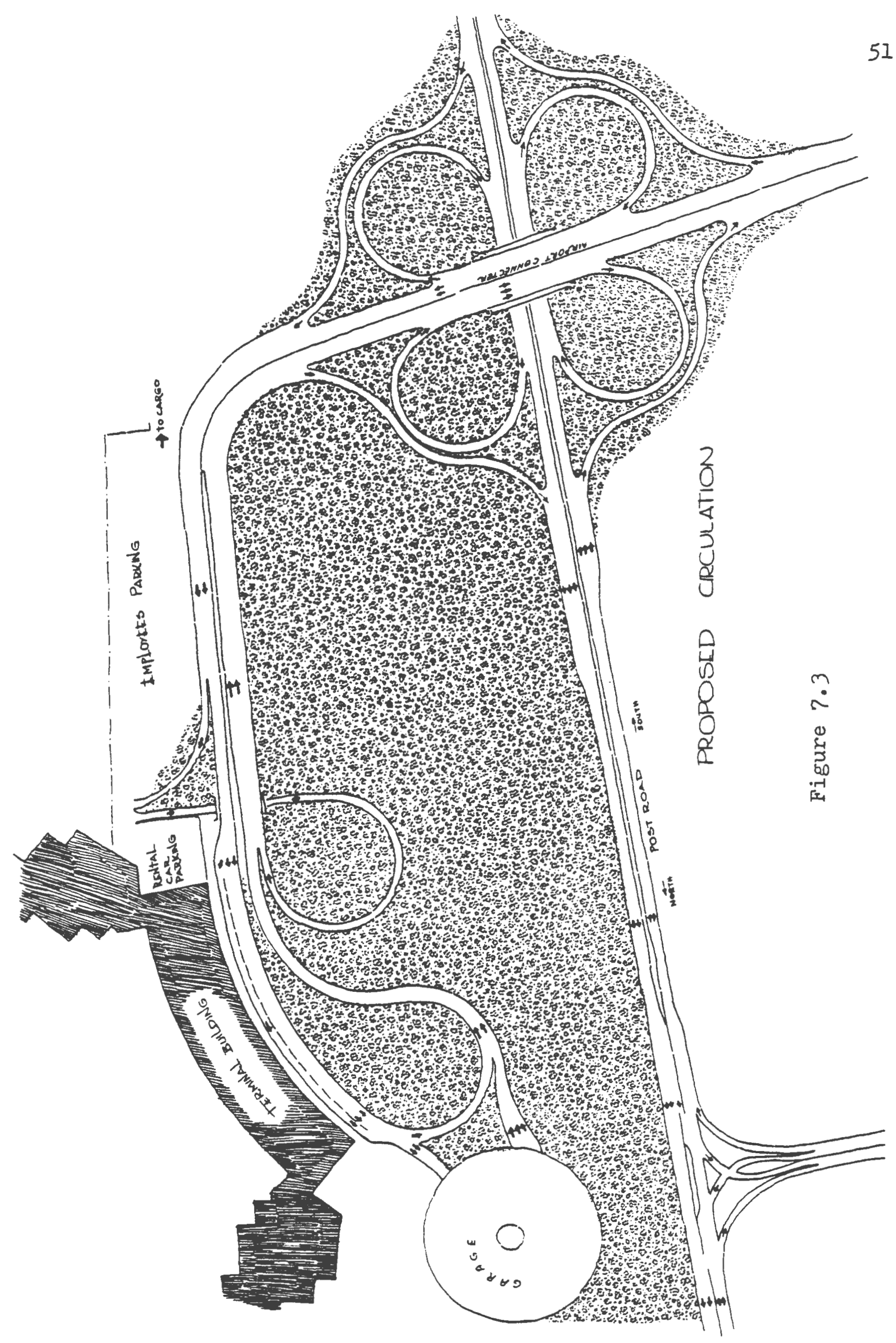




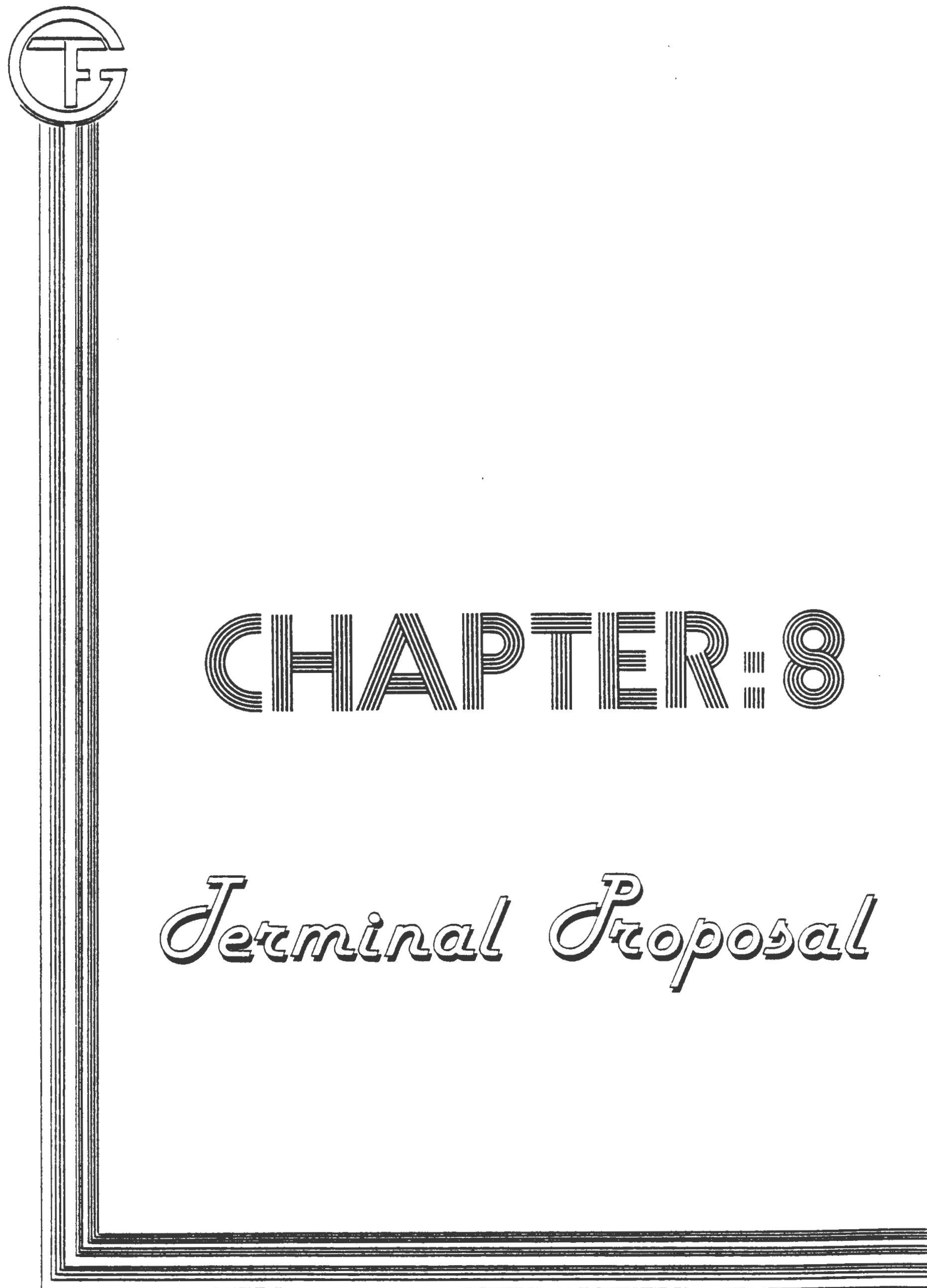




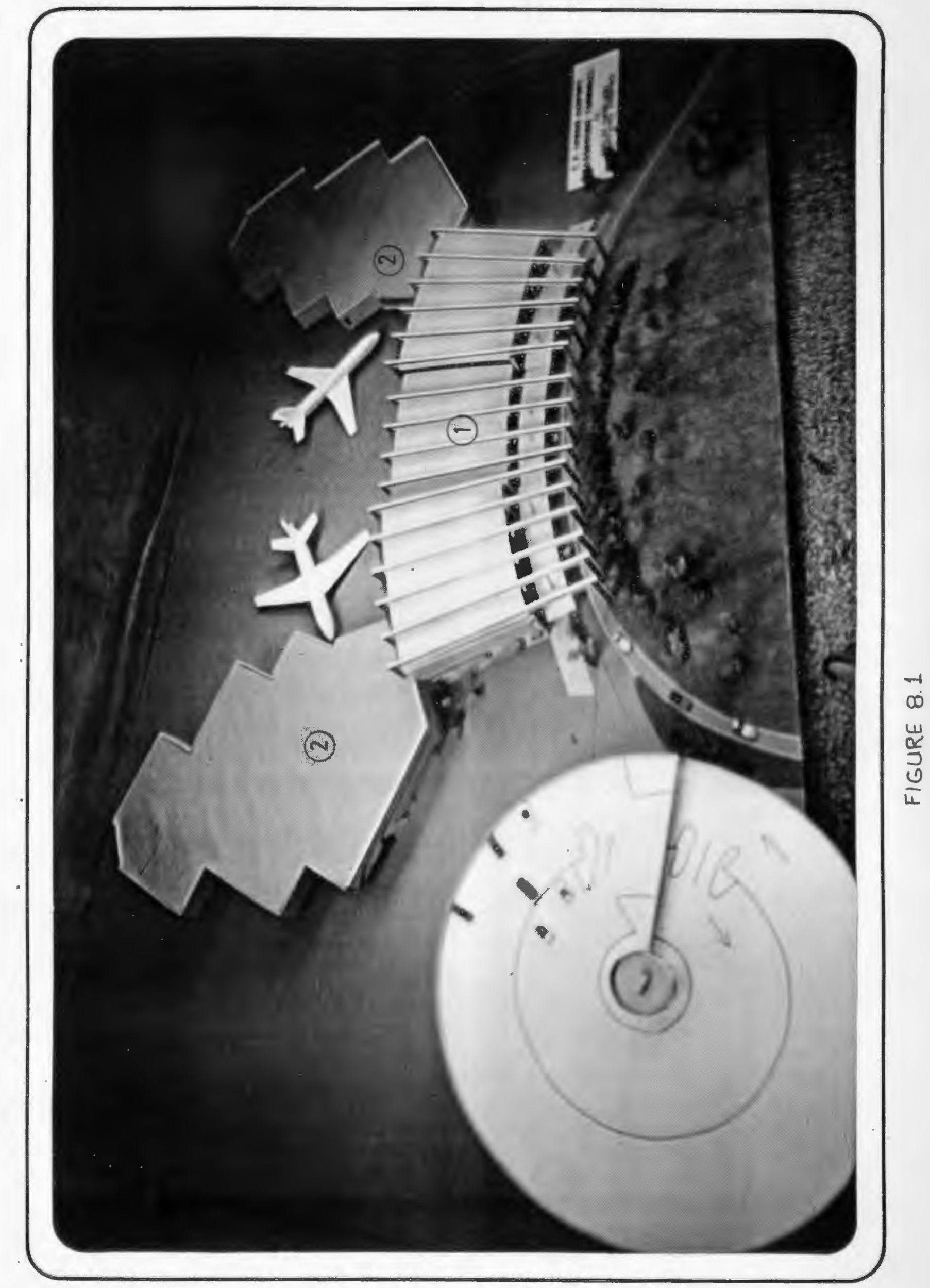




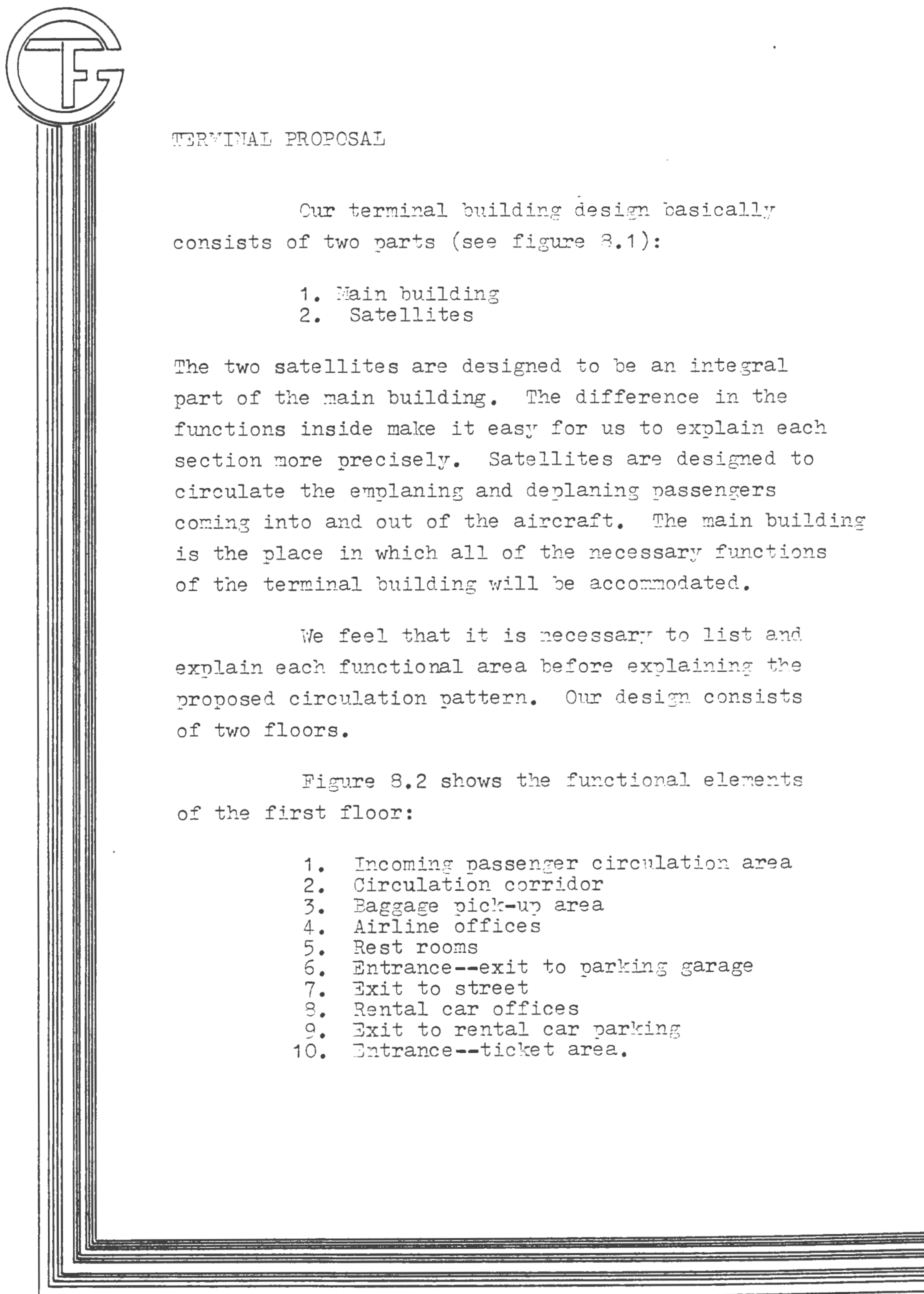




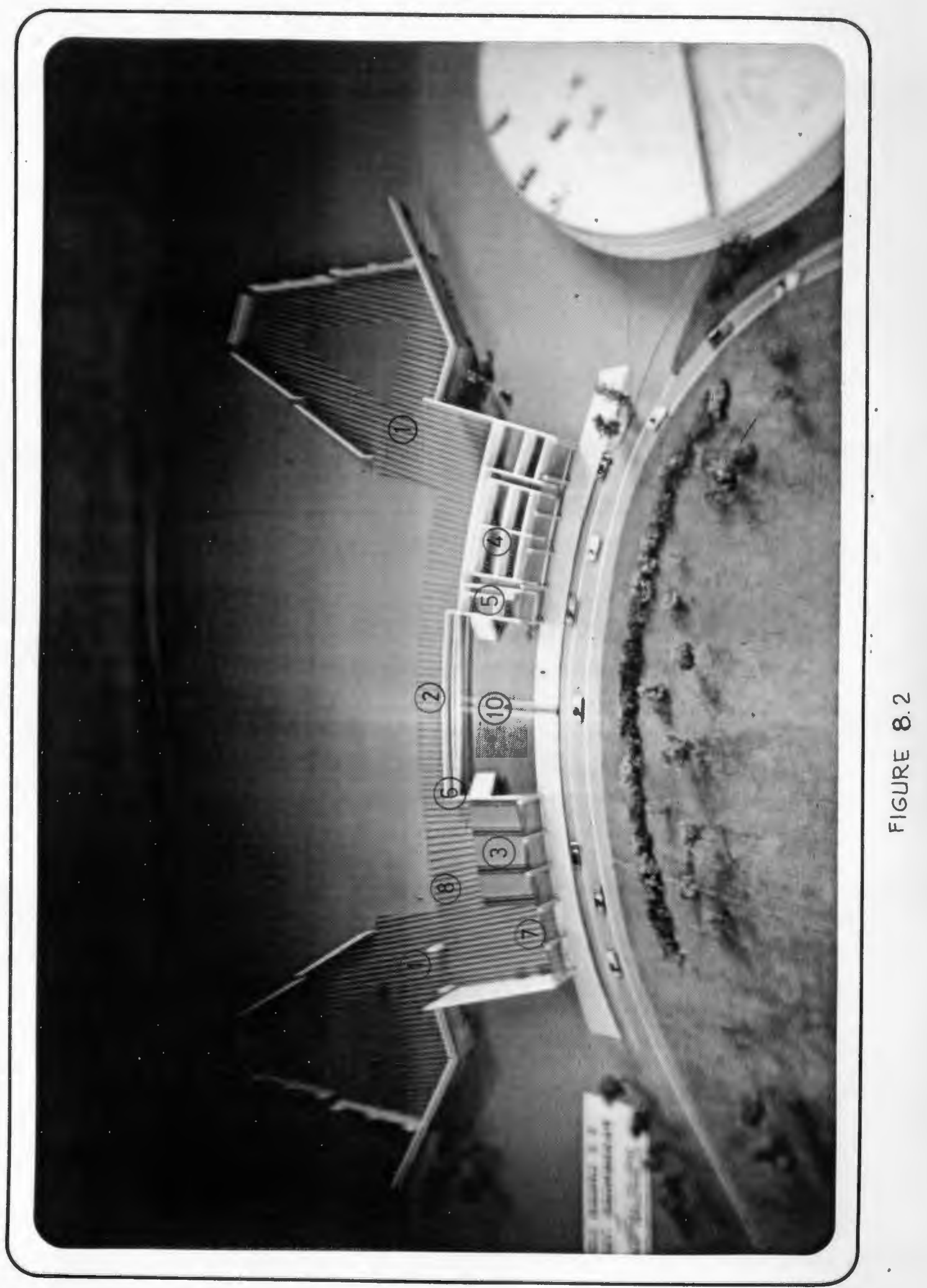




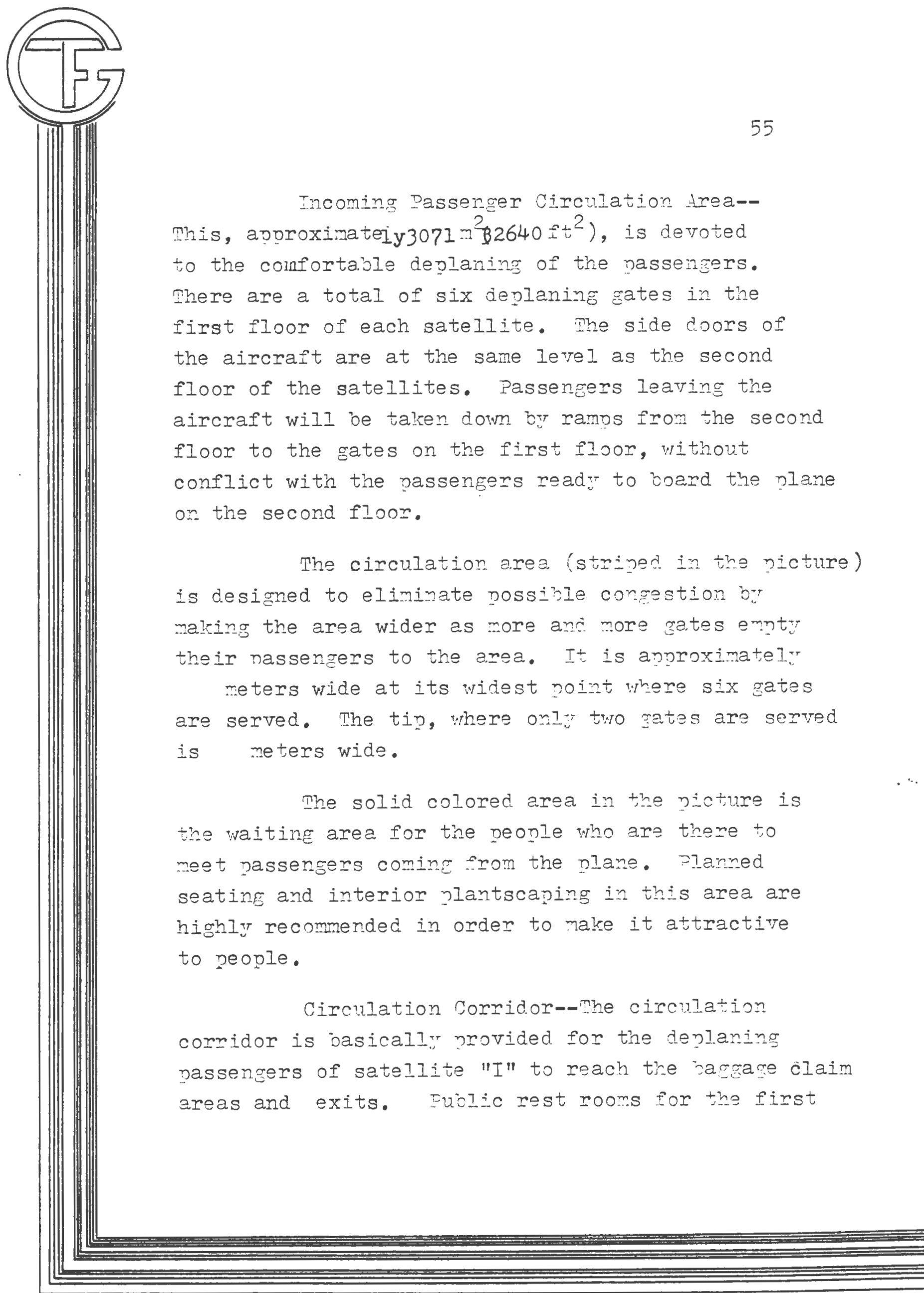




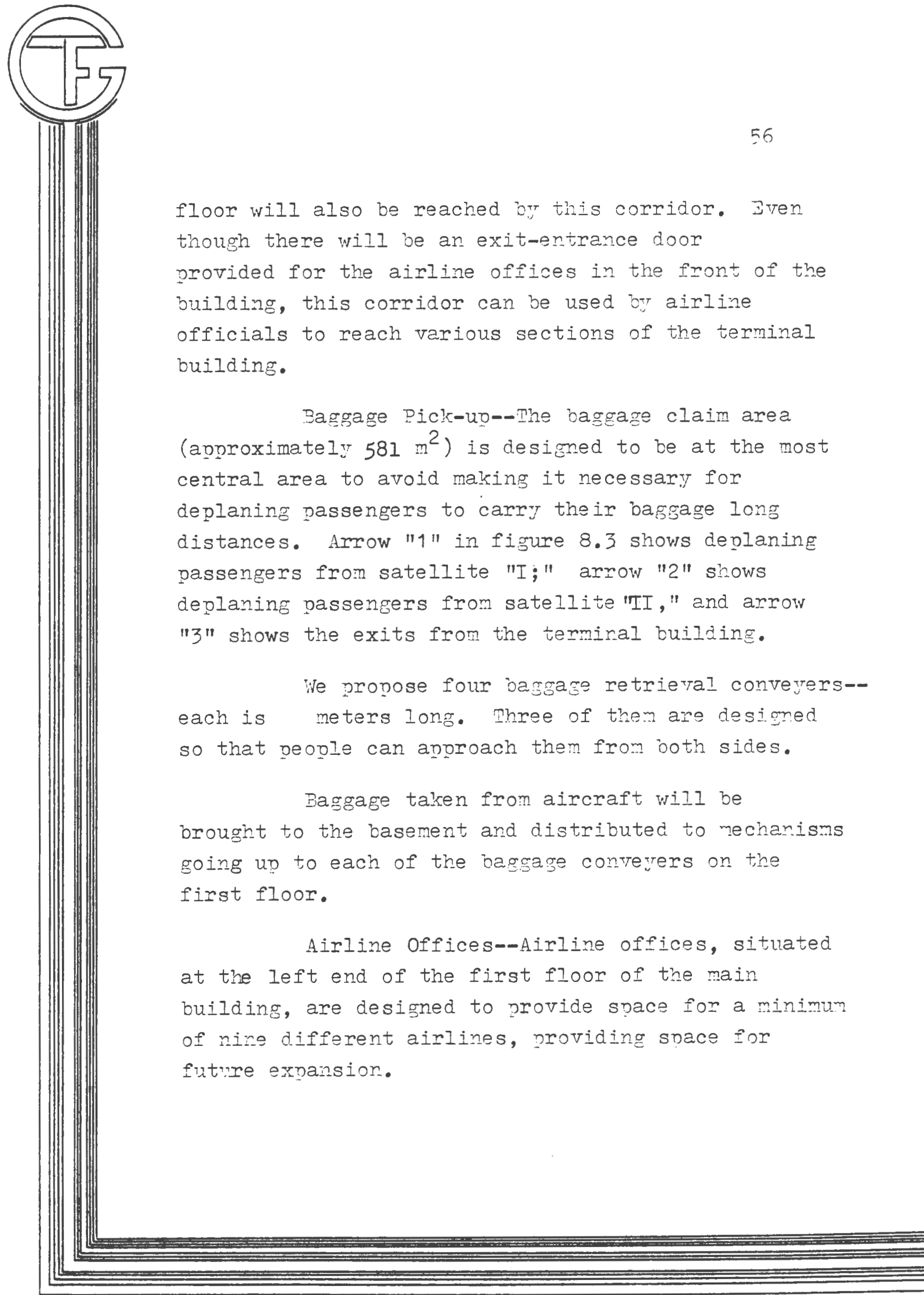




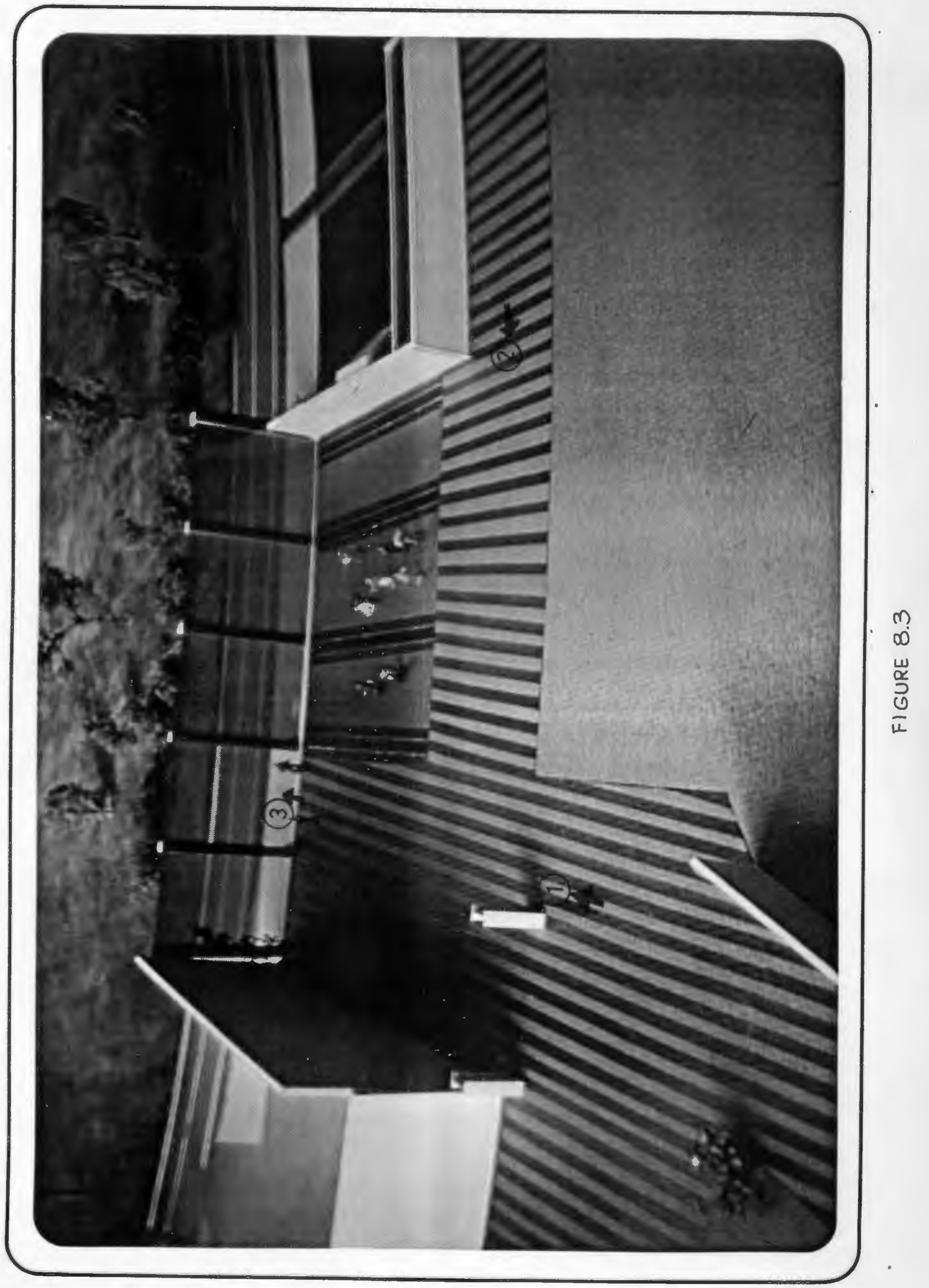




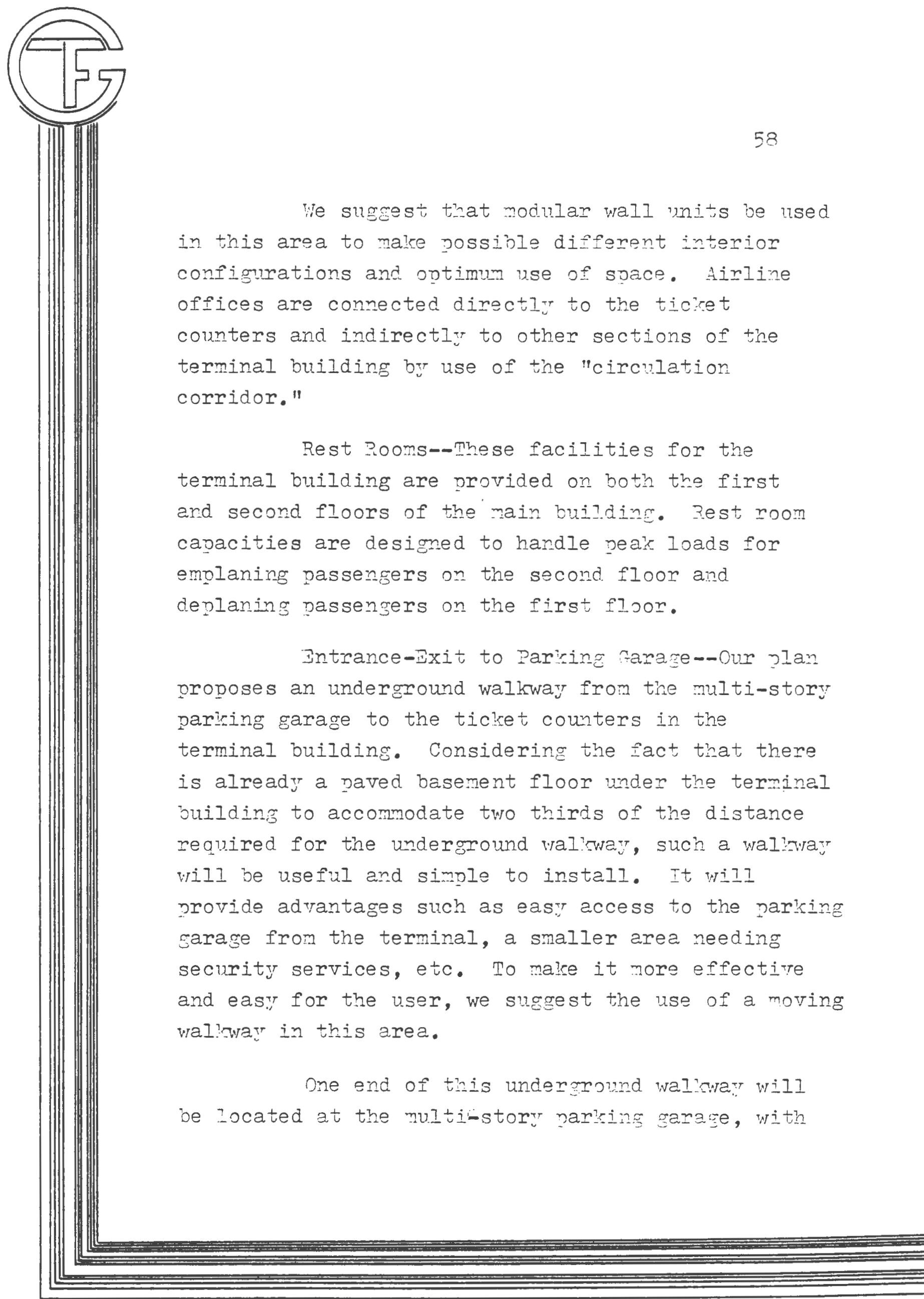




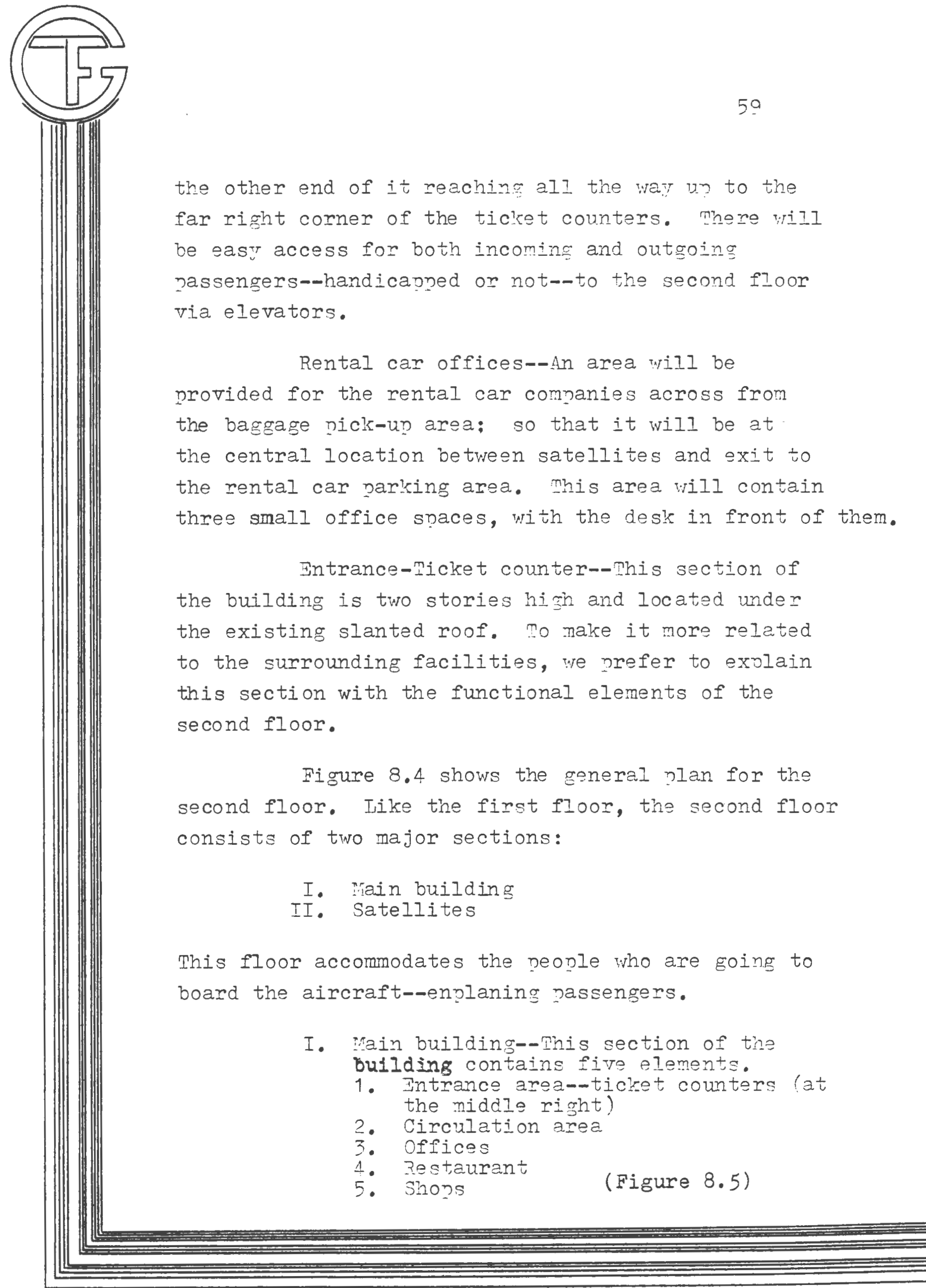




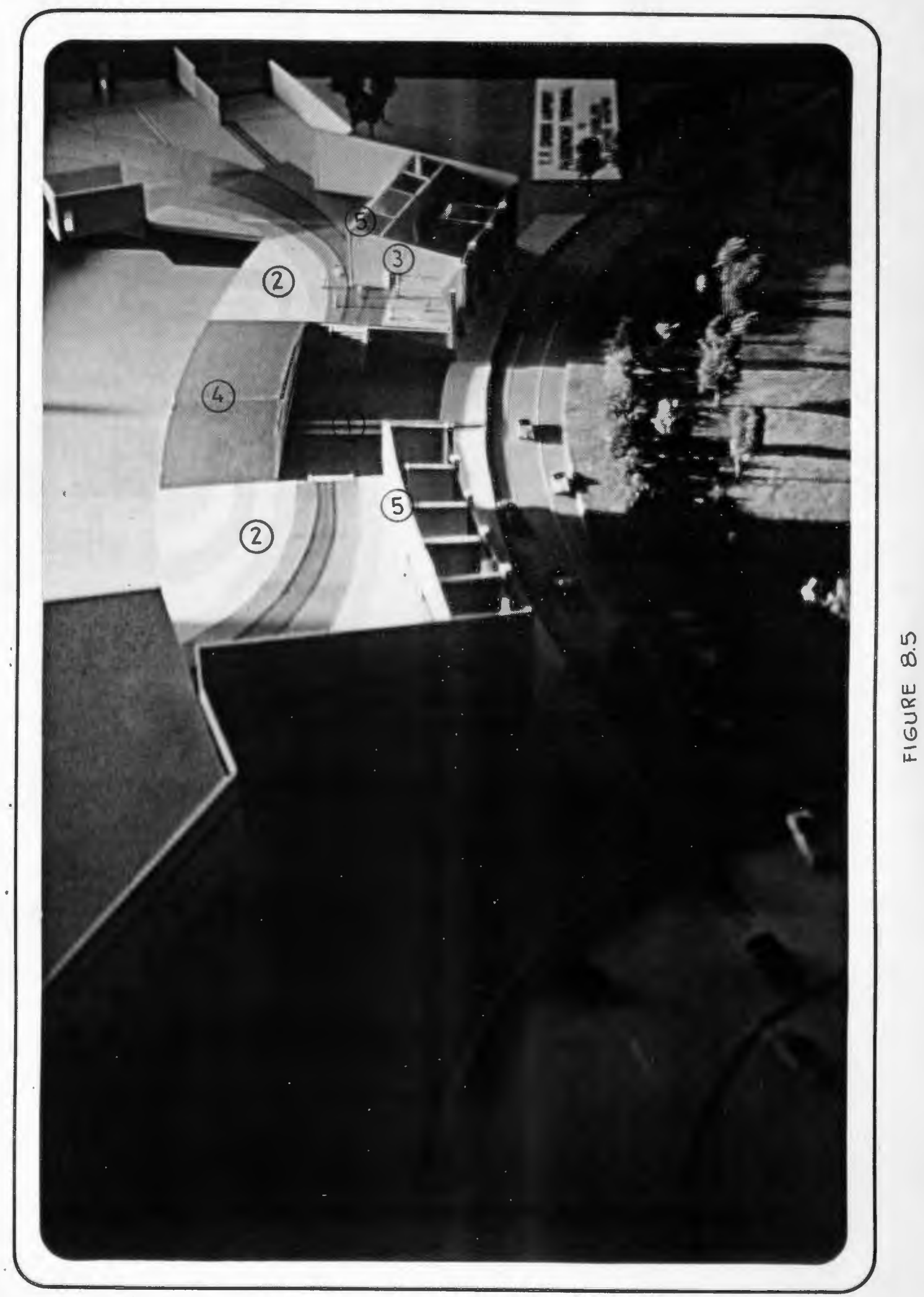




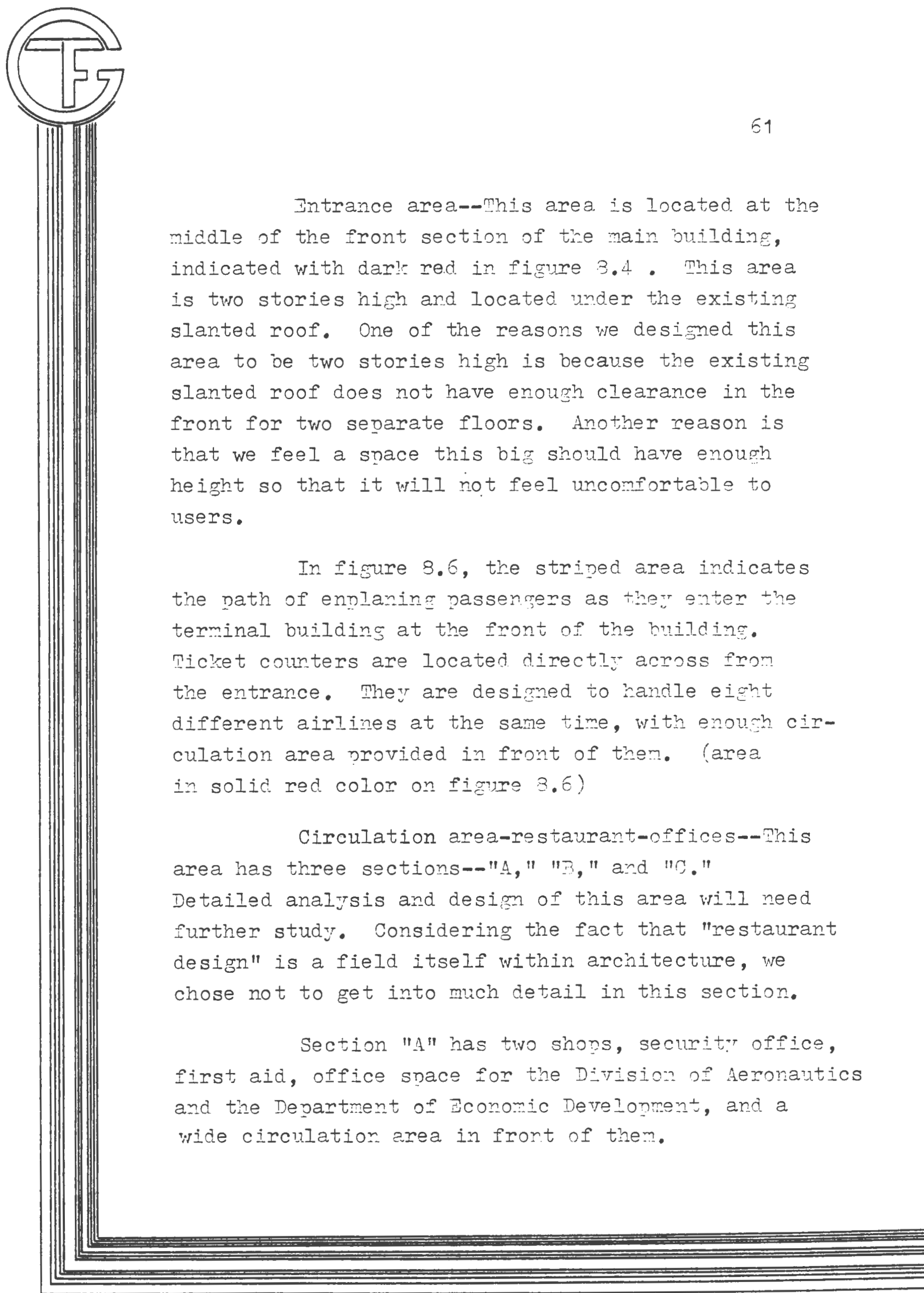




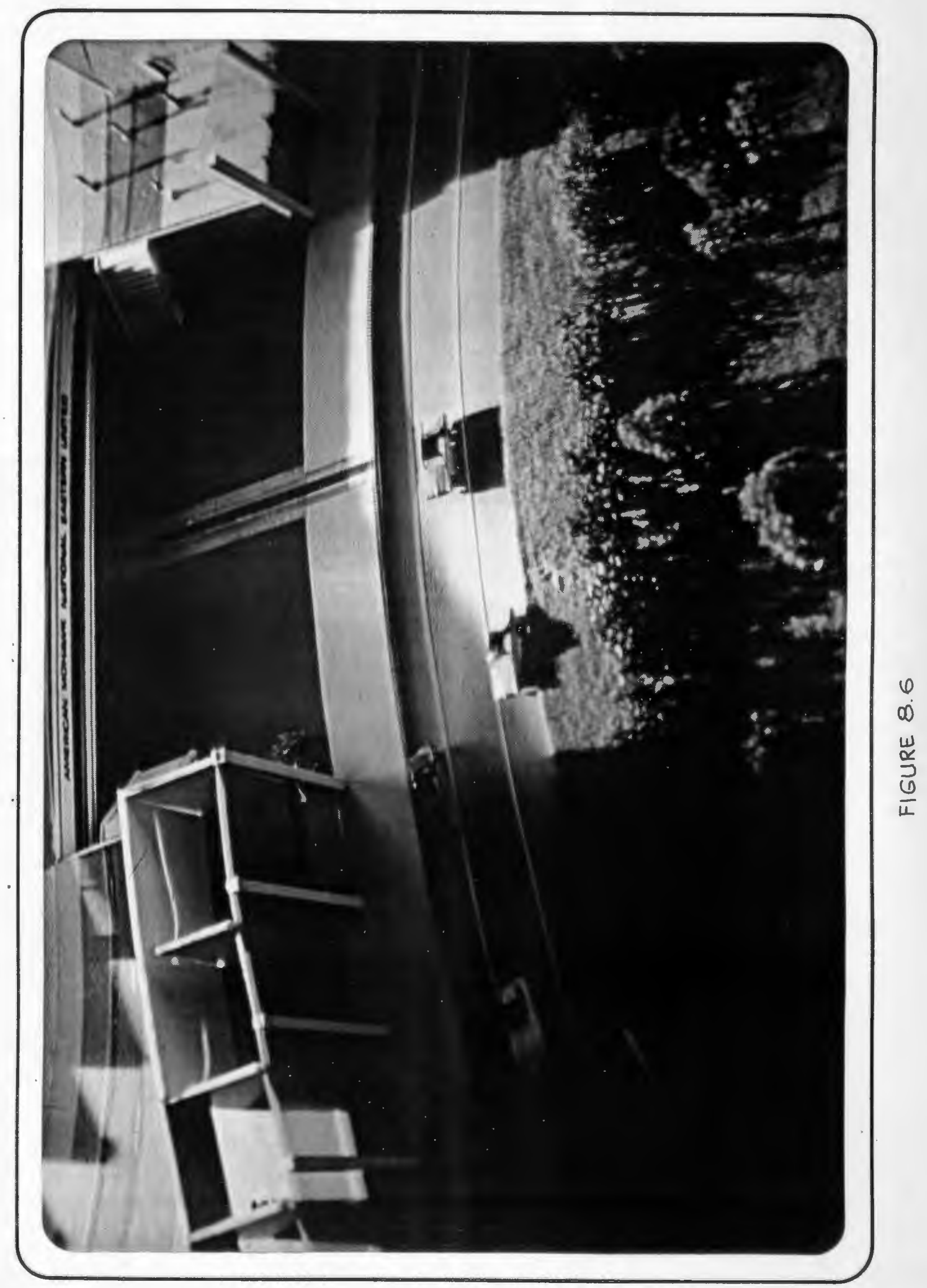




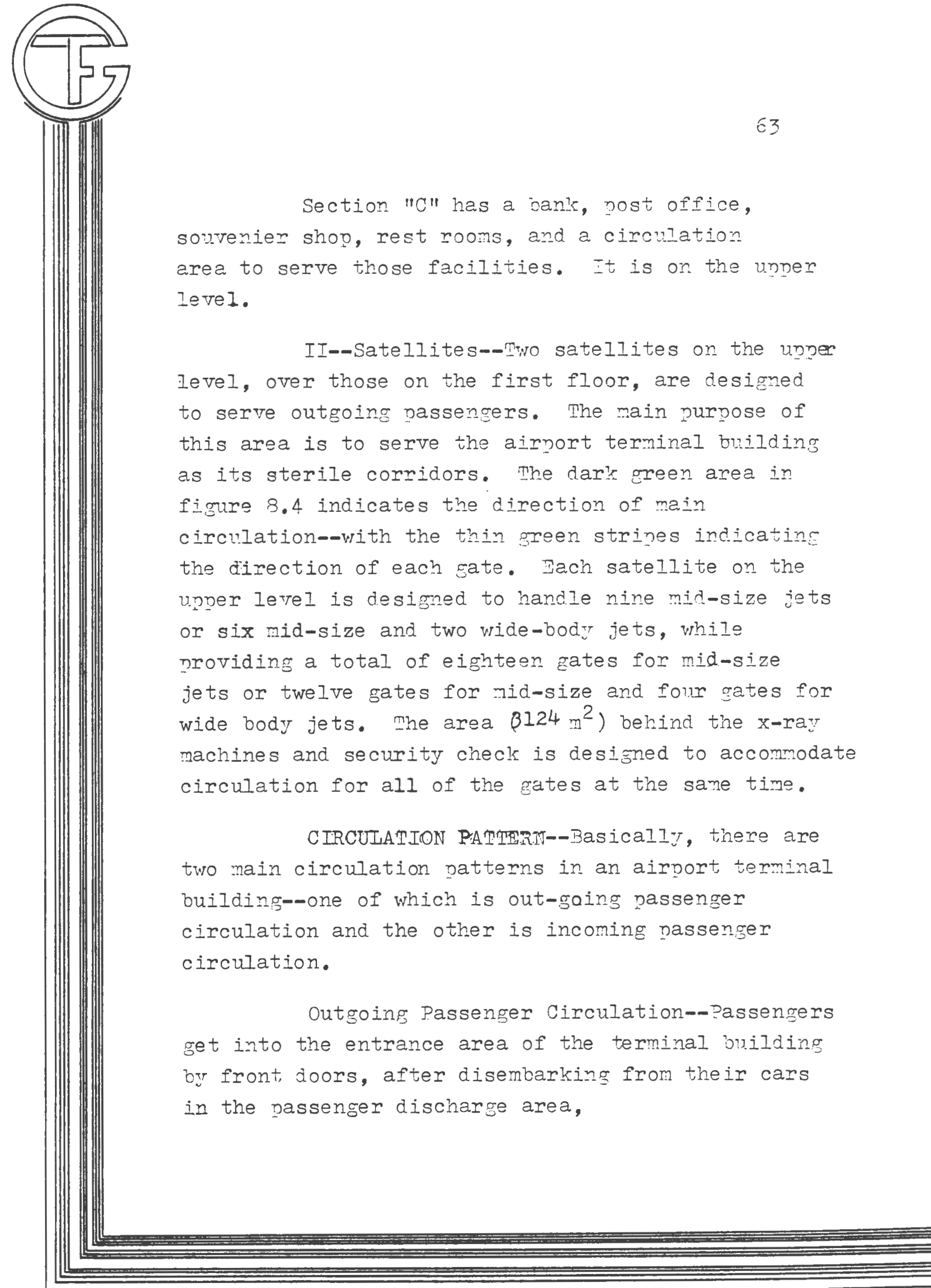




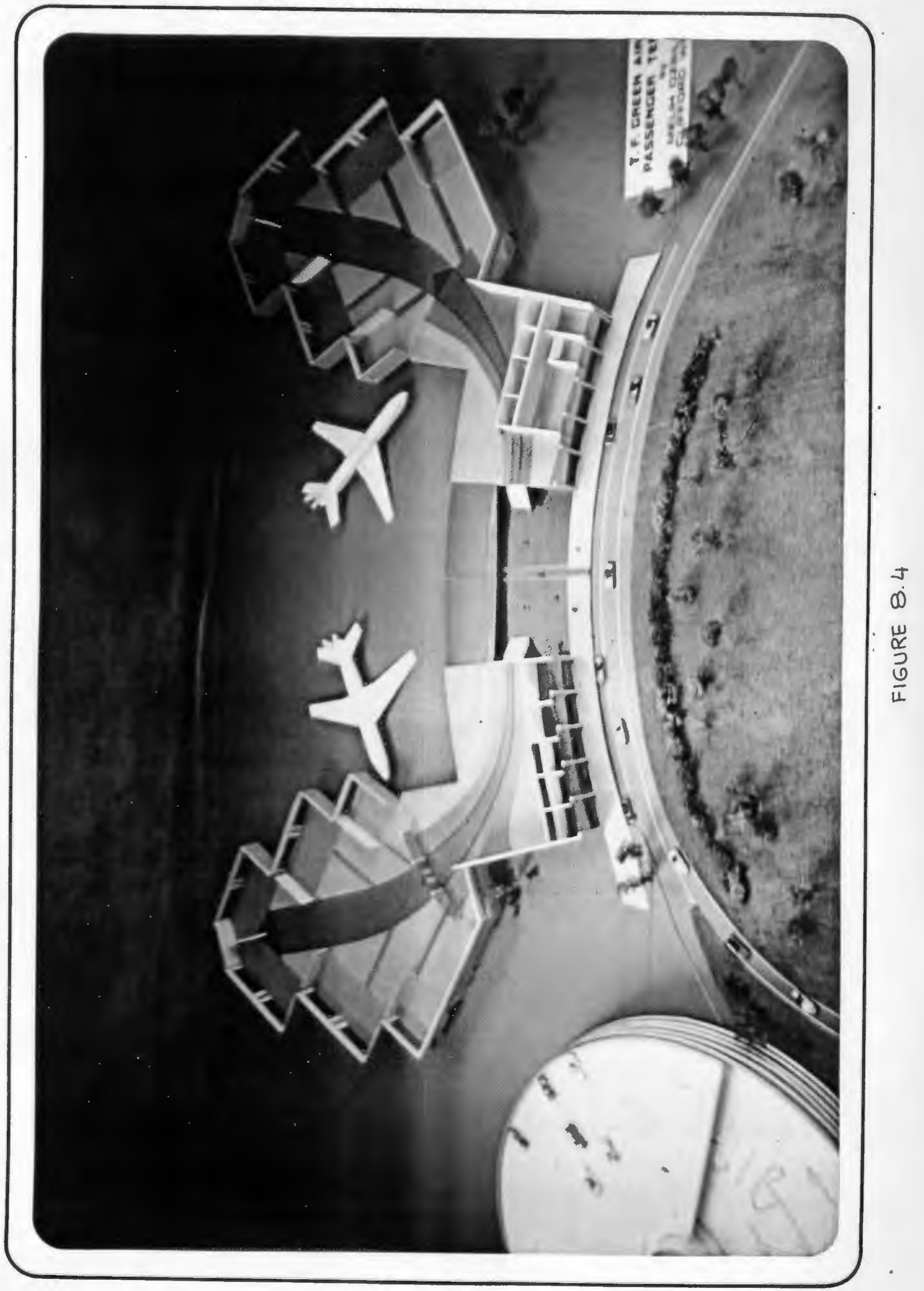




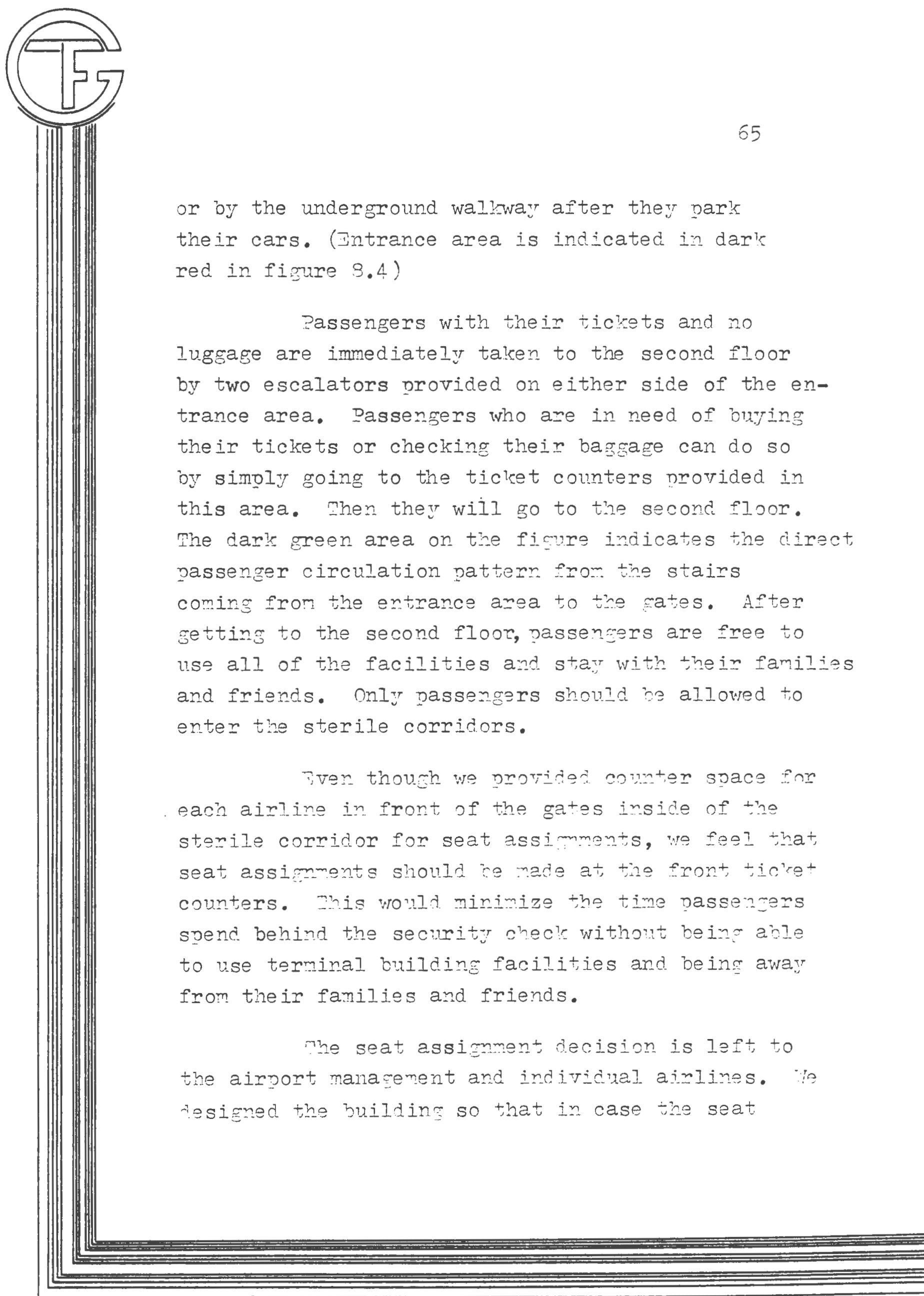




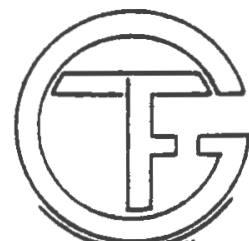

assimments are mace at the ticlyt counters, oy noving the security check further inside of the satellites, maximum raitinr area ontsida of tine sterile corridors yill be provided.

Incoming yassengor circulaticn--lrrovs indicated in black in figure 3.2 show the direction of incomino vassenger circulation. Jassencens vill ie talen to the first floor b+r ramps after leaving the aircraft at the second floor level. Fin they will be directed to the bargare retrieral area. Jassengers, after picting up their bagrage, ma-r leave the building eitrer or the exit toors in front of the buildine or br tine undermpond wal' war to the paring garase. Dotted lines in the firre indicate the diroction of the mdermoumd ral trat. Dassengers, who are going to rert a car, can r.o so by picking un their ters from rental car offices and leaving the buildirg from the exit provided on the right side of the building, which leads directlot to the rental car parring lot.

We designed the building so that incoming and outgoing passenger contact is minimized. The only area in which these two groups contact is the walkwars in front of tine building. Fren this contact is minimized by dividing the incoming nassengers into three groups:

1. Those Ieaving the building by the front doors 


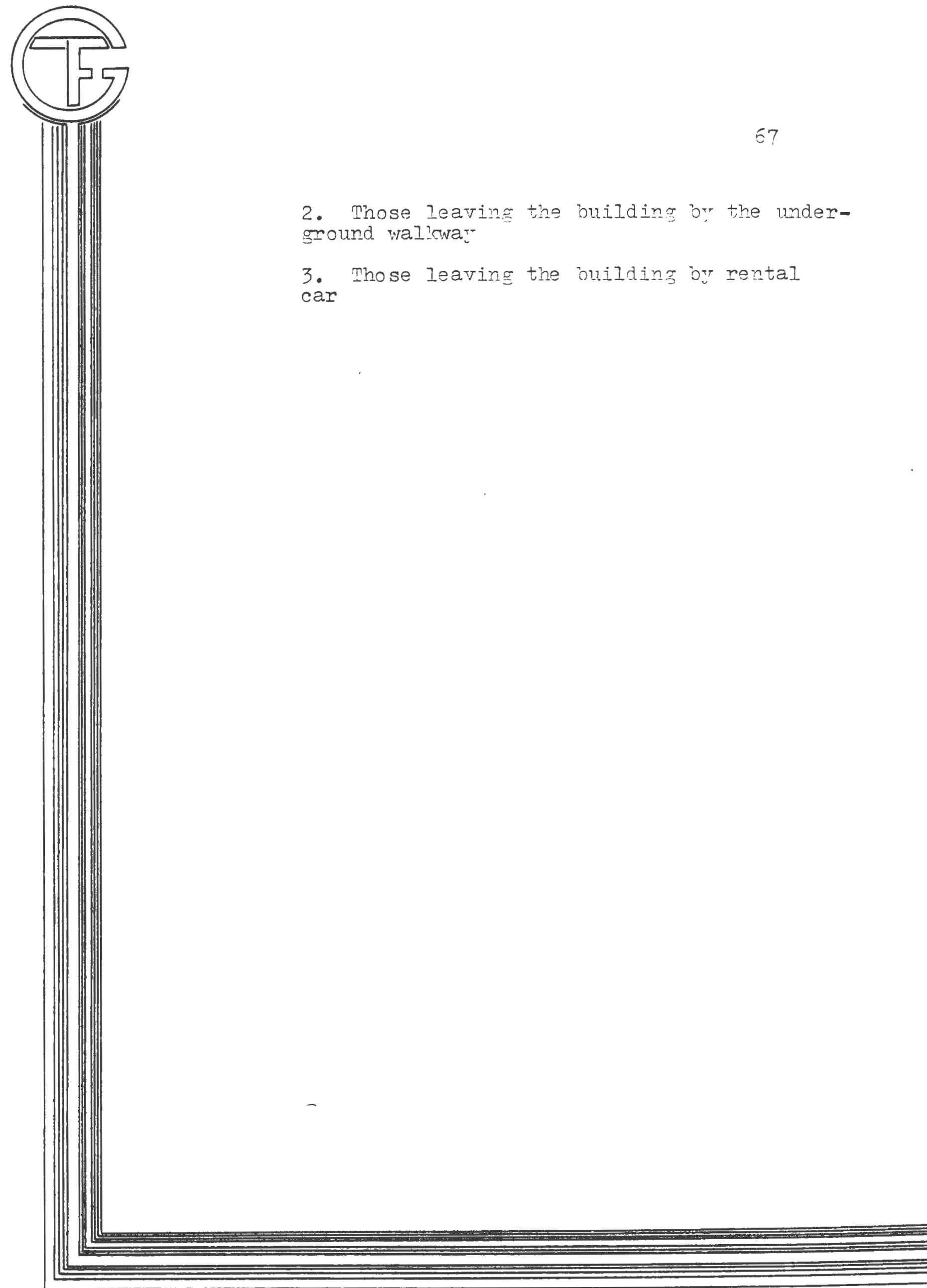




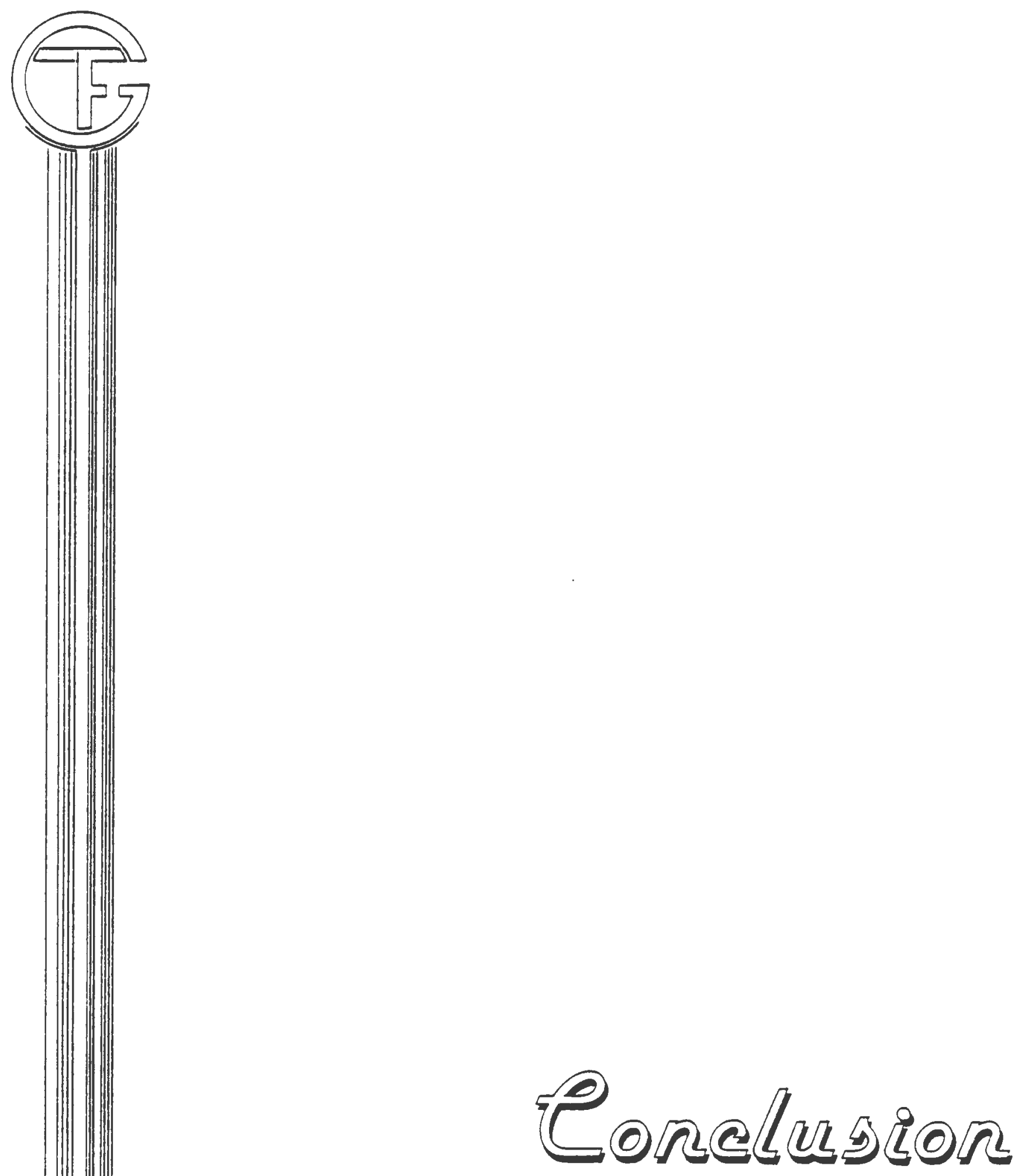




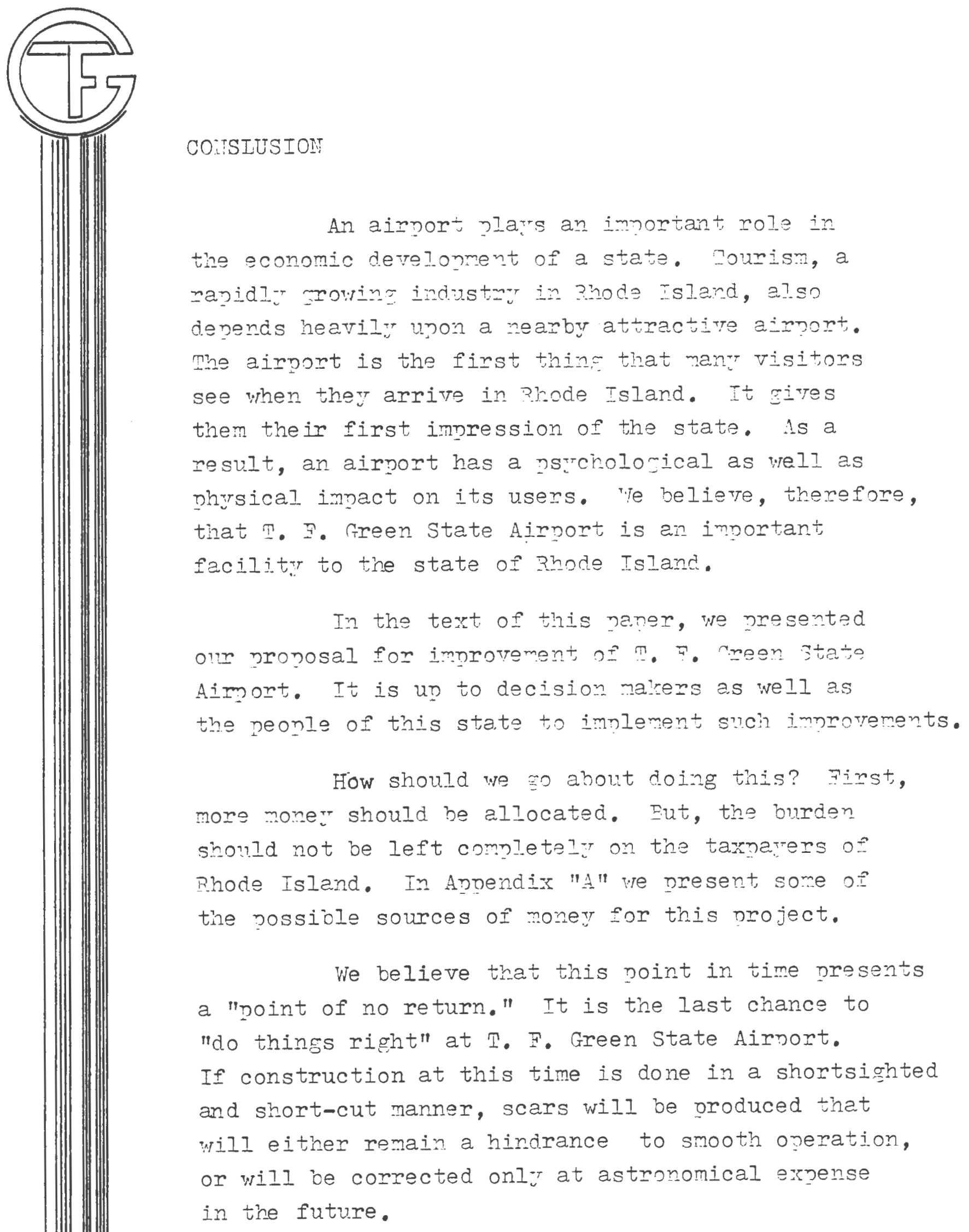




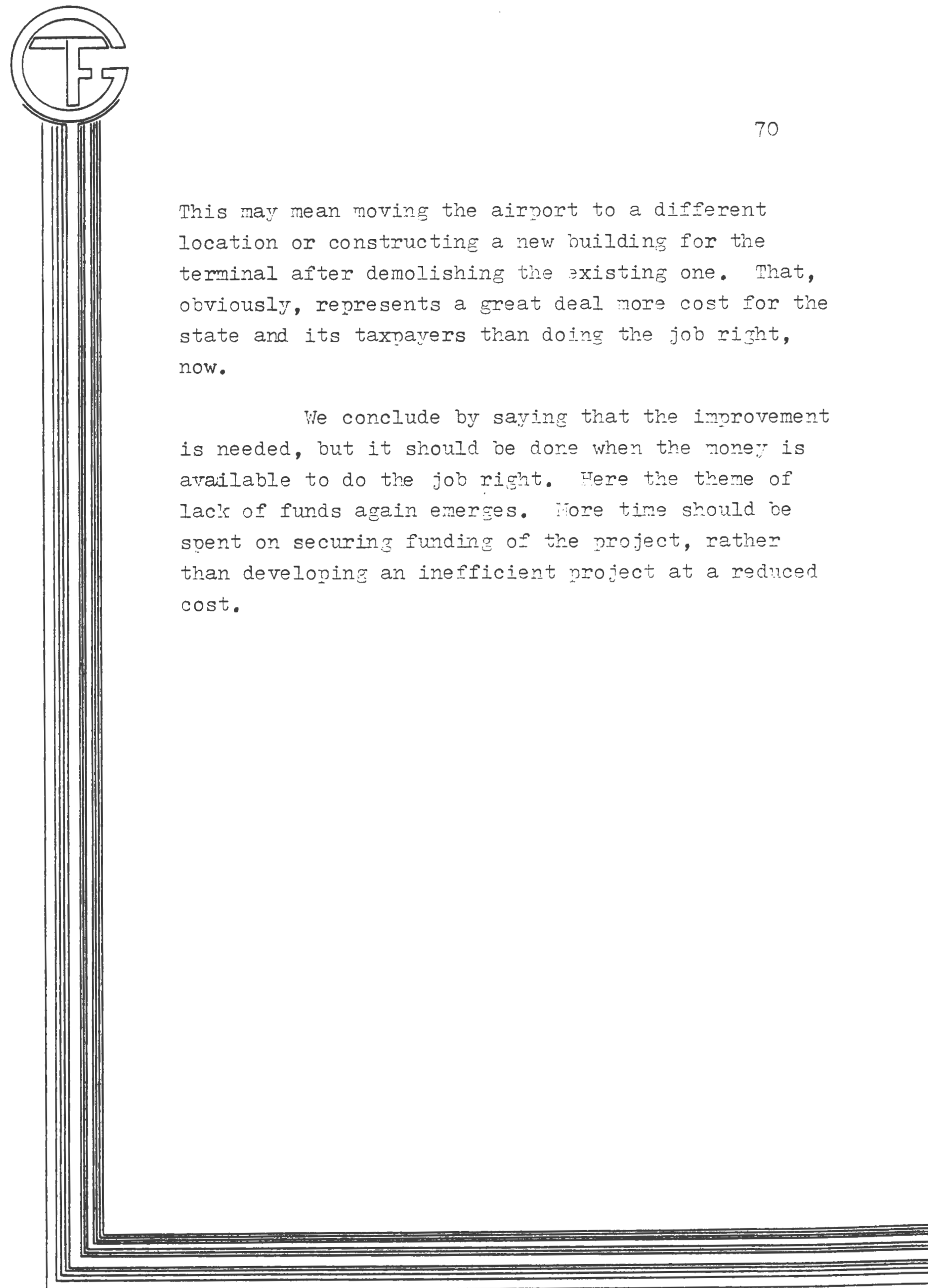




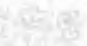

Crats.

(ellaty 


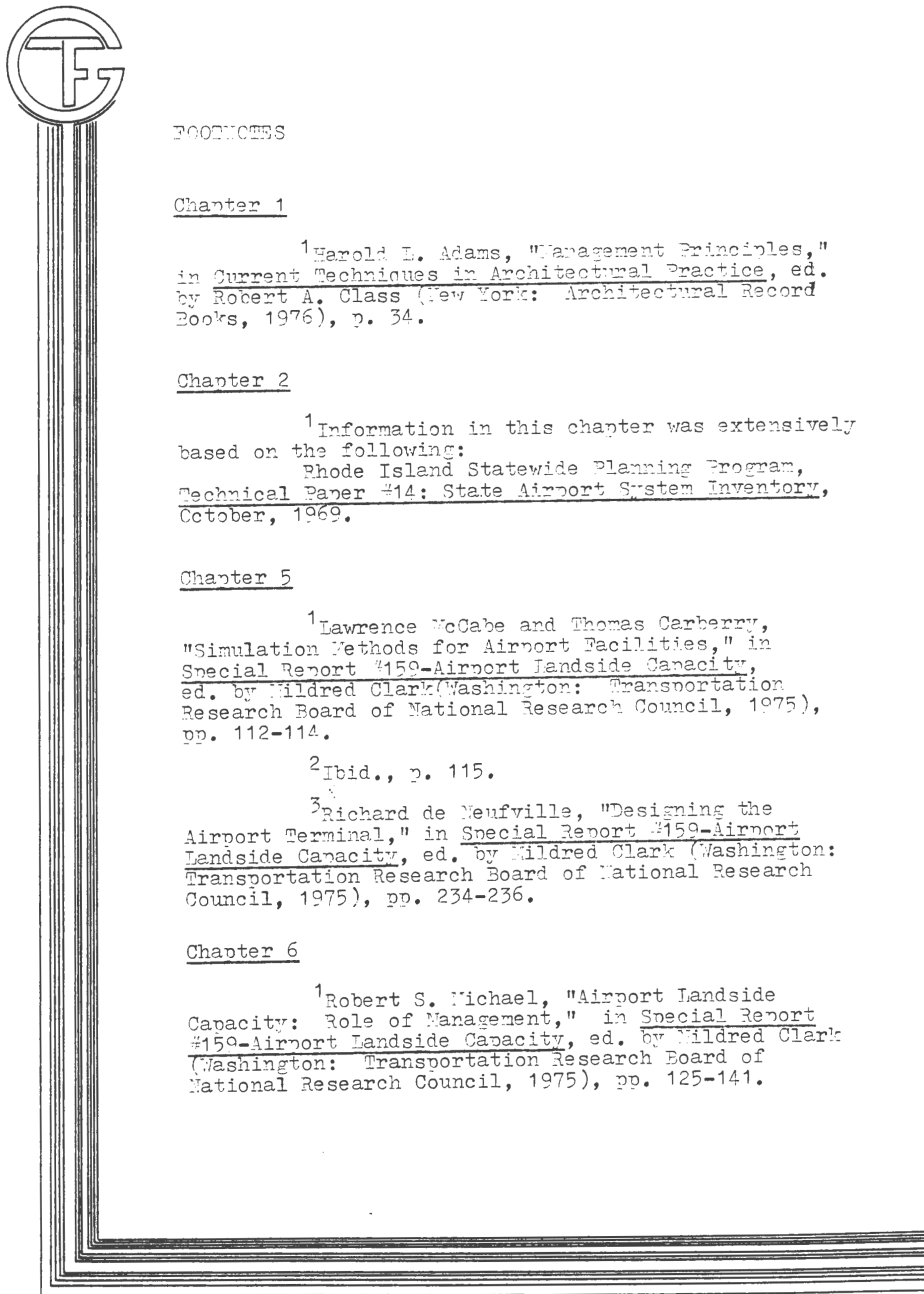




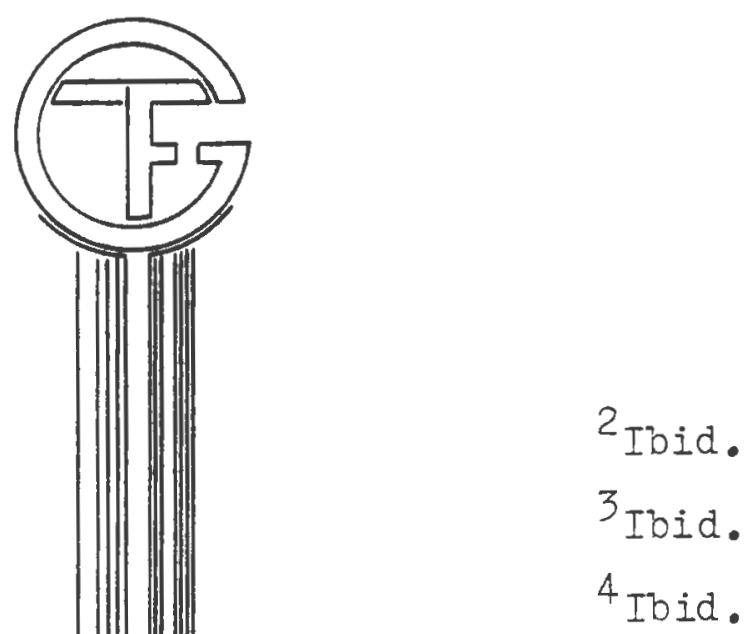

$$
\begin{aligned}
& { }^{2} \text { Ibid. } \\
& { }^{3} \text { Ibid. } \\
& { }^{4} \text { Ibid. }
\end{aligned}
$$




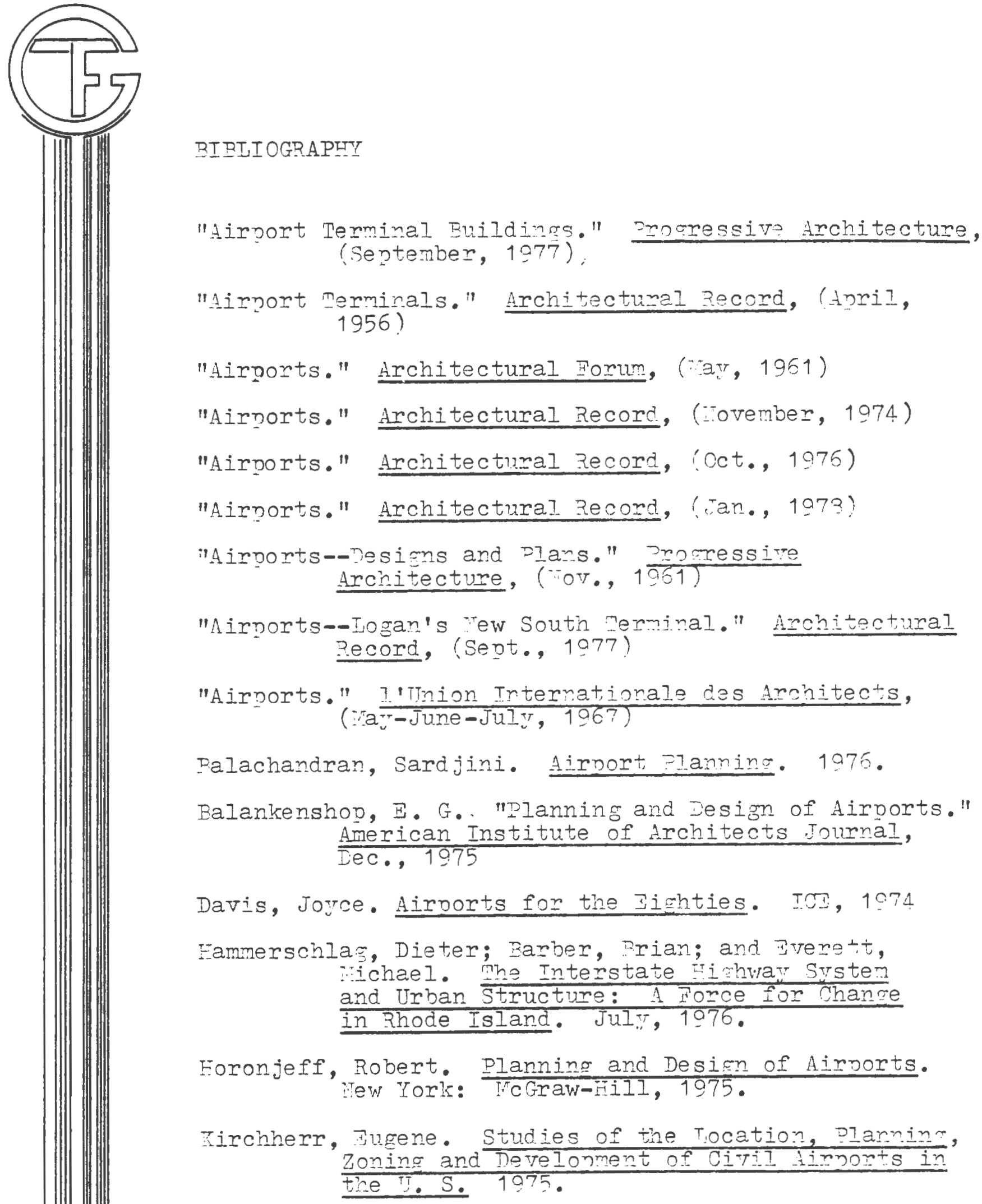




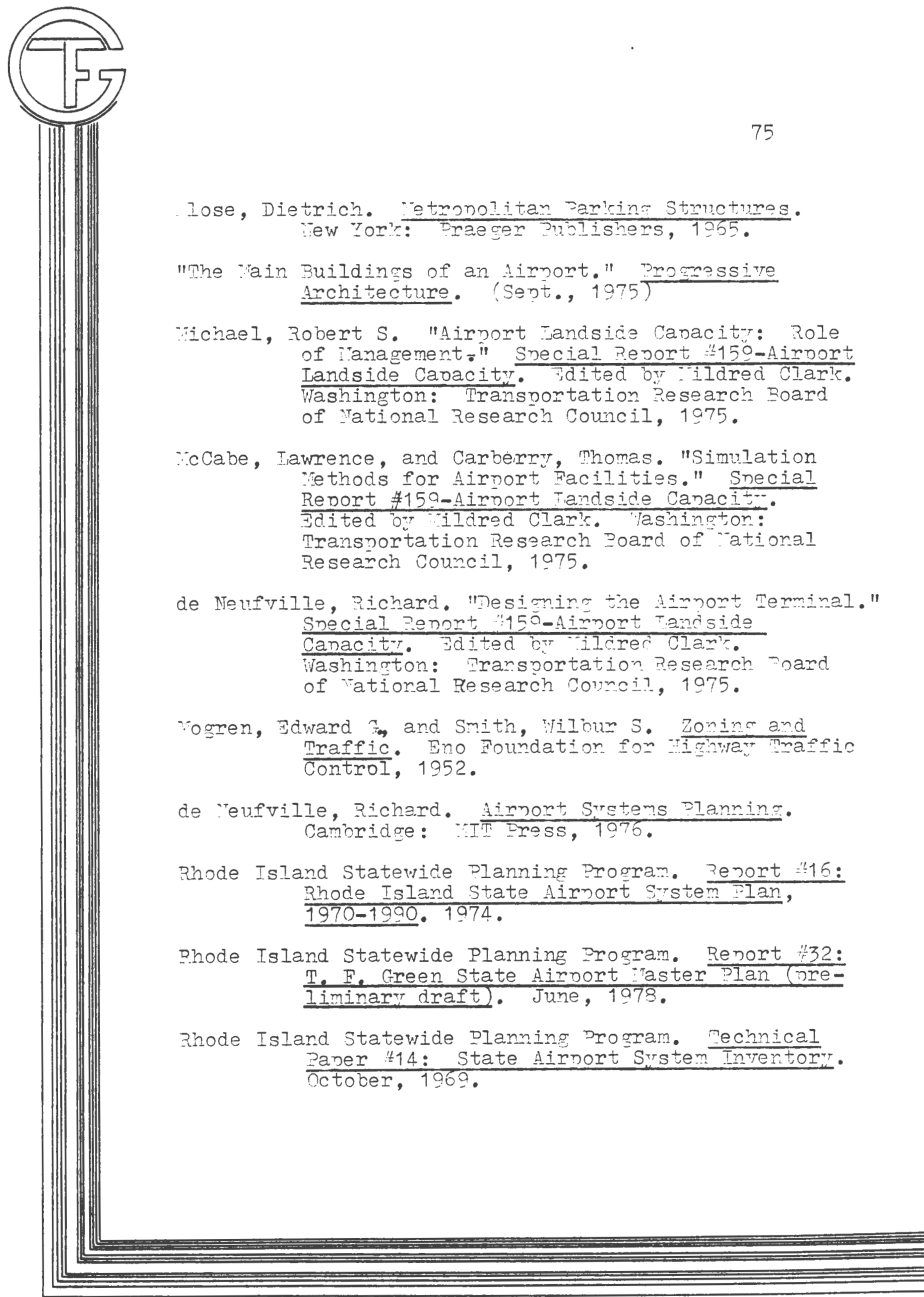




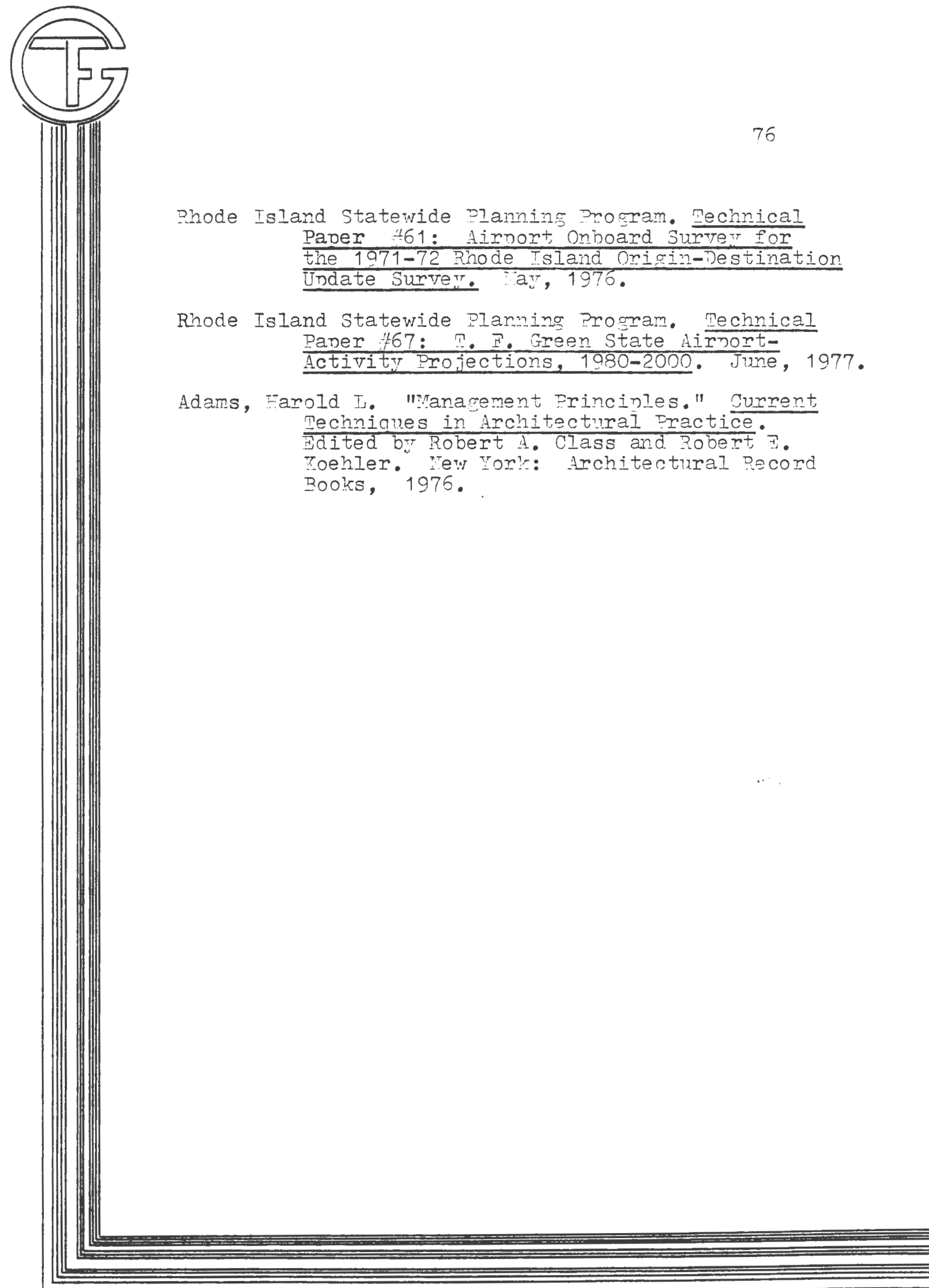


Dy DAV RID

PROVIDENCE - A new hotel and parking garage planued for Green State Arport will aro the state about \$1 willion a year once it is ngished in 1982 Governar Gurrahy seid yesterday.

It aloo will produce at least $\$ 150,000$ for the Clty of Warwick, Gerrahy said.

The \$17-miltion development will be built privately on state land around the Green terminal and then donated to the state.

In return, the developer, Aerial Group Inc., will receive a 30 -year lease from the state. The development group aiso will take over operation of the sirport colfee shop and newsstand.

The state will get 10 percent of the botel's gross profits, and at least $\$ 60,000$ from the opertion of the coffee shop. newsstand and garage.

Warwick will get payments in lieu of taxes for the 200-room hotel and, 1,000 . car parking curre.

The parking garage will he built directly in froat of the Green terminal, between the short-tem parking lot and Post Road. It may be finished as soon as October.

Once the garase is completed, construction will begin on the six-story hotel on part of the north parking lot. The hotel will be connected to the north end of the terminal building and should be completed in about two years, Garrahy said.

Combined with renovation of the ter. minal building, which is now under way with state bond money, the hotel-garage compiex will make Green "a totalservice complex unequaled by any medium-sized airport in the country." Gar. rahy said.

The new hotel will be smaller than the 350-room Marriott Int, the 330-room Biltmore Plaza and the 275-room Holiday Inn. But it will be larger than the 125-room Sheraton Airport Inn nearby on Post Road.

Hotel owners in Providence say the hotel business currently is very competi. tive in the Providence area with only the Marriott maintaining a high level of occupancy. Several botel people believe the Cranston Hilton folded recently and was sold to Johnson \& Wales Collere becadse it was not druwing enoug? business.

But Garraby and Martin G. Olson, the head of Acrtal Group, said market studies have indicated a need for hotel rooms at the airoort.

Olson raid bis fecility is not intended to conipete with downtown hotels, which are oriented toward convention business. He suggested that the presence of an airport hotel might attract more airline flights, and with them, more business for ail Rhode Isiand hotels.

Peter Austin, general managet of the
Sheraton, agreed. "I think it's excellent," he seid. "I would enjoy any extre compe. tition coming into the area. It's a good thing. It gives more fobs to the communi. ty, as well, and that's important."

The new garage will increase the number of parking spaces at Green from about 800 to $1,54 \mathrm{~h}$ according to plans unveiled in the governor's State House offiçe.

The four-level garage will have five sets of sthirs and three elevators, as well as $302-$ foot enclosed walkway to the second floor of the terminal building.

The project is expected to create about 100 construction jobs and provide about 150 positions in the hotel and garage. 
A-8 The Providence Journal, Wehreday, Jume 7, 1978

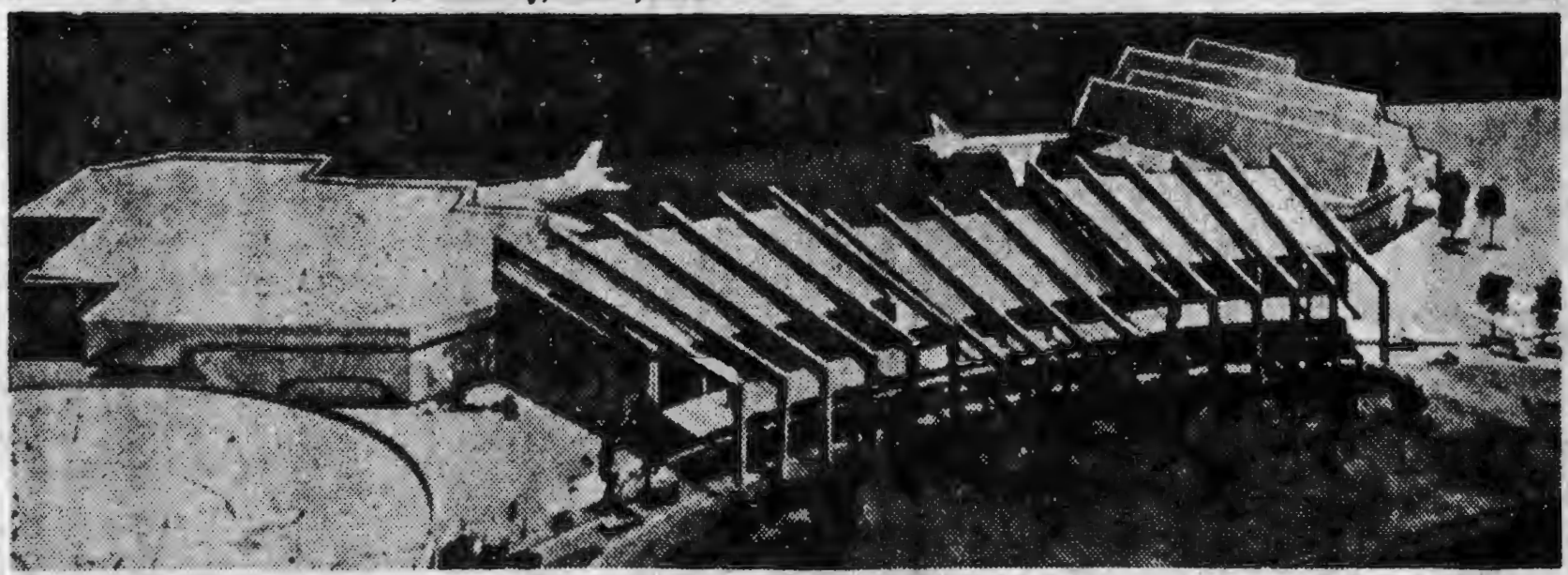

- Joumet-Bulletin Photo

NEW LOOK: A model of proposed changes at, If. Green Airport in Warwick.

\section{Student plan to revamp airport too expensive for state's tastes}

8) DOUG CUMMMNG

WARWICK - Two graduate students from the University of Rhode Island have come up with a new version of the T.F. Green State Airport that solves fust about cvery problem anybody has ever encoun. tend there.

Only one hitch: The state isn't about to pay the $\$ 12$ million it would cost.

Clifford Wester and Melih Ozbilgin. after destgning the make-believe airport improvements for an independent project in community design, presented a detailed model and slide show yesterday to state officials at the airport.

Vetor C. Riccl, acting director of the Division of Airports, told the students later that thatr statement of the problems was sccurite. How the state eventually will solve these problems, he added, will dlfier from their model because the state doesn't wast to pick up wich a large tab.

Hill MOBrims at the airport, the students said, inchude automoble tieups, inconvenient parking, overcrowding at the baggage pickup and poorly designed waiting areas. The students compared the appearance of the terminal to an Ans\& Hope store - showing a sllde of frot the store they had in mind.

Ricel flinched vidbly at the comparison and said that the airport was built for the state's needs in 1960. At that time, the airport served only 300,000 people a year. Last year, it served 941,099 , Riced said.

"In the future, when our consultants go to work, these are the kinds of studies they can go back to," Ricci said of the students' work. The state has $\$ 1.4$ million from a bond issue which will be uned to Improve basease pickup, trafflc, recurity and intertor design of the airport, he said.

ACTUACIX, the state aiready his contributed to Wester and Ozbilgin's proposal - $\$ 135$ came from the Statewide Planiting Program to help bulld their model.
The modet includes a spiraled six-level parking garage, two new double-leveled wings to accommotate 10 airplanes each and second floor on the main terminal. Existing steel beams would be extended to cover the entrance drive and pedestrians no longer would noed to Gloss lanes of traffic.

Dieter Hammerschlag, the community planning professor who is the students adviser, noted that the beauty of the proposed design was its conpactnes. Outgoing and incoming passengers, who would remain on separate levels, nevor would have to walk very far.

Roland J. Frappier, supervisor of transportation for the Statewide Planning Program, said the students' concept was considerably different from the state's concept. "The state's concept is to spend as little as posstble and make it work as well as possible, which I perconalty think b riot the best approach, wo it is state policy.

But "this conctiot makes somutim really attrictive out of the dirouth" the said. 